ARTHUR QUINTÃO DE ANDRADE

\title{
SEQUENCIAMENTO E PROGRAMAÇÃO DE LAVRA COM ALOCAÇÃO DE EQUIPAMENTOS DE CARGA
}

Dissertação apresentada à Escola

Politécnica da Universidade de São Paulo para obtenção do título de Mestre em Engenharia de Sistemas Logísticos.

São Paulo

2014 
ARTHUR QUINTÃO DE ANDRADE

\section{SEQUENCIAMENTO E PROGRAMAÇÃO DE LAVRA COM ALOCAÇÃO DE EQUIPAMENTOS DE CARGA}

Dissertação apresentada à Escola

Politécnica da Universidade de São Paulo para obtenção do título de Mestre em Engenharia de Sistemas Logísticos.

Área de Concentração:

Engenharia de Sistemas Logísticos

Orientador: Prof Dr.

Miguel Cezar Santoro

São Paulo 
Este exemplar foi revisado e corrigido em relação à versão original, sob responsabilidade única do autor e com a anuência de seu orientador.

São Paulo, 06 de junho de 2014.

Assinatura do autor

Assinatura do orientador

FICHA CATALOGRÁFICA

Andrade, Arthur Quintão de

Sequenciamento e programação de lavra com alocação de equipamentos de carga / A.Q. de Andrade. -- versão corr. -- São Paulo, 2014.

$108 \mathrm{p}$.

Dissertação (Mestrado) - Escola Politécnica da Universidade de São Paulo. Departamento de Engenharia de Transportes. Sistemas Logísticos..

1.Pesquisa operacional 2.Planejamento da produção 3.Mineração 4.Equipamentos de carga I.Universidade de São Paulo. Escola Politécnica. Departamento de Engenharia de Transportes. Sistemas Logísticos. II.t. 


\section{DEDICATÓRIA}

À família que sempre apoiou a minha educação e fará parte de todas as minhas conquistas. 


\section{AGRADECIMENTOS}

Agradeço a Deus que guiou meus passos para chegar até aqui.

A Maritha cujo amor e dedicação tornaram esse sonho possível.

Ao meu orientador prof. Santoro pela paciência, disponibilidade, bom-humor, todo o suporte e inúmeros ensinamentos que direcionaram o trabalho.

A minha família e amigos pelo apoio e torcida e compreender minha ausência por acreditarem na importância dessa conquista.

A todos meus amigos em especial à Karim, Nadya, Renata e Pedro pelo acolhimento e pelos bons momentos.

Ao programa de Pós Graduação em Sistemas Logísticos de Transporte e a Universidade de São Paulo pela oportunidade 


\section{RESUMO}

Este trabalho tem seu foco no problema de sequenciamento e programação da lavra em mina a céu aberto, com alocação de equipamentos de carregamento. Neste estudo considera-se a existência de uma frota heterogênea de equipamentos de carga e dois tipos de material lavráveis, sendo minério ou estéril. Para a lavra de minério são considerados requisitos de qualidade a serem atingidos pela mistura de minério, um britador, uma capacidade de operação atribuída à usina de beneficiamento e uma pilha de estoque objetivando abastecer a usina quando faltar minério nas frentes de lavra, denominada pilha de ROM. Em uma mina o carregamento pode ser gerido por um plano de lavra que descreve a movimentação e a produção horária de cada equipamento de carga ao longo do tempo. Neste contexto, apresenta-se um modelo matemático apoiado por um algoritmo responsável por mover o horizonte de tempo a cada execução do modelo com intuito de gerar ordens de lavra resolvidas com otimalidade. Juntas, essas ordens descreverão o plano de lavra dos equipamentos de carga. Os experimentos computacionais, realizados utilizando dados de uma jazida de cobre, mostram a efetividade da proposta considerando um horizonte de médio prazo.

Palavras Chaves: Pesquisa Operacional. Planejamento de lavra. Mistura de minério. Pilha de ROM. 


\begin{abstract}
This paper focuses on the mining scheduling problem in open pit, considering the allocation of loading equipment. This study considers the existence of a heterogeneous fleet loading equipment and two types of mineable material, namely ore or waste. For the mining of ore are considered quality requirements to be met by the ore blending, $a$ crusher, the capacity of operation of the processing plant and a stockpile which feed the plant when there is lack of ore in mining fronts, called ROM stockpile. In a mine, loading can be managed by a mining plan that describes the movement and the schedule of each load equipment over time. In this context, we present a mathematical model supported by an algorithm that is responsible for moving the time horizon for each model run, with the goal of generating mining orders till resolved to optimality. Together, these orders describe the mining plan of the loading equipment. The computational experiments, conducted using data from a copper deposit, show the effectiveness of the proposal considering a medium-term horizon.
\end{abstract}

Keywords: Operation Research. Mine Planning. Allocation Loading Equipment. Ore Blending. ROM Stockpile. 


\section{LISTA DE ILUSTRAÇÕES}

Figura 2.1 - Contribuição financeira pela exportação de recursos minerais. .8

Figura 2.2 - Fluxograma das fases da mineração. .9

Figura 2.3 - Possível representação de um modelo de blocos de uma mina . 10

Figura 2.4 - Coordenadas no modelo de bloco .11

Figura 2.5 - Identificações dos blocos no modelo geológico 12

Figura 2.6- Exemplo de avanços. 15

Figura 2.7 - Relações da precedência de blocos 15

Figura 2.8 - Possíveis blocos a serem retirados com restrição de cinco blocos acima

Figura 2.9 - Exemplo de rede precedência de blocos 16

Figura 2.10 - Estrangulamento da cava 17

Figura 2.11 - Mistura de ROM 18

Figura 3.1 - Representação da lavra de minério 23

Figura 3.2 - Representação da lavra de estéril. 24

Figura 3.3 - Fluxograma do processo estudado. .25

Figura 3.4 - Gráficos de Gantt representando uma sequência de. .28

Figura 3.5 - Movimentação dos equipamentos de carga. 31

Figura 4.1 - Heurística para otimização sequencial. 41

Figura 5.1 - Fluxograma das atividades executadas pelo algoritmo. .70

Figura 5.2 - Matriz nível e conversão para índice sequencial dos blocos da superfície .72

Figura 5.3 - Ordem de lavra completa. 81

Figura 6.1 - Imagem tridimensional da mina utilizada. .82

Figura 6.2 - Vista superior da jazida KD. 84

Figura 6.3 - Determinação do nível minimo para cada posição (nLinha x nColuna). 85 
Figura 6.4 - Área selecionada como avanço. .86

Figura 6.5 - Número de blocos de minério contidos em cada posição LinhaxColuna .87

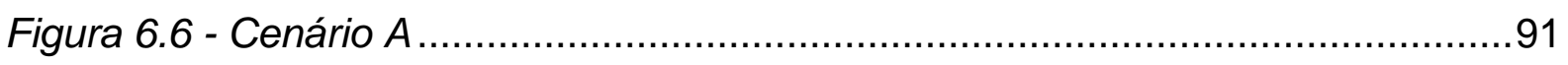

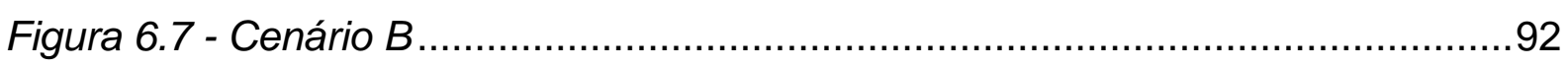

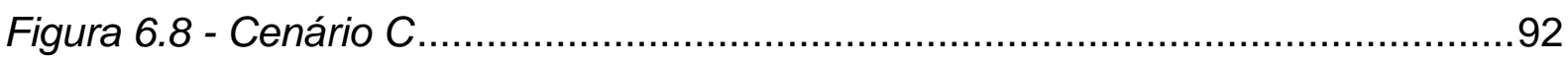

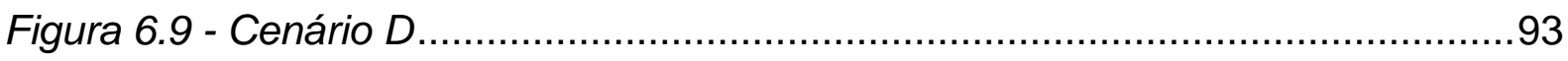

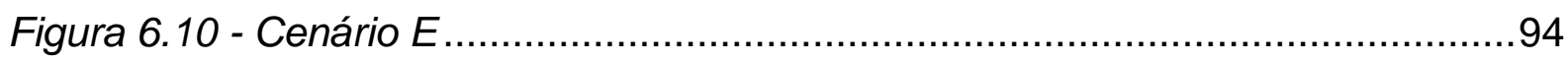

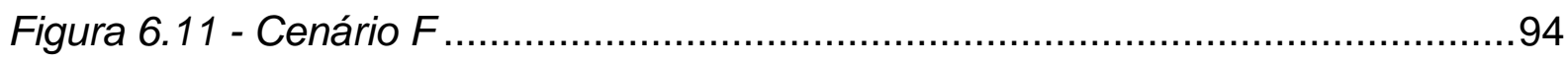

Figura 6.12 - Duração de cada ordem de lavra (horas)...........................................97

Figura 6.13 - Blocos de minério e estéril disponíveis ...........................................97

Figura 6.14 - Ritmo de lavra total dos equipamentos de carga...............................98

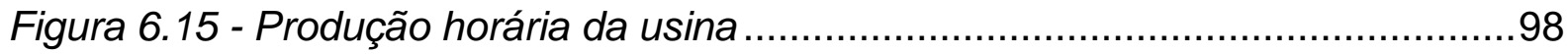

Figura 6.16 - Evolução do tamanho da pilha ...........................................................99

Figura 6.17 - Retomada da pilha de ROM......................................................99

Figura 6.18 - Teor da mistura enviado a usina a cada ordem de lavra ..................100 


\section{LISTA DE TABELAS}

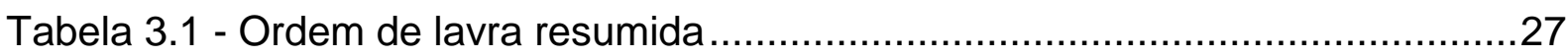

Tabela 3.2 - Exemplo de ordens de lavrarem formato reduzido ..........................29

Tabela 5.1 - Principais resultados gerados pelo modelo matemático .....................75

Tabela 6.1 - Dados gerais dos blocos selecionados ..................................... 88

Tabela 6.2 - Dados dos equipamentos de carga........................................... 89

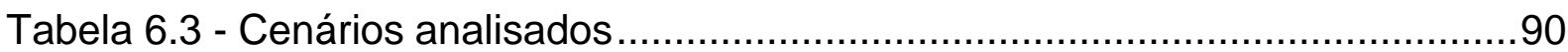

Tabela 6.4 - Resumo dos resultados obtidos .................................................95 


\section{LISTA DE SIGLAS}

CPIT Constrained Pit Limit Problem

PAEC Planejamento de Alocação Estática de Caminhões

PAED Planejamento de Alocação Dinâmica de Caminhões

PCPSP Precedence Constrained Production Scheduling Problem

PMM Problema da Mistura de Minério

POLAEC Planejamento das Operações de Lavra com Alocação de Equipamentos de Carga

REM Relação Estéril -Minério

ROM Run Of Mine

SPLAEC Sequenciamento e Programação de Lavra com Alocação de Equipamentos de Carga

UPIT Ultimate Pit Problem

VPL Valor Presente Líquido 


\section{SUMÁRIO}

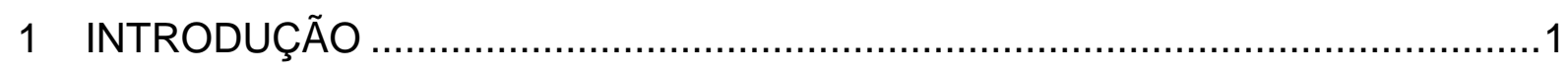

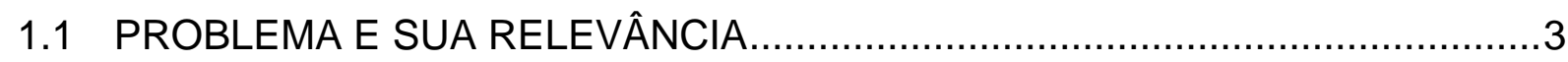

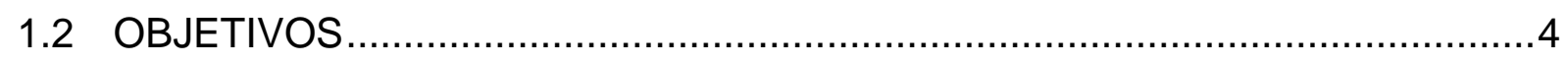

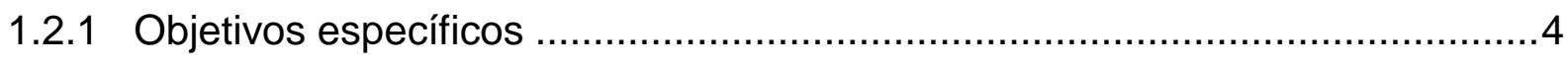

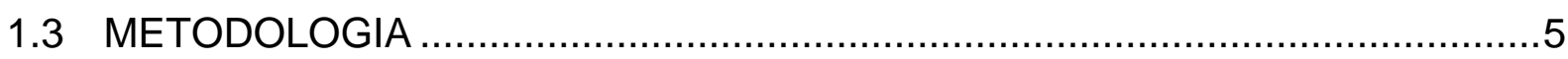

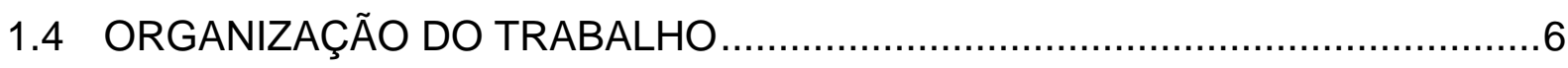

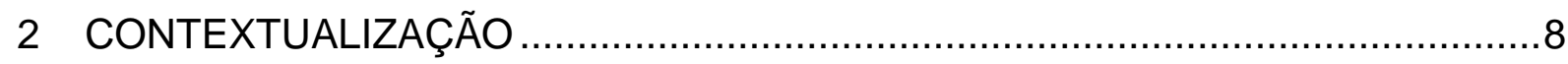

2.1 MINERAÇÃO

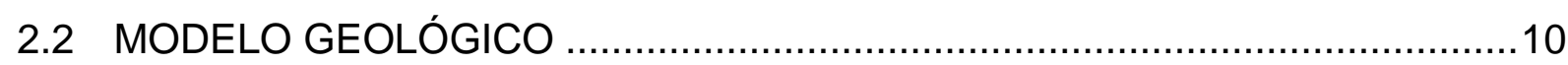

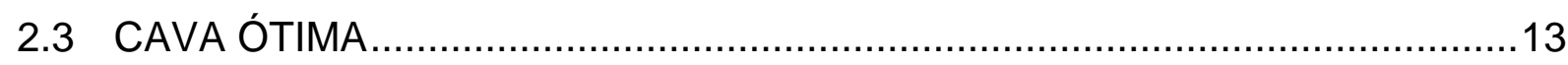

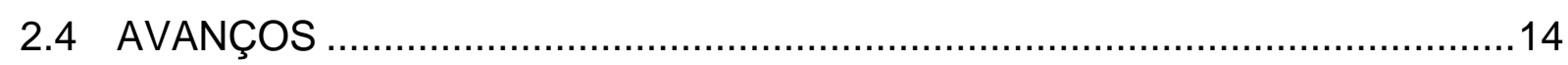

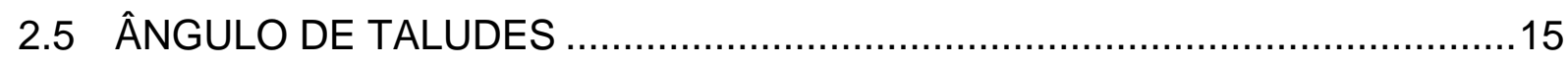

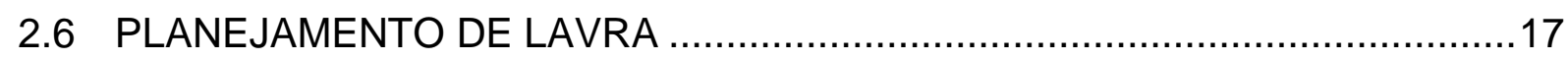

2.7 SEQUENCIAMENTO E PROGRAMAÇÃO DA LAVRA ................................19

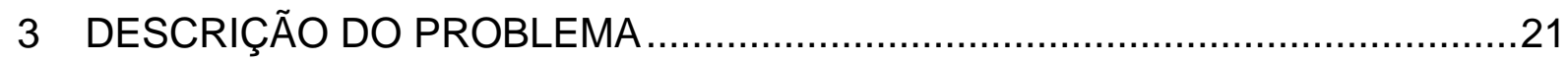

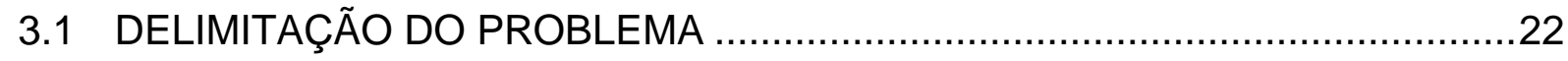

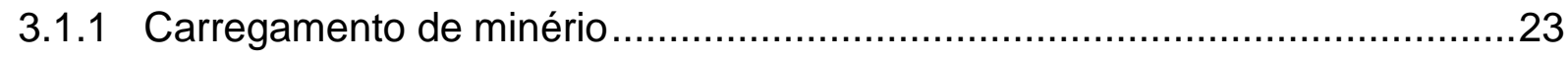

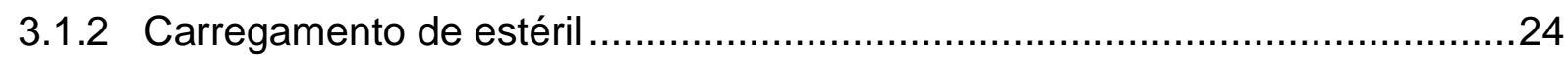

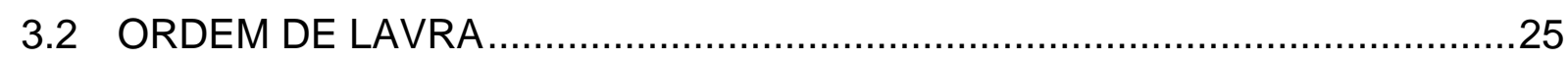

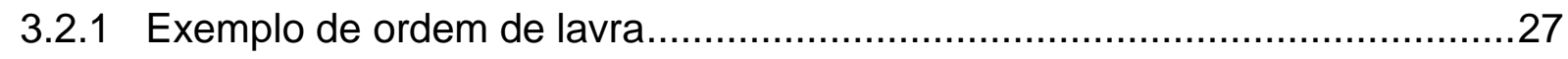

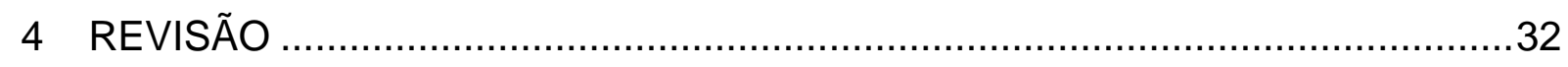

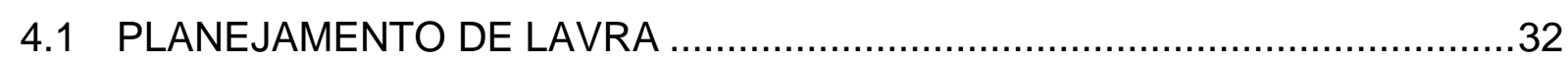

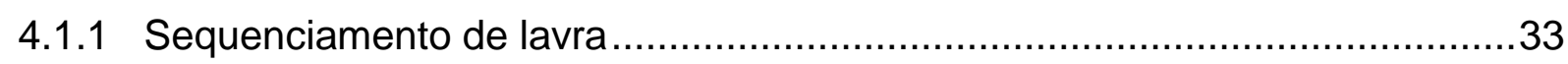

4.1.2 Planejamento operacional de lavra de curto prazo ......................................38 
4.2 PROBLEMA DO PLANEJAMENTO DE OPERAÇÕES DE LAVRA EM MINAS À CÉU ABERTO.. 39

4.2.1 Heurística e modelo matemático (AMARAL, 2008) ......................................40

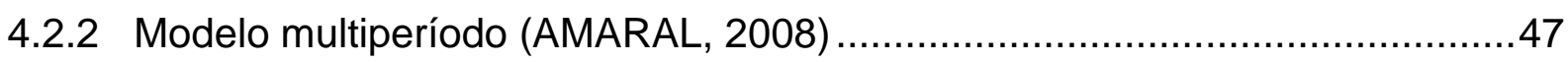

4.3 SEQUENCIAMENTO E PROGRAMAÇÃO DE MÁQUINAS PARALELAS .......54

5 MÉTODO MATEMÁTICO PARA O PROBLEMA.............................................58

5.1 MODELO DO PROBLEMA DE ALOCAÇÃO DE EQUIPAMENTOS DE CARGA EM UMA MINA A CÉU ABERTO CONSIDERANDO A EXISTÊNCIA DA PILHA DE ROM .59

5.2 ALGORITMO PARA ABORDAGEM DO HORIZONTE MÓVEL........................69

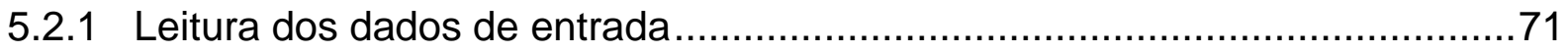

5.2.2 Definição de blocos disponíveis ...............................................................

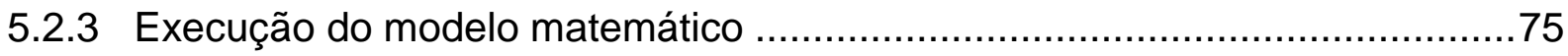

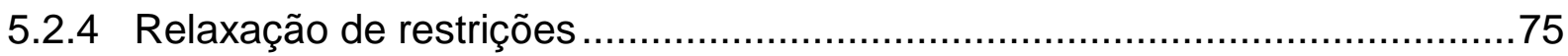

5.2.5 Determinar o instante da próxima execução do modelo ………………......76

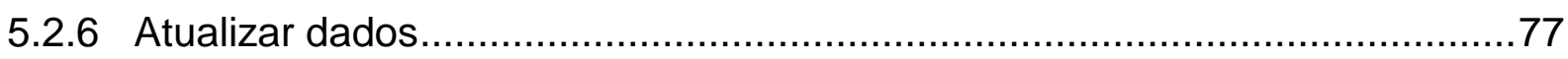

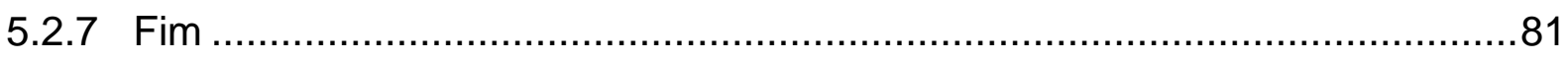

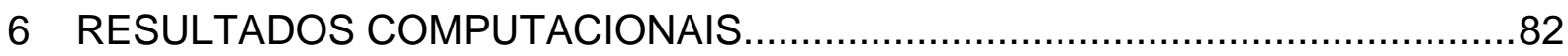

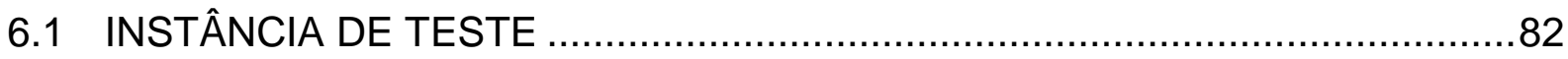

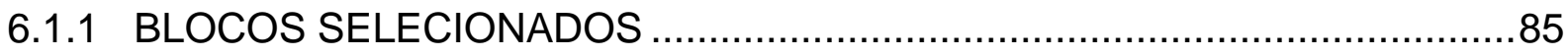

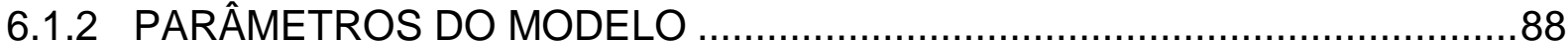

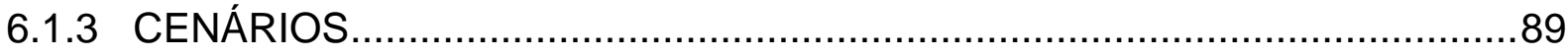

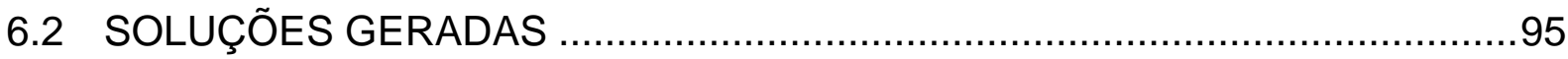

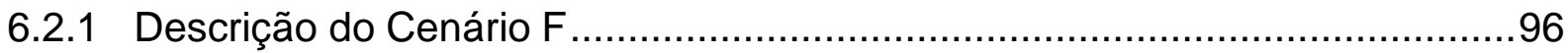

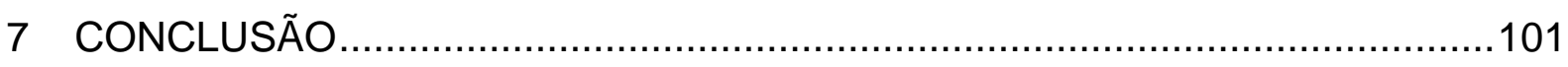

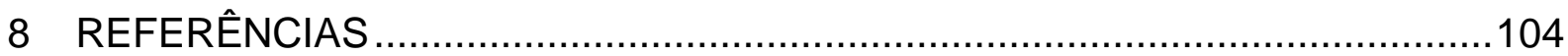




\section{INTRODUÇÃO}

Uma forma de aumentar a competitividade das empresas é implantar um sistema eficiente de planejamento e controle da produção, assegurando assim, a execução do que foi planejado no tempo, na quantidade e qualidade adequadas e com os recursos corretos (CACCETA \& HILL, 2003).

O planejamento pode ser elaborado considerando-se três fases: estratégico, tático e operacional. No planejamento estratégico, o objetivo é determinar metas para um futuro mais distante, como, por exemplo, estudos que abordam alguns anos à frente. Já no planejamento tático, geralmente pensa-se em um cenário de até um ano, enquanto no operacional, trabalha-se com um planejamento bimestral, mensal ou até diário. Estes intervalos não são rígidos e podem variar de empresa para empresa (ARAÚJO, 2008).

Em uma mineradora, uma das tarefas atribuídas ao planejamento estratégico consiste na elaboração de um planejamento de lavra que subdivide a mina em diversas regiões, chamadas de extensões ou avanços, que serão lavradas até exaurir todo o material da cava definida como ótima. Segundo Dagdelen (2001), uma maneira de tratar essas regiões é através de um conjunto de blocos, os quais possuem características físico-químicas derivadas de um estudo geoestatístico. Dependendo de suas características, um bloco pode ser considerado como bloco de minério ou bloco de estéril. (TOLWINSKI \& UNDERWOOD, 1996).

Blocos considerados como minério possuem um material cujos processos de beneficiamento e logísticos seguintes até o produto chegar ao cliente, resultarem em lucro, enquanto blocos de estéril são aqueles que não atendem a esses requisitos.

Segundo Costa (2005), o planejamento da produção da lavra, realizado em cenário de curto prazo, busca determinar o ritmo de extração (t/h) para cada frente de lavra capaz de atender à demanda do cliente, seja a usina de beneficiamento ou algum cliente externo. As produções de ROM (run-of-mine), minério bruto retirado da frente de lavra de minério, oriundas de diferentes frentes de lavra de minério, devem proporcionar a quantidade desejada, não excedendo a capacidade física do sistema 
e não impactando na redução da utilização de equipamentos e recursos, de forma a cumprir os compromissos contratuais da mineradora sem acarretar multas contratuais. Outro aspecto importante está na busca por atender metas de qualidade da mistura de minério, reduzindo a flutuação de parâmetros controlados e tornando seu beneficiamento mais eficiente. Ainda segundo o autor, outras metas do planejamento de lavra estão relacionadas à exploração de estéril, essencial para liberar minério no futuro e buscar atingir a máxima produtividade dos equipamentos de carga alocados à frente de lavra, visando assim a conciliar tanto a produção de minério como a extração de estéril das frentes de lavra.

O material extraído das diferentes frentes é transportado, geralmente, por caminhões ao seu destino; no caso de frentes de minério, o material é descarregado em um britador ou pilhas de estoque, enquanto, por outro lado, o material proveniente de frentes de estéril é transportado e descarregado em pilhas de estéril (ARAÚJO, 2008).

O presente trabalho apresenta um novo modelo matemático e um algoritmo de apoio capaz de elaborar o sequenciamento e a programação dos equipamentos de carga, considerando fatores operacionais importantes para alcançar objetivos comerciais como produção e qualidade da mistura do minério, comumente encontrados em trabalhos que abordam o planejamento de curto prazo. Assim como considerar a existência de um modelo de blocos e de ângulos de talude, contemplados principalmente em trabalhos que abordam o planejamento de lavra de médio e longo prazo. Dessa forma, pretende contribuir para suprir necessidades reais de planejamento de indústrias mineradoras, assim como reduzir a lacuna teórica existente entre a determinação da cava ótima e modelos de planejamento de curto prazo.

O modelo matemático desenvolvido é pertencente à classe de modelos em PLIM (Programação Linear Inteira Mista), pode ser caracterizado como on-line, utilizando informações atualizadas provenientes de tecnologia de localização remota e sistemas embarcados, disponíveis em grande parte das minas. Dados como a localização atual dos equipamentos, quantidade de ROM na pilha de estoque e a qualidade do ROM beneficiado, são informações cruciais para geração do sequenciamento e programação da lavra cujas soluções dependerão de tais informações. 
Será utilizado um modelo de blocos disponibilizado por Espinoza et al. (2012b) que representa uma mina de cobre. Os equipamentos de carga, pilha de estoque e usina de beneficiamento, foram estimados nesse trabalho para validação do sistema.

\subsection{PROBLEMA E SUA RELEVÂNCIA}

O Brasil é um país com grande extensão territorial, diversidade de terrenos e formações geológicas que proporcionaram a presença de inúmeros minérios em seu solo. Os números são expressivos e abrangem mais de 70 substâncias minerais. Quanto ao método utilizado, considerando as minas com produção superior a 10.000 t/ano, 2.597 minas operam a céu aberto, 47 por lavra subterrânea, e 3 operam com os dois métodos. (MME, 2010)

Empresas mineradoras que lavram e processam os diferentes tipos de minério devem lidar com a flutuação dos preços do mercado (NEWMAN et al., 2010). Sendo assim, uma das formas de maximizar os lucros é através de um planejamento e controle da produção eficiente capaz de gerir as ações a serem tomadas (CACCETA \& HILL, 2003).

No planejamento das operações de lavra, os desafios estão em atingir as metas estabelecidas para ROM cuja mistura deve fornecer a qualidade requerida, muitas vezes tendo diferentes características físico-químicas analisadas como granulometria e teor de contaminantes, além de extrair o estéril para liberar novas áreas com minério. Outro requisito da operação de lavra que em alguns casos pode ser conflitante com as metas para ROM é de evitar o estrangulamento da cava, de onde, devido ao seu aprofundamento, os equipamentos de carga, por motivo de segurança, devem retirar materiais apenas do topo para irem alargando a cava em busca de minério (AMARAL, 2008).

Lidar com essas características torna o planejamento e controle operacional de lavra desafiador no que se refere, por exemplo, a determinar qual a sequência de blocos deve ser lavrada, onde cada bloco é análogo a uma tarefa, a qual ritmo de lavra (t/h), por cada equipamento de carga existente responsável por carregar material, minério 
ou estéril, nas frentes de lavra e descarregar geralmente em caminhões. Quando mal executado, esse sequenciamento e programação da produção pode impactar na diminuição da receita ao longo do tempo.

\subsection{OBJETIVOS}

O objetivo geral desta dissertação é o desenvolvimento de um método matemático utilizando a estratégia de horizonte móvel capaz de gerar o Sequenciamento e a Programação da Lavra com Alocação de Equipamentos de Carga (SPLAEC).

O algoritmo desenvolvido move o horizonte de tempo e atualiza os dados de entrada do modelo a cada período de planejamento até o fim do horizonte a ser estudado ou caso todos os blocos contidos no avanço a ser lavrados sejam extraídos pelos equipamentos de carga. O modelo deve considerar restrições tipicamente de planejamento de longo e médio prazo como modelo de blocos, ângulo de talude e em alguns casos pilha de estoque de ROM e restrições operacionais ligadas à mistura de minério e minimização de deslocamento dos equipamentos de carga.

\subsubsection{Objetivos específicos}

1. Desenvolver um novo modelo matemático para o problema de planejamento operacional de lavra considerando restrições tipicamente abordadas em planejamento de curto e médio/longo prazo;

2. Desenvolver um algoritmo responsável pela retroalimentação de dados baseado em horizonte móvel capaz de solucionar o problema em tempo computacional aceitável;

3. Verificar e validar o sistema desenvolvido;

4. Comparar o sistema desenvolvido com instâncias realistas. 


\subsection{METODOLOGIA}

A presente pesquisa, do ponto de vista metodológico, tem objetivo exploratório e abordagem quantitativa, que terá procedimento de resolução na Pesquisa Operacional.

A classificação do objetivo como exploratório foi adotado, pois pretende-se buscar um maior conhecimento do processo-alvo.

Segundo Morabito \& Pureza (2010), modelos quantitativos são uma representação abstrata em linguagem matemática que utilizam técnicas analíticas (matemáticas, estatísticas) e experimentais (simulação) para calcular valores numéricos das propriedades do sistema. Modelos quantitativos possuem um conjunto de variáveis de controle que variam em um domínio específico, e as variáveis de desempenho que resultam na qualidade obtida a partir das relações entre essas variáveis. As variáveis consideradas podem ser tanto físicas como nível de estoque quanto econômicas como maximização dos lucros ou minimização dos custos.

Segundo Costa (2005), o problema de planejamento operacional de lavra pode ser atribuído à classe do Problema da Mochila Inteira Múltipla, ao qual pertence à classe de problemas NP-difícil. No caso da presente pesquisa, cada equipamento de carga representa uma mochila, e a atribuição de blocos a cada um deles dependerá da qualidade da mistura de ROM, a utilização de recursos, da minimização de deslocamento, entre outras restrições apresentadas futuramente.

Entre os objetivos possíveis, optou-se pela minimização do tempo total necessário para processar todas as tarefas, chamado makespan, associado diretamente à maximização da utilização dos recursos.

Segundo Arenales et al. (2007), Pesquisa Operacional é a aplicação de métodos científicos a problemas complexos para auxiliar no processo de tomada de decisões, tais como planejar e operar sistemas que de forma geral requerem alocações eficientes de recursos escassos. Para Morabito \& Pureza (2010), a modelagem quantitativa tem sido de grande importância na Pesquisa Operacional. Segundo os 
autores, a abordagem da resolução de um problema sob a ótica da Pesquisa Operacional envolve:

I. Definição do problema: a partir de um problema, é definido o escopo do problema, quais são os objetivos e o modelo conceitual para o problema. Nesta fase, são definidas as alternativas de decisões e limitações do modelo;

II. Construção do modelo: As decisões e estimativas da etapa anterior são utilizadas para desenvolver e analisar um modelo matemático para o problema. Em geral, modelos matemáticos construídos a partir do modelo conceitual são baseados em outros modelos matemáticos existentes na literatura. Nessa etapa, é realizada a coleta de dados para determinar parâmetros para o modelo; nesta fase, é comum a realização de análises e experimentos para conhecer o comportamento do modelo e sua adequação;

III. Solução do modelo: para a resolução do problema construído na fase anterior através de métodos de solução e algoritmos em geral, utilizando software e hardware. Verificam-se as respostas geradas, assim como seu desempenho computacional. Também é comum o teste da robustez do modelo através de variações nos parâmetros;

IV. Validação do modelo: Verifica-se se o modelo proposto descreve adequadamente o comportamento do sistema real, considerando as hipóteses admitidas na fase I. A qualidade dos resultados também depende dos dados de entrada em que dados falsos geram resultados falsos;

V. Implementação: Em alguns casos, a pesquisa desenvolvida pode ser implementada para utilização na prática de empresas ou organizações, traduzindo os resultados obtidos em decisões a serem tomadas.

Na presente dissertação, optou-se o pelas abordagens dos itens I a IV.

\subsection{ORGANIZAÇÃO DO TRABALHO}

Este trabalho está organizado como segue.

Uma contextualização resumida de informações importantes para compreensão do 
trabalho é apresentada no capítulo 2.

No capítulo 3, é descrito o problema objeto de estudo deste trabalho, bem como apresentado um exemplo e algumas respostas geradas.

No capítulo 4, são revistos trabalhos relevantes ao tema "planejamento de lavra de minas a céu aberto" e são descritos aspectos de sequenciamento e programação da produção (scheduling) utilizados nesse trabalho.

O capitulo 5 descreve o modelo matemático e algoritmo desenvolvido, utilizando a abordagem de horizonte móvel com a finalidade de gerar ordens de lavra.

O capítulo 6 mostra uma aplicação do modelo matemático utilizando como instância uma jazida de cobre e os resultados gerados.

Por último, no capítulo 7, faz-se considerações a respeito dos modelos e métodos de solução desenvolvidos, bem como sugestões para a realização de trabalhos futuros. 


\section{CONTEXTUALIZAÇÃo}

\subsection{MINERAÇÃO}

Mineração é o processo de extrair material da terra para obter lucro. A atividade mineira no Brasil envolve números expressivos (Figura 2.1), sendo uma das commodities mais importantes do país.

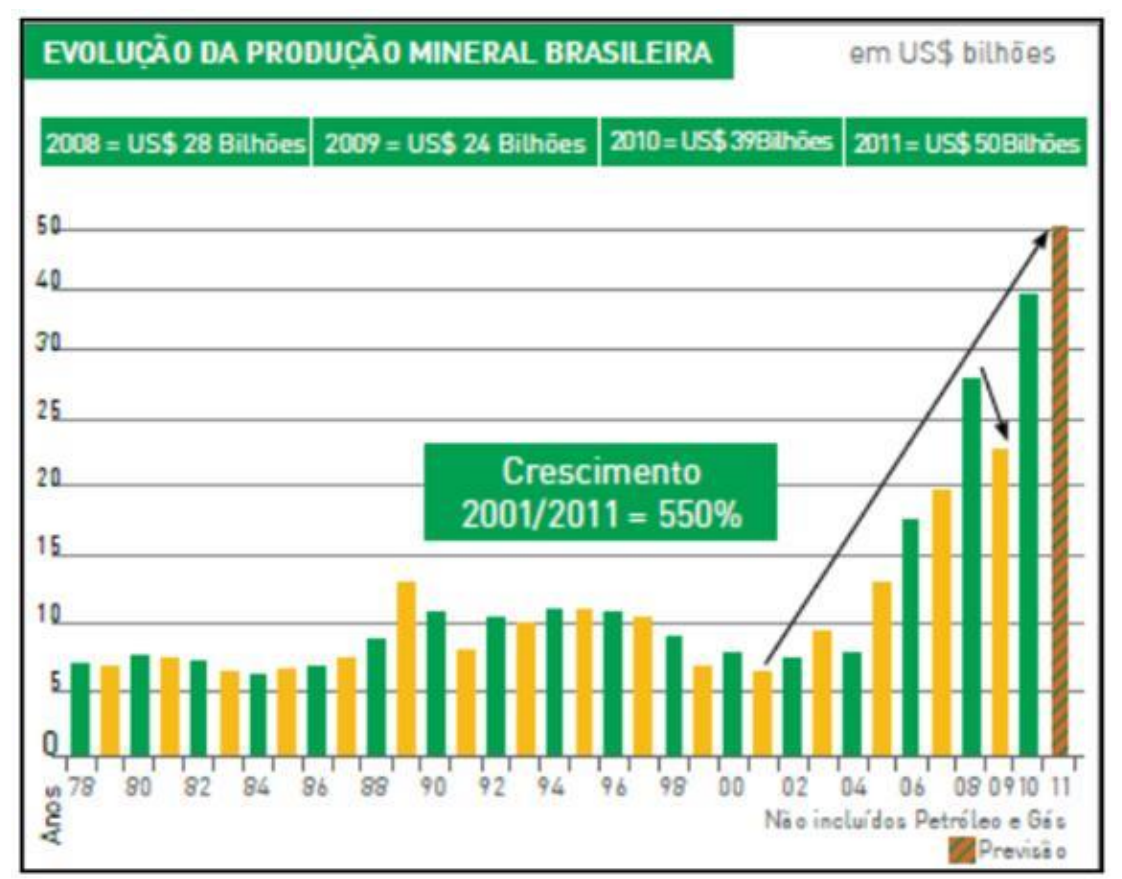

Figura 2.1 - Contribuição financeira pela exportação de recursos minerais Fonte: IBRAM, 2011

A mineração possui cinco estágios distintos: (1) prospecção, (2) pesquisa mineral, (3) desenvolvimento, (4) lavra e (5) recuperação ambiental.

Na etapa de prospecção, os geólogos realizam análises visuais e laboratoriais através de amostragem para descobrir jazidas minerais.

$\mathrm{Na}$ pesquisa mineral, geólogos determinam o valor do depósito a ser lavrado por sondas para estimar o mineral, sua concentração e sua variabilidade na jazida. 
Técnicas de interpolação são aplicadas utilizando os parâmetros fornecidos pelas amostras obtidas de diferentes áreas com intuito de estimar o valor econômico da jazida.

As atividades de desenvolvimento contemplam direitos de acesso à terra, remoção da camada superior do terreno, assim como determinar o método de mineração adequado, estimar a capacidade de produção e engenharia detalhada.

$\mathrm{Na}$ fase de lavra, o minério é extraído da superfície (mineração a céu aberto) ou do subterrâneo. No caso da mineração a céu aberto, o material é transportado por caminhões ou correias para diferentes destinos, podendo ser armazenado para ser enviado a uma planta de beneficiamento posteriormente, enviado direto para uma planta de beneficiamento ou para um aterro (Newman et al., 2010).

A última etapa, recuperação, consiste em desmobilizar equipamentos e infraestrutura e recuperação ambiental para liberar a área para outros fins (Nery, 2010). A Figura 2.2 apresenta um resumo das cinco etapas descritas anteriormente.

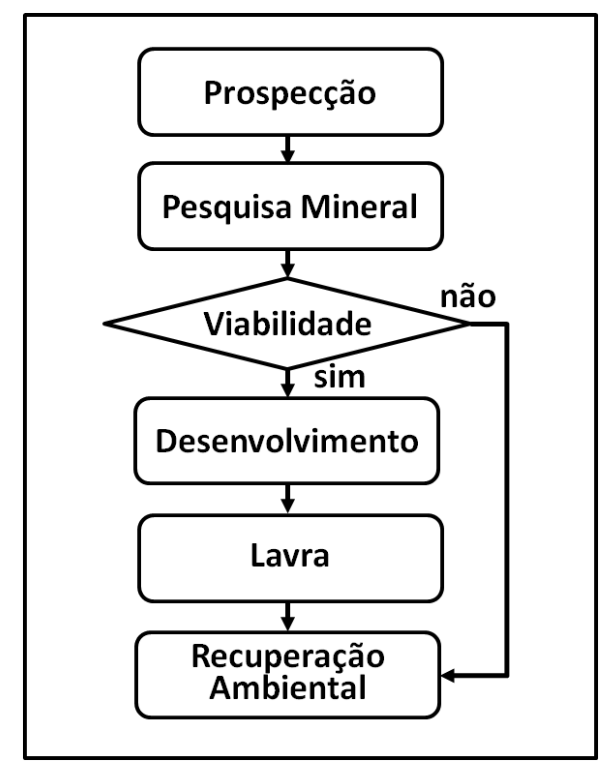

Figura 2.2 - Fluxograma das fases da mineração

Todas as etapas descritas podem ser revistas ao longo do tempo para garantir a confiabilidade e atualização das informações que orientarão os planejamentos estratégico, tático e operacional. 


\subsection{MODELO GEOLÓGICO}

Uma forma comum de representar uma mina é através de referências espaciais chamadas blocos. O modelo geológico composto por blocos é uma representação tridimensional de uma mina, discretizando o volume de terra da mina em milhares ou milhões de blocos (ESPINOZA, 2012a). Tal modelo representa uma importante ferramenta computacional à mineração destinado, por exemplo, para estimação dos teores, da quantidade de material contido na reserva e para a visualização do depósito mineral (AMARAL, 2008). A Figura 2.3 apresenta uma reprodução hipotética de um modelo de blocos geológicos em 3-D, representando um corpo mineral de uma mina.

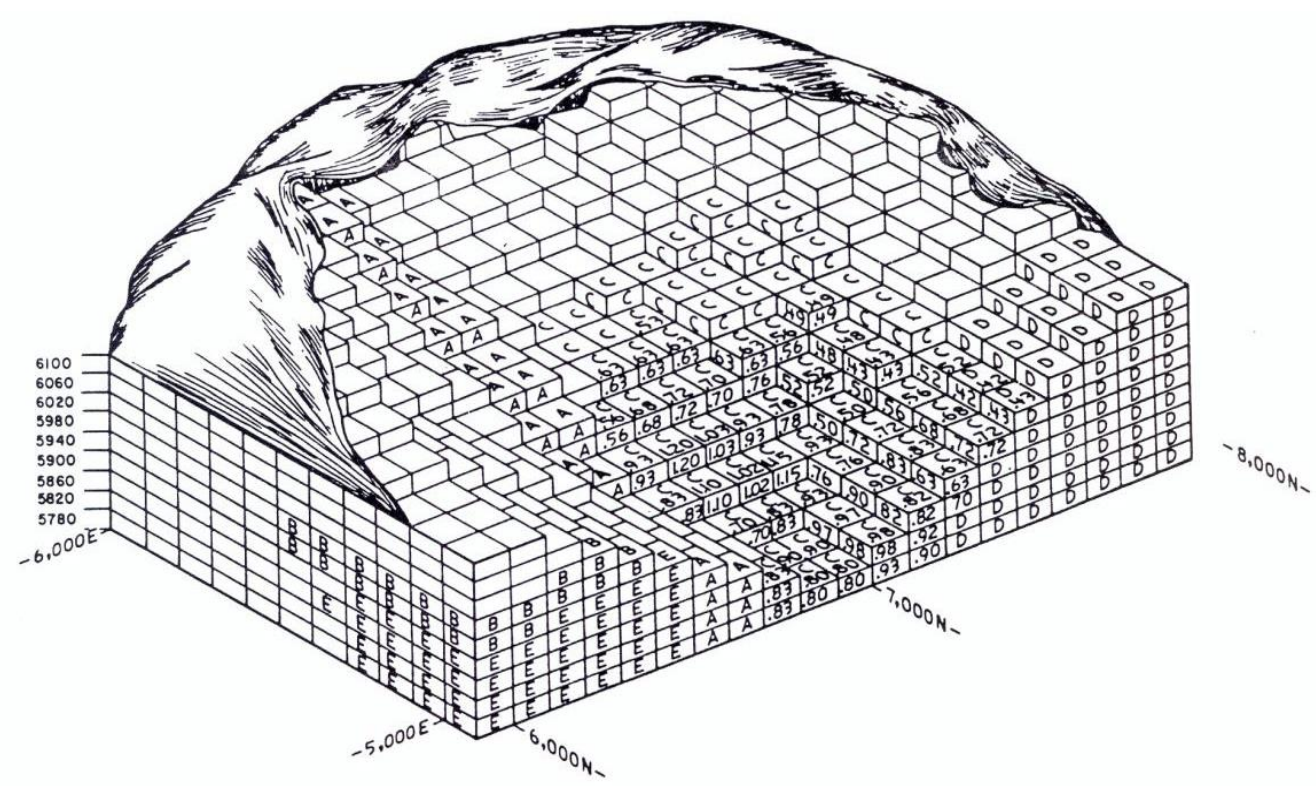

Figura 2.3 - Possível representação de um modelo de blocos de uma mina Fonte: CRAWFORD \& DAVEY, 1979

Segundo Thorley (2012), a dimensão de cada bloco varia em geral conforme cada depósito. A altura definida para cada bloco normalmente depende da altura da bancada. O tamanho de cada bloco deve considerar se existe uma maior necessidade de seletividade. Todas três dimensões do bloco podem possuir o mesmo tamanho (metros) ou não.

Em depósitos cuja seletividade não é um problema, um bloco com dimensões maiores 
pode ser utilizado. Caso contrário, quando a seletividade é importante, indica menor altura de bancada e de menores equipamentos, visando a diluir a suavização dos teores. O autor argumenta que tamanhos muito reduzidos devem ser evitados por aumentar o tamanho do modelo, tempo de processamento e aumento do erro de estimativas de teores.

A mina é considerada como um modelo de blocos, no qual cada bloco é identificado como uma coordenada representando a linha $(\mathrm{L})$, a coluna $(\mathrm{C})$ e o nível $(\mathrm{H})$. Como apresentado na Figura 2.4.

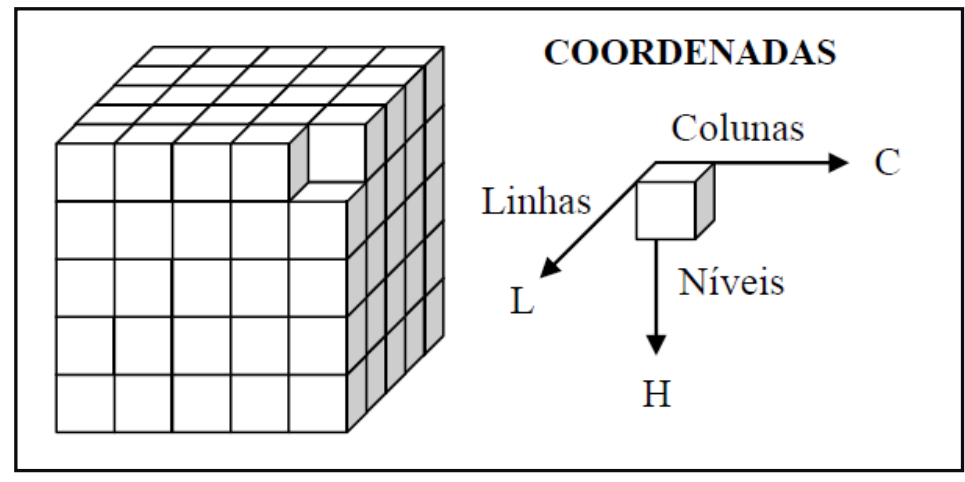

Figura 2.4 - Coordenadas no modelo de bloco

Fonte: AMARAL, 2008

Além das coordenadas, todos os blocos são enumerados progressivamente (n), no presente trabalho, o início é atribuído ao bloco da primeira coluna da primeira linha do nível superior. Avançando o índice (n) coluna a coluna, após término das colunas muda-se de linhas, após o fim das linhas muda-se para o nível inferior. Esse procedimento é repetido até o último bloco. A Figura 2.5 apresenta essa enumeração de uma forma mais simplificada. 


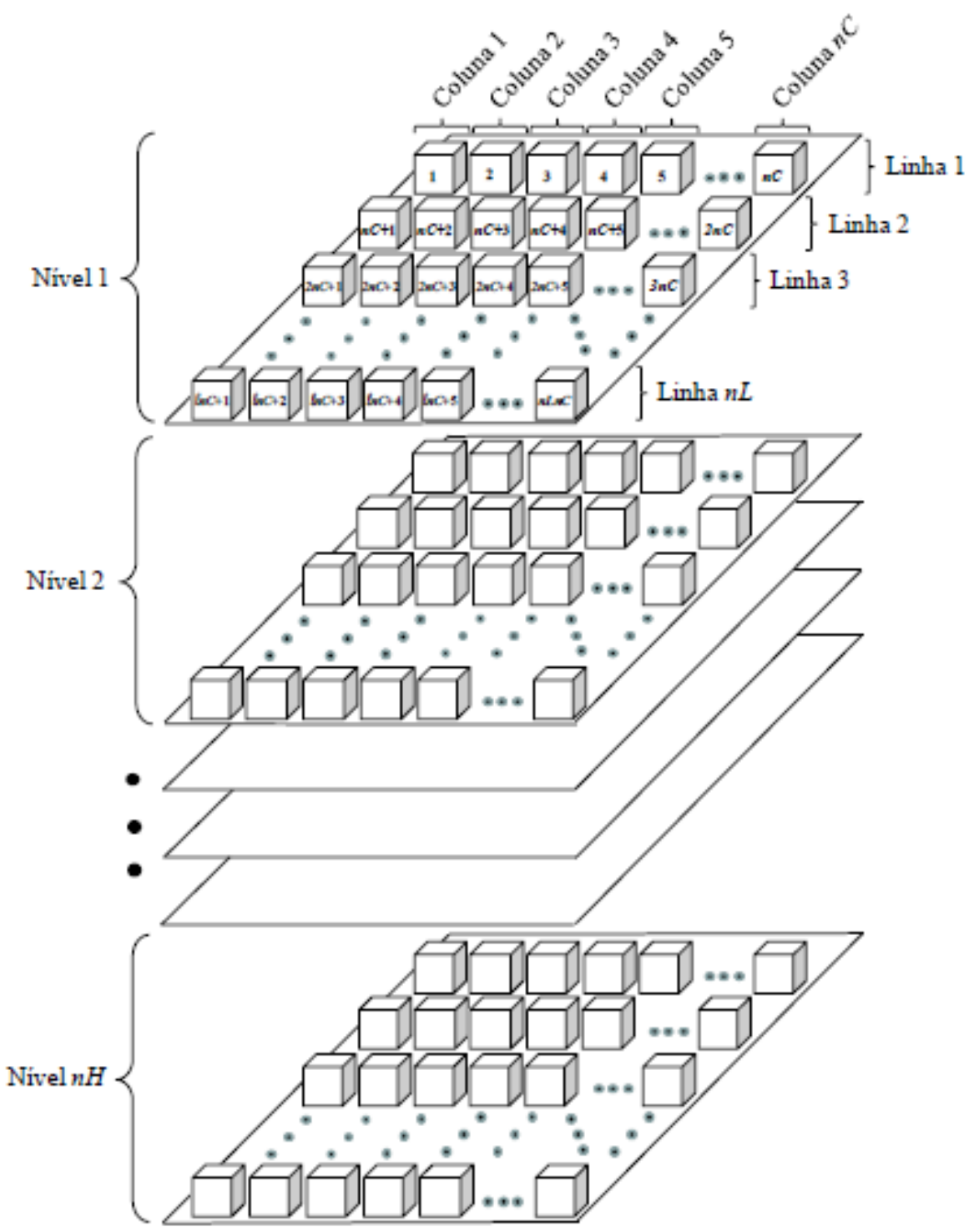

Figura 2.5 - Identificações dos blocos no modelo geológico Fonte: AMARAL, 2008

Sendo que $\mathrm{nL}$ corresponde ao número total de linhas, $\mathrm{nC}$ corresponde ao número total de colunas e $\mathrm{nH}$ corresponde ao número total de níveis.

Considerando as coordenadas linha, coluna e nível $(\mathrm{L}, \mathrm{C}$ e H) de um bloco é possível calcular seu índice sequencial, $n$, conforme a equação 2.1 :

$$
n=(H-1) \times n L \times n C+(L-1) \times n C+C
$$




\subsection{CAVA ÓTIMA}

A cava ótima define o tamanho e a forma de uma mina a céu aberto no final das operações, e sua determinação tem como objetivo em geral a maximização dos lucros. A definição da cava ótima delimita a extensão das reservas e a quantidade de minério e estéril a ser lavrada, obtendo a fronteira limite que maximiza o lucro. Também demarcam locais onde instalações permanentes não devem ser construídas, como a usina de beneficiamento. (GUIMARÃES, 2007).

A determinação da cava ótima é uma das primeiras atividades a serem desenvolvidas pelo planejamento de lavra sendo revisto durante a vida útil do empreendimento. O primeiro algoritmo específico relacionado ao tema foi publicado em 1965 por Lerchs \& Grossman e é aceito até os dias de hoje como referência para teste de outros métodos propostos (CARMO et al., 2006). Atualmente, o método proposto por Hochbaum \& Chen (2000) através do algoritmo de fluxo máximo, denominado pushrelabel, apresenta uma evolução comparado com os resultados obtidos pela implementação do algoritmo de Lerchs e Grossmann (AMARAL, 2008; NEWMAN et al., 2010; KOZAN \&LIU, 2012).

Segundo Newman et al. (2010), outro método aplicado ao problema, cone flutuante, determina um ponto de referência no interior da cava e o expande até a superfície, removendo os blocos necessários, respeitando as regras de declive impostas pelo ângulo de segurança de taludes, assim resulta em um cone em que é possível determinar o ganho na extração, VPL (valor presente líquido). Os autores apontam dois problemas do método: (1) a cava ótima depende dos blocos selecionados e (2) a cava pode depender de um número grande de blocos de referência para atingir uma resposta considerável, embora não seja ótima.

O método cone flutuante é utilizado amplamente na prática (NEWMAN et al. 2010; PERONI, 2005), já o algoritmo de Lerchs \& Grossmann (1965) é encontrado mais vezes na literatura (Newman et al., 2010).

Para Kawalec (2008), a precisão, análise e validação de dados imputados deve ser minuciosa, caso contrário, pode tornar todas as análises seguintes inválidas. Portanto, 
a construção do modelo de bloco econômico merece dados representativos, de outra forma, a aplicação dos algoritmos de otimização avançada como o projeto da cava ótima é inútil. Destaca-se a importância de uma modelagem geológica adequada capaz de construir um modelo de blocos de qualidade, avaliação adequada da receita com a venda do minério contido (baseado em dados da bolsa de valores ou fórmulas para preços futuros) e a precisão da distribuição espacial dos custos de mineração.

\subsection{AVANÇOS}

Parte do processo de planejamento em uma mineradora é a definição de avanços, também chamadas de extensões, fases ou pushbacks, gerando cavas intermediárias e assim produzir a evolução do poço ao longo do tempo (DAGDELEN, 2001). Estes poços são gerados por modelos matemáticos que visam a maximizar o VPL, valor presente líquido, da operação no período estudado (MEAGHER et al., 2008).

Em casos mais simples, é lavrado um avanço por vez, preferencialmente do topo até o nível inferior do mesmo. Após término da quantidade programada, repete-se o processo no próximo avanço. Em muitos casos, para satisfazer as metas de produção, é gerado mais de um avanço a ser lavrado simultaneamente. De posse das definições de onde serão os avanços a serem lavrados em dado período, é programada a construção de estradas e outras obras que garantam acesso entre a lavra e o ponto de destino do material (MEAGHER et al., 2008).

Diante do exposto, dadas informações contidas no modelo geológico, e considerando o contorno da cava final ótima da mina, são definidas regiões da mina a serem lavradas por período. Essas regiões são chamadas de avanços, extensões, pushbacks ou fases. Elas podem ser vistas como fatias da mina a serem lavradas em determinado período (EPSTEIN et al., 2010). Um exemplo de avanço é apresentado na Figura 2.6. 


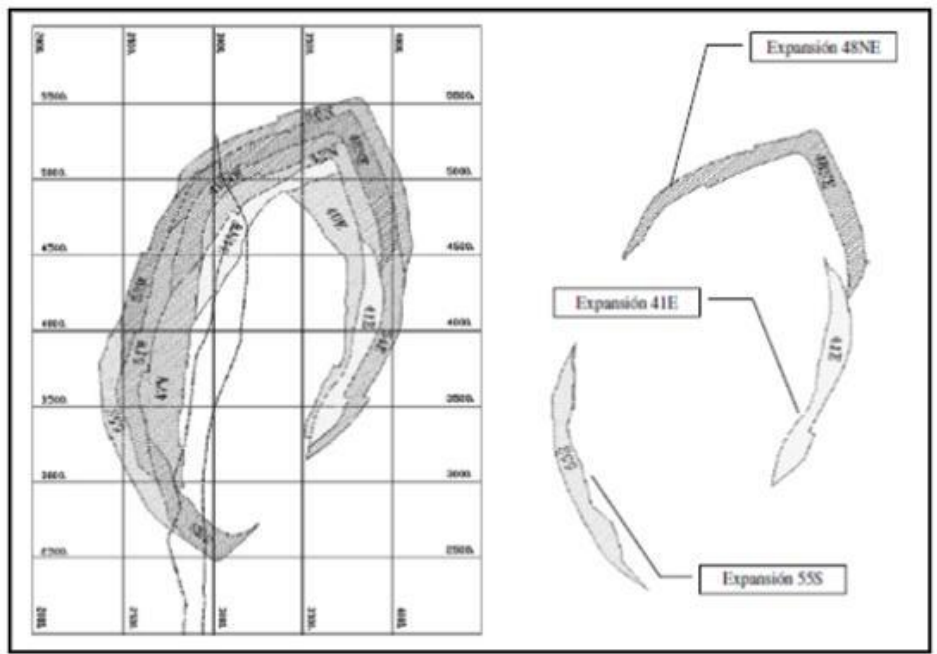

Figura 2.6- Exemplo de avanços

Fonte: EPSTEIN et al., 2010

\section{5 ÂNGULO DE TALUDES}

Entre outros desafios da definição de um sequenciamento e programação da lavra eficiente, destacam-se as restrições de ângulo de talude. Tal restrição impõe precedências a serem cumpridas para atingir o acesso a blocos de níveis inferiores. Para acessar blocos de níveis abaixo ao atual existem restrições operacionais que visam a assegurar que as paredes da cava são estáveis, e que os equipamentos de carregamento e transporte possam acessá-las (NEWMAN, et al., 2010). A Figura 2.7 apresenta duas das restrições mais comuns: 1-5 (cinco blocos acima) e 1-9 (nove blocos acima).

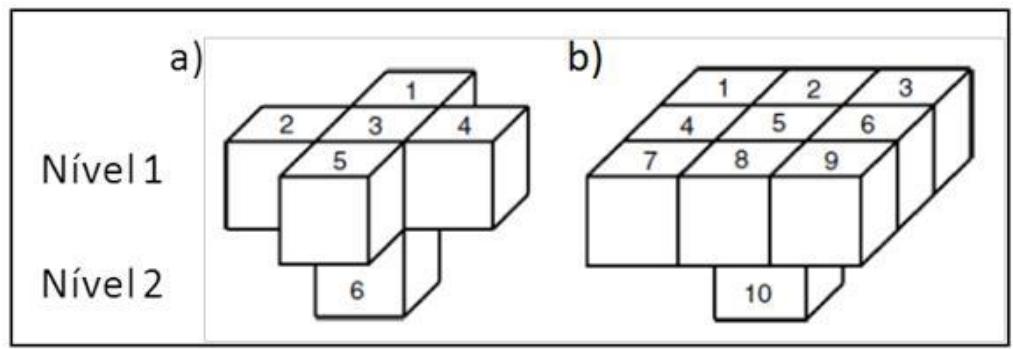

Figura 2.7 - Relações da precedência de blocos

Fonte: NEWMAN et al., 2010 
A restrição de 1-5, também chamada de $45^{\circ}$ (ESPINOZA, et al., 2012a), impõe que para extrair o bloco 6 , é necessário lavrar completamente os 5 blocos do nível superior; na restrição de 1-9, para acessar o bloco 10, é necessário lavrar os nove blocos superiores.

As precedências descritas impõem o ângulo máximo entre as bancadas, construindo geometria da mina ao longo do tempo. Na Figura 2.8, são apresentadas possíveis formações da retirada de blocos distintas pelo número de blocos extraídos, dada lavra sequencial dos blocos considerando a restrição de cinco blocos acima.

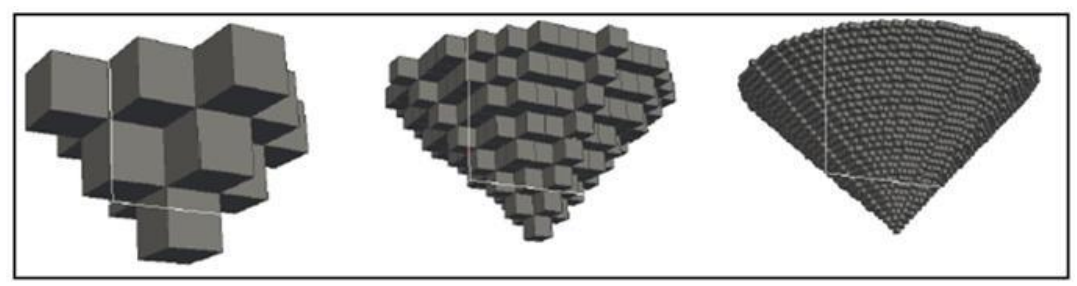

Figura 2.8 - Possíveis blocos a serem retirados com restrição de cinco blocos acima

Fonte: ESPINOZA et al., 2012a

A Figura 2.9 apresenta um exemplo de como será considerada a determinação dos índices ( $n$ ) e demonstra os blocos a serem retirados para a lavra de um bloco no terceiro nível. Nota-se que blocos do primeiro nível não possuem precedentes, pois não existem blocos acima que possam impedir sua remoção.

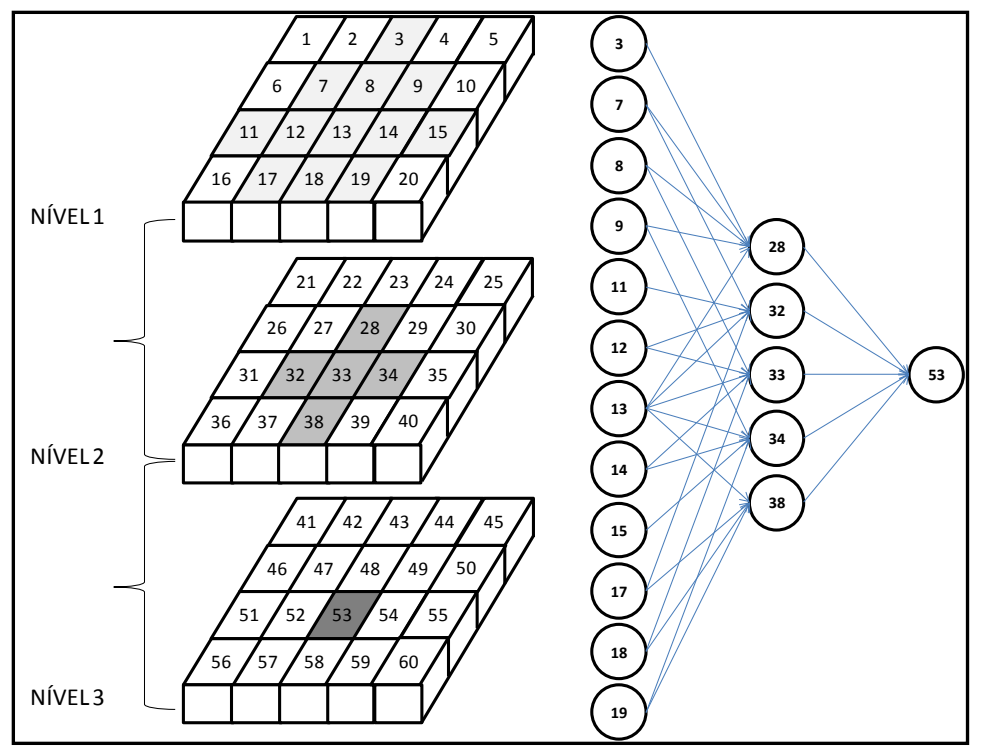

Figura 2.9 - Exemplo de rede precedência de blocos 
$\mathrm{Na}$ busca pelo minério, pode ser necessário o aprofundamento de uma cava e dependendo do formato desta cava, não é possível escavar o material de seu interior por questões de segurança, causando o estrangulamento da mesma. Nessa situação, apresentada na Figura 2.10, na qual blocos vermelhos representam minério e os brancos representam estéril, é necessário que o equipamento de carga alocado a um bloco no interior da cava (Figura 2.10 a.) seja alocado à um bloco de estéril localizado na superfície da cava com o intuito de provocar um alargamento da mesma como mostrado na Figura $2.10 \mathrm{~b}$.

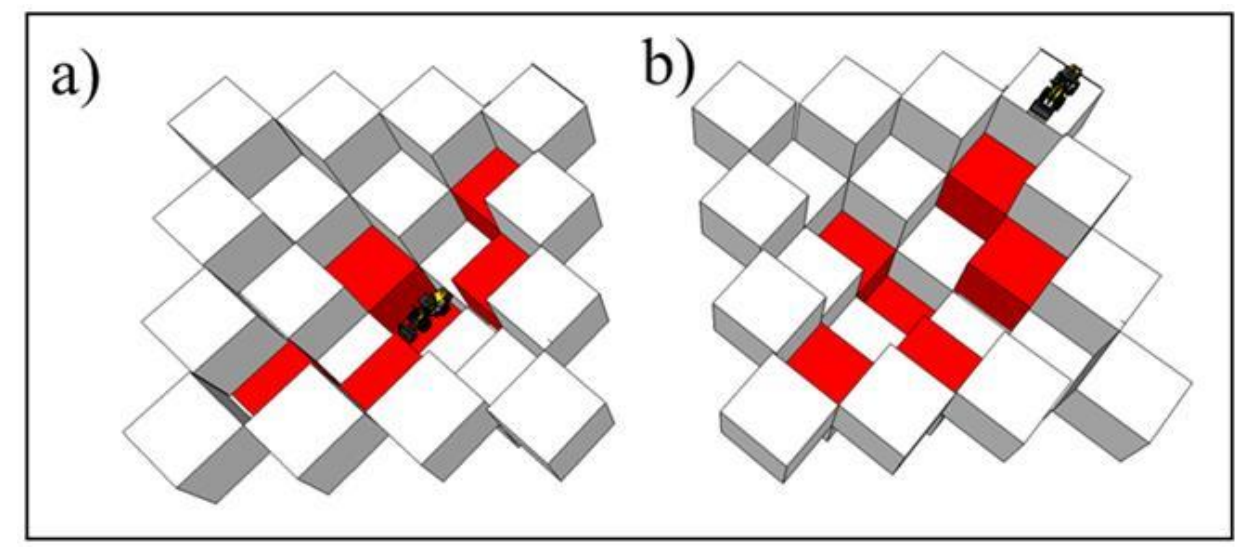

Figura 2.10 - Estrangulamento da cava

\subsection{PLANEJAMENTO DE LAVRA}

Segundo Amaral (2008), a importância do planejamento de lavra está relacionada ao longo de todas as atividades de exploração da mina. Dependendo do horizonte abordado e seu objetivo, os planejamentos de lavra podem ser classificados como de longo, médio e curto prazo.

No planejamento de lavra de longo prazo, as atividades são ligadas, por exemplo, à definição do tamanho e localização de ativos, capacidade da usina de beneficiamento e desenho da cava ótima, o desenho final do poço (NEWMAN et al., 2010).

Para Kozan et al. (2012), do ponto de visto do planejamento de lavra de médio prazo, 
ou tático, comumente são agregadas metas de produção gerando um sequenciamento da retirada de um conjunto de blocos a serem extraídos atendendo restrições de ângulos de segurança para satisfazer as demandas de ROM. Segundo o mesmo autor, modelos de scheduling de veículos de transporte do material lavrado são decisões operacionais tomadas em um horizonte de curto prazo, visando à maximização dos recursos envolvidos e atendimento das metas de produção.

Para atender as necessidades do planejamento operacional de lavra de curto prazo quanto ao sequenciamento e programação das atividades, deve-se garantir, sempre que possível, que a lavra efetuada pelos equipamentos de carga comece e termine de forma a atender as metas de produção horária. A taxa de extração (ritmo de lavra horário) em cada frente de lavra de minério define a quantidade extraída do poço, formando a qualidade do produto (SOUZA et al., 2010), uma vez que cada bloco possui composição definida. A Figura 2.11 apresenta uma situação comum em minas a céu aberto onde os equipamentos de carga, nesse caso pás carregadeiras, carregam caminhões com ROM, run-of-mine, de características distintas.

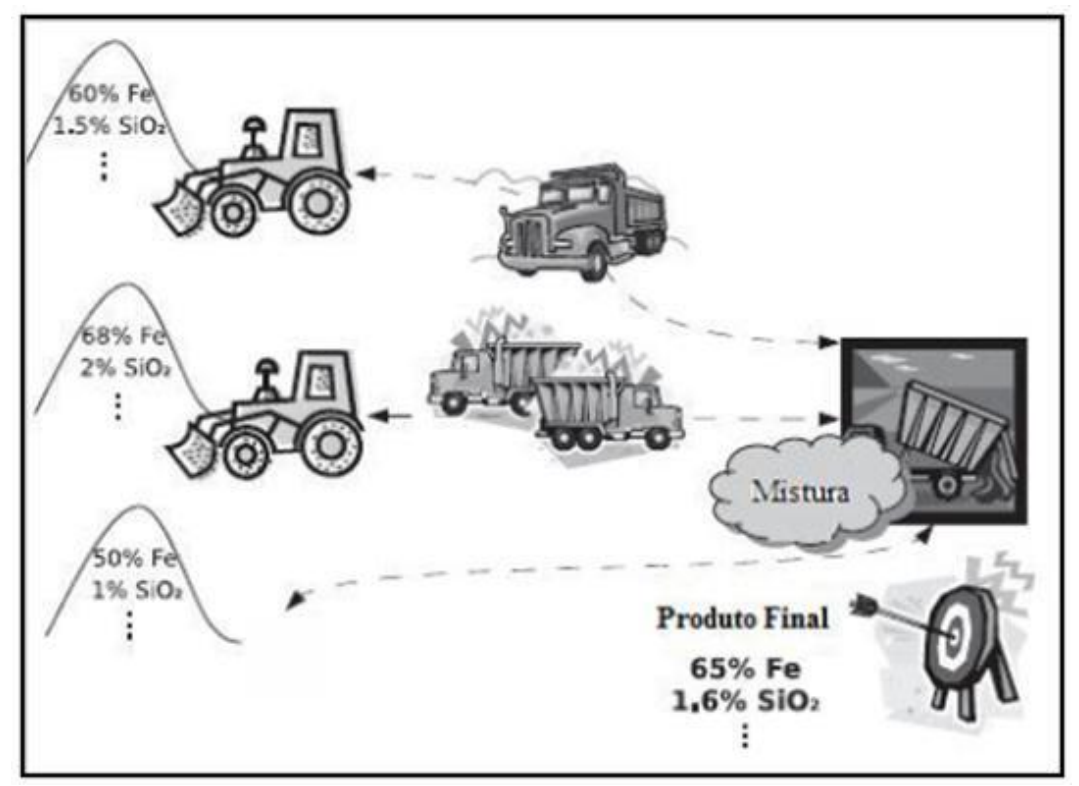

Figura 2.11 - Mistura de ROM

Fonte: PANTUZA JÚNIOR, 2011 


\subsection{SEQUENCIAMENTO E PROGRAMAÇÃO DA LAVRA}

Sequenciamento e a programação da produção, scheduling, é um processo de tomada de decisão realizado regularmente, desempenhando um papel crucial em indústrias de manufatura e serviços. No atual ambiente competitivo, um sequenciamento e programação da produção eficaz tornou-se uma necessidade, sendo de grande importância para atingir metas e uso eficiente dos recursos. (PINEDO, 2008).

O problema de sequenciamento em minas a céu aberto consiste em encontrar a sequência em que os blocos devem ser removidos, de forma a maximizar o lucro total descontado, geralmente expresso pelo VPL (valor presente líquido) e está sujeito a uma variedade de restrições técnicas e econômicas (TOLWINSKI \& UNDERWOOD, 1996).

Segundo Kozan \&Liu (2012), o termo scheduling é utilizado erroneamente em alguns casos por autores em trabalhos sobre planejamento de lavra abordando horizontes de longo e médio prazo, a solução na maioria das vezes é uma agregação de blocos a ser extraído durante períodos de tempo respeitando a quantidade máxima a ser extraída por período. $O$ autor considera tais modelos como sequenciamento, ponderando que eles não determinam elementos detalhados de temporização (por exemplo, hora de início, flowtime, conclusão ou atraso), nota-se também que nesses trabalhos não é determinada a relação entre recursos e tarefas.

A modelagem normalmente feita em níveis de planejamento específicos dificulta a construção de modelos mais flexíveis, que possam apoiar decisões em mais de um horizonte de planejamento. Muitas vezes impede que as soluções ótimas de um modelo sejam viáveis para o outro, dificultando o uso integrado desses modelos na prática. Grandes oportunidades de pesquisa e investimento no planejamento de melhorias para o setor podem, portanto, ser relacionadas ao desenvolvimento de modelos integrados de planejamento em horizontes de médio prazo, que consideram tanto a retirada de blocos do modelo geológico como aspectos operacionais referentes à alocação de equipamentos na mina (AMARAL \& PINTO, 2009). 
A presente dissertação propõe um método matemático composto por um algoritmo que apoia consecutivas iterações de um modelo matemático para geração do sequenciamento e programação da lavra com alocação de equipamentos de carga (SPLAEC). O modelo matemático proposto considera fatores tipicamente abordados em problemas com horizonte de curto prazo como tentar assegurar qualidade e quantidade do ROM lavrado e maximizar a utilização dos recursos. Também são consideradas restrições ligadas a problemas que abordam planejamento tático e estratégico como angulo de talude e a existência da pilha de ROM (análoga a um estoque).

Dessa forma, em aplicações reais, caso a mineradora possua um sistema de comunicação e controles automatizados o modelo matemático poderá direcionar as ações dos equipamentos de carga em tempo real auxiliando à tomada de decisão de curto prazo. Por outro lado, considerando a situação atual da mina, por exemplo, tamanho da pilha e localização dos equipamentos de carga, o algoritmo de horizonte móvel desenvolvido em conjunto com o modelo matemático é capaz de gerar um sequenciamento e programação da lavra a ser seguido pelos equipamentos de carga para um horizonte maior de tempo. 


\section{DESCRIÇÃO DO PROBLEMA}

O problema abordado está relacionado ao planejamento de lavra em minas a céu aberto. Em uma mina a céu aberto, o processo de carregamento pode ser descrito da seguinte maneira, equipamentos de carga (pás carregadeiras e ou escavadeiras) são destinadas a diferentes pontos da mina, realizando a lavra de forma simultânea. Nesse trabalho, a alocação de equipamento de carga a um bloco de material disponível cria uma frente de lavra ativa. De forma geral, caminhões são destinados a cada frente de lavra para serem carregados e depois são direcionados conforme o material transportado a um destino para o descarregamento.

A lavra de uma mina geralmente é feita em diversas frentes de lavra, de tal forma, realizando a mistura do ROM proveniente das frentes de minério, para a usina de tratamento, fornecendo um ROM que esteja em acordo com as especificações de qualidade e quantidade adequadas. Dessa forma, precisa-se definir o ritmo de lavra ( $t / h)$ a ser implementado em cada frente de lavra de minério que atenda a esses requisitos. Também é necessária a lavra em frentes de estéril com intuito de liberar futuras áreas de minério.

Segundo Pinto \& Merschmann (2009), em um trabalho que aborda o planejamento operacional da lavra (curto prazo), no que se refere à lavra de minério, diversas questões podem surgir:

- Com quais frentes deve-se trabalhar para atender as especificações de qualidade da usina de tratamento de minério?

- Com a frota de equipamentos disponíveis, será possível atender um ritmo de lavra que possibilite $o$ atendimento das especificações da usina?

- A partir de uma determinada frota de equipamentos e das especificações impostas pela usina, qual é a máxima produção que pode ser obtida? E qual é o ritmo de lavra de cada frente?

No presente trabalho além dessas questões apontadas em trabalhos que abordam o planejamento de curto prazo ao considerar um modelo de blocos surge a seguinte questão: 
- Como atender as questões operacionais ligadas à lavra de minério e estéril e minimizar o deslocamento que cada equipamento de carga realiza entre o bloco atual e o novo bloco a ser alocado?

Esse deslocamento pode ser considerado análogo ao setup, durante o período de tempo necessário para o equipamento de carga sair do bloco atual e se dirigir até o próximo bloco definido pelo planejamento, não existe o carregamento. Dessa forma, minimizar o deslocamento garante uma maior produtividade na lavra.

\subsection{DELIMITAÇÃO DO PROBLEMA}

Dependendo do porte do empreendimento e da produção almejada, uma mina pode variar quantitativamente os recursos utilizados. Pode-se operar um ou mais avanços simultaneamente, podem existir uma ou mais pilhas de ROM assim como britadores primários e usinas de beneficiamento.

Nesse trabalho o sistema a ser estudado contempla:

1. Avanço (um): Blocos com distintas características que contemplam a região a ser lavrada. Os métodos matemáticos que selecionam avanços são abordados na revisão bibliográfica.

2. Britador Primário (um): Todo ROM lavrado segue diretamente para o britador que diminuirá o material, podendo ser direcionado para a usina e para a pilha de estoque de ROM. A capacidade do britador limita a produção total dos equipamentos de carga alocados em frentes de lavra de minério.

3. Usina de beneficiamento (uma): Representada por uma capacidade de produção, no presente trabalho o valor atribuído a essa capacidade é inicialmente a demanda horária média de ROM. Além da quantidade, são definidos parâmetros de qualidade a ser atendida pela lavra de blocos de minério ao longo do tempo.

4. Pilha de ROM (uma): Responsável por suprir a demanda de ROM da usina na 
falta de produção provinda das frentes de lavra de minério.

5. Equipamentos de Carga $(n \geq 1)$ : Equipamentos responsáveis pela lavra com distintas capacidades de produção (t/h), onde cada recurso possui uma faixa de ritmo de lavra permitido entre um mínimo aceitável definido por exemplo economicamente e máximo definido pela sua capacidade ponderando perdas recorrentes na mineração como quebras, paradas entre turnos, ociosidade, entre outros.

\subsubsection{Carregamento de minério}

A Figura 3.1 ilustra de forma sucinta o processo de lavra de minério, equipamentos de carga são alocados a blocos de minério originando as frentes de lavra de minério. A mistura formada pela quantidade de minério extraída de cada frente de lavra de minério deve sempre que possível atender a metas de qualidade.

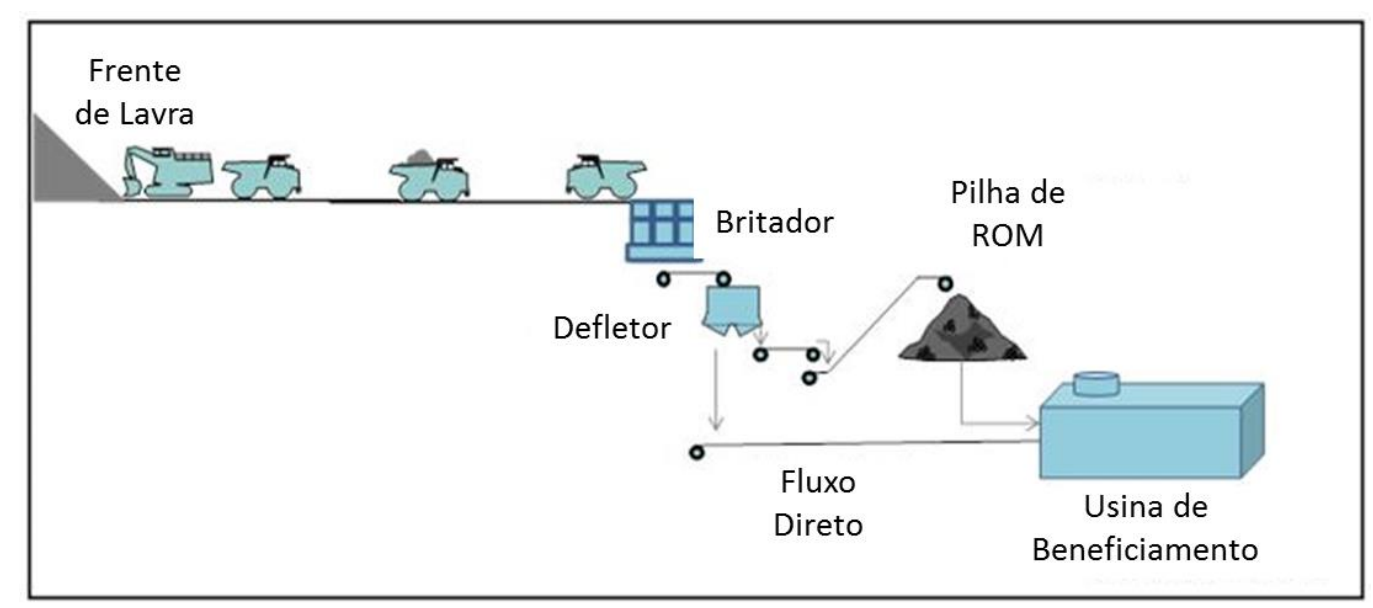

Figura 3.1 - Representação da lavra de minério

Nessa pesquisa, o minério extraído é enviado ao britador para ser cominuído (britado). Após ser processado, por meio do defletor (divisor de fluxo), existe a possibilidade de envio direto à usina, assim como a possibilidade de envios distintos simultaneamente, em que parte do material pode ser enviada diretamente à usina de beneficiamento $\mathrm{e}$ caso a quantidade exceda a capacidade atribuída à usina, esse excesso será enviado 
a outra parte para uma pilha de estoque.

O valor atribuído no modelo matemático (apresentado no Capítulo 5) à capacidade da usina de beneficiamento não está necessariamente ligada à sua capacidade operacional. De fato, nessa pesquisa, a capacidade da usina é atribuída por meio de uma meta de produção (demanda horária) que deve ser menor ou igual à capacidade operacional da usina e atendida pelos equipamentos de carga alocados a blocos de minério ou pela pilha de ROM quando essa lavra é insuficiente.

O problema abordado não contempla diretamente três atividades que podem pertencer ao planejamento de lavra, a perfuração e desmonte (detonação) dos blocos e o transporte de material. Segundo Amaral \& Pinto (2009), em alguns casos devido às características físicas do material, não é necessário a perfuração e o desmonte. Outra atividade não contemplada é o transporte de material, em que nessa pesquisa é considerado que existem meios de transporte suficientes para atender o ritmo máximo de produção dos equipamentos de carga.

\subsubsection{Carregamento de estéril}

Na Figura 3.2, é representado o processo de lavra de estéril. Quando alocado em uma frente de estéril, a carregadeira lavra o material e esse é transportado para uma ou mais pilhas de estéril. No caso dessa pesquisa, sempre que o equipamento de carga for alocado ao bloco de estéril será atribuído o ritmo máximo de lavra permitido ao recurso.

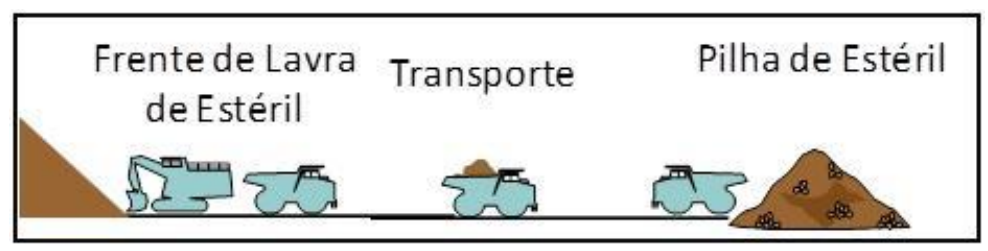

Figura 3.2 - Representação da lavra de estéril

Diante do que foi exposto, quanto ao carregamento de minério e demais processos envolvidos assim como o carregamento de estéril, a Figura 3.3 resume os processos 
e decisões a serem consideradas. No britador, o minério lavrado dos blocos de minério é misturado e cominuído, o defletor envia o material diretamente à usina. Caso a lavra seja superior à capacidade da usina, o excedente é enviado à pilha. Por outro lado, caso o material lavrado não atenda à capacidade atribuída à usina, havendo material na pilha de ROM, este é retomado da pilha para usina, não havendo, registra-se que a usina não foi atendida. Já a lavra de estéril no presente problema não envolvem demais processos e decisões.

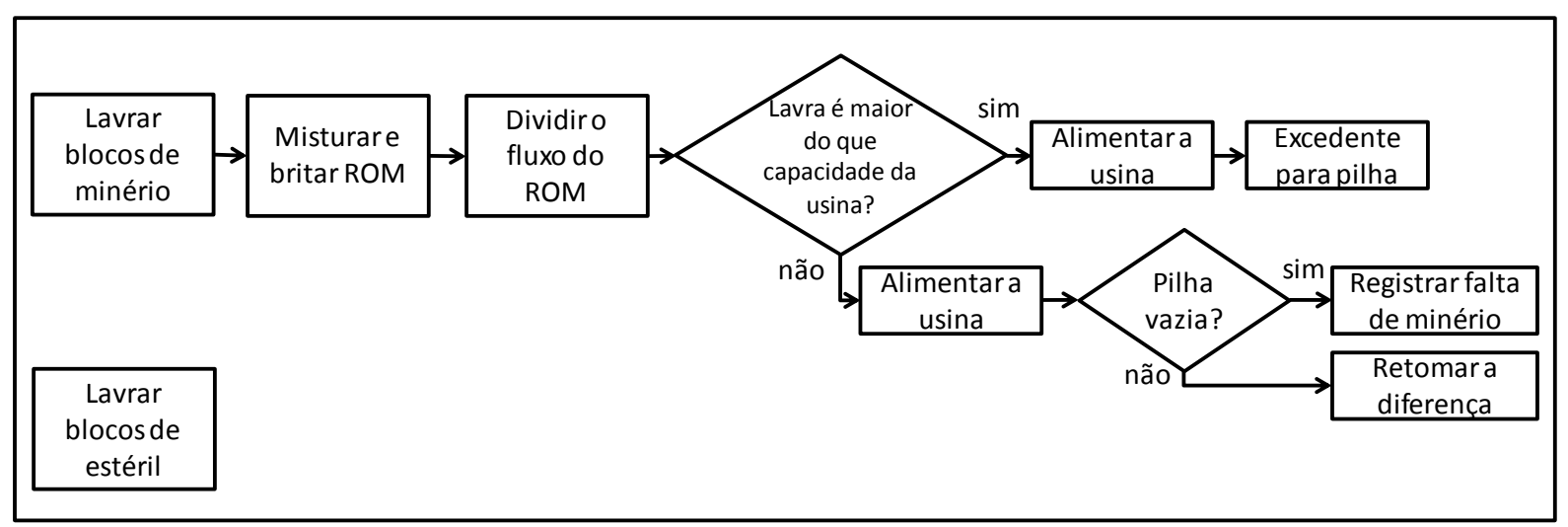

Figura 3.3 - Fluxograma do processo estudado

\subsection{ORDEM DE LAVRA}

O Sequenciamento e Programação de Lavra com Alocação de Equipamentos de Carga (SPLAEC) proposto nessa dissertação é uma das atividades que podem ser atribuídas ao planejamento de lavra.

Neste trabalho, serão incorporadas características presentes no planejamento operacional de lavra de curto prazo e no sequenciamento de lavra de médio prazo. Dessa forma, são relacionadas características consideradas em cenários de longo e médio prazo como considerar o modelo de blocos, restrição de ângulos de talude e o controle do estoque de ROM durante a operação, assim como características de curto prazo, por exemplo, manter as metas de produção como quantidade e qualidade de ROM.

No problema estudado, considera-se a formação e manutenção de uma pilha pulmão 
de minério representando um estoque intermediário responsável por amortecer as variações da produção oriundas das diferentes frentes de lavra e pela alimentação regular para o processo de beneficiamento (CECILIANO, 2007; BLEY et al., 2012).

O SPLAEC é elaborado utilizando um algoritmo responsável por sequenciar inúmeras iterações do modelo matemático, a ser descrito no Capítulo 5, cada iteração gera uma nova ordem de lavra com efeito por um período limitado de tempo. As ordens de lavra são responsáveis por criar um roteiro a ser seguido por cada equipamento de carga informando o bloco a ser alocado e o respectivo ritmo de lavra horário a ser implantado durante um determinado período de tempo. Contribuindo para a previsibilidade e controle da lavra ao longo do tempo.

Segundo GOODWIN et. al. (2008), muitos problemas de otimização têm um caráter temporal (ou seja, se deseja otimizar sobre algum horizonte de tempo futuro). Além disso, muitas vezes é verdade que as ações planejadas para o futuro distante podem ter um efeito decrescente sobre o que é a melhor ação agora. Neste caso, faz sentido reduzir a janela de tempo para capturar o horizonte sobre a qual a decisão atual tem o seu maior impacto. Tendo realizado a otimização ao longo deste horizonte restrito, pode-se bloquear a ação atual e, em seguida, mover a janela para a frente começando no próximo passo de tempo. O conjunto de decisões projetados com um horizonte torna-se uma boa estimativa inicial para as decisões sobre o próximo horizonte deslocado. Verifica-se que às vezes é possível usar horizontes de planejamento muito curtos.

O modelo matemático proposto no presente trabalho é considerado monoperíodo, ou seja, apresenta uma solução destinada à situação atual do sistema estudado e não é multiperíodo. Para realizar o estudo em mais de um horizonte de tempo um algoritmo utilizando a técnica horizonte móvel registra a solução gerada pelo modelo, calcula a duração dessa ordem e atualiza os dados para uma nova iteração.

A duração de uma ordem de lavra é calculada ao projetar a solução obtida em uma execução do modelo matemático ao sistema atual e pesquisar qual "evento" ocorrerá primeiro, tais como: 1) fim de um ou mais blocos, 2) limite da capacidade da pilha excedido por excesso de ROM ou 3) fim da pilha que foi consumida para compensar baixa produção de ROM; então é criada uma nova ordem de lavra, que direcionará os 
recursos disponíveis a novos blocos caso o bloco anterior tenha exaurido e atribuindo novos ritmos de lavra horários a todos os recursos adequando-os ao novo cenário. A Tabela 3.1 apresenta a forma reduzida genérica de uma ordem de lavra.

Tabela 3.1 - Ordem de lavra resumida

\begin{tabular}{|c|c|c|c|c|c|c|}
\hline \multirow{2}{*}{$\begin{array}{c}\text { ORDEM } \\
\text { DE } \\
\text { LAVRA }\end{array}$} & ALOCAÇÂO & RITMO (t/h) & \multirow[b]{2}{*}{ ROM } & \multirow[b]{2}{*}{ ESTÉRIL } & \multirow[b]{2}{*}{ INÍCIO } & \multirow[b]{2}{*}{ FIM } \\
\hline & Maq1, Maq2 ... MaqN & Maq1, Maq2 ... MaqN & & & & \\
\hline$K$ & $b l_{b}, b l_{b} \ldots b l_{b}$ & $v_{1}, v_{2} \ldots v_{N}$ & $R^{2} M_{k}$ & $E S T_{k}$ & $t i_{k}$ & $t f_{k}$ \\
\hline
\end{tabular}

\subsubsection{Exemplo de ordem de lavra}

O exemplo a ser descrito considera o seguinte sistema:

1. Quatro equipamentos de carga e a produção mínima e máxima permitida: $A$ $\left(200 \leq x_{A} \leq 800\right), \quad$ B $\left(200 \leq x_{B} \leq 1000\right), \quad$ C $\left(200 \leq x_{C} \leq 1000\right)$ e D $(200 \leq$ $\left.x_{D} \leq 1000\right)$.

2. Tamanho da pilha de ROM: Nível de Pedido (60\%), Quantidade Atual (20.000) e Quantidade Máxima Permitida (50.000).

3. Capacidade de Britagem: $3600 \mathrm{t} / \mathrm{h}$.

4. Capacidade da usina: $1800 \mathrm{t} / \mathrm{h}$.

5. Blocos: 100 blocos disponíveis na superfície, 48 blocos de Minério e 52 blocos de Estéril. A massa de cada bloco é em média 22.500 ton.

Para simplificação o exemplo a seguir omitiu as especificações de teores de qualidade do minério e será apresentada de forma geral a quantidade produzida em cada ordem. Nos gráficos apresentados na Figura 3.4 o tamanho de cada barra colorida representa a duração do bloco caso o ritmo de lavra imposto pelo equipamento alocado fosse estendido por um período indeterminado de tempo. O Gráfico da Pilha de ROM apresenta o nível da pilha no início de cada ordem de lavra. 

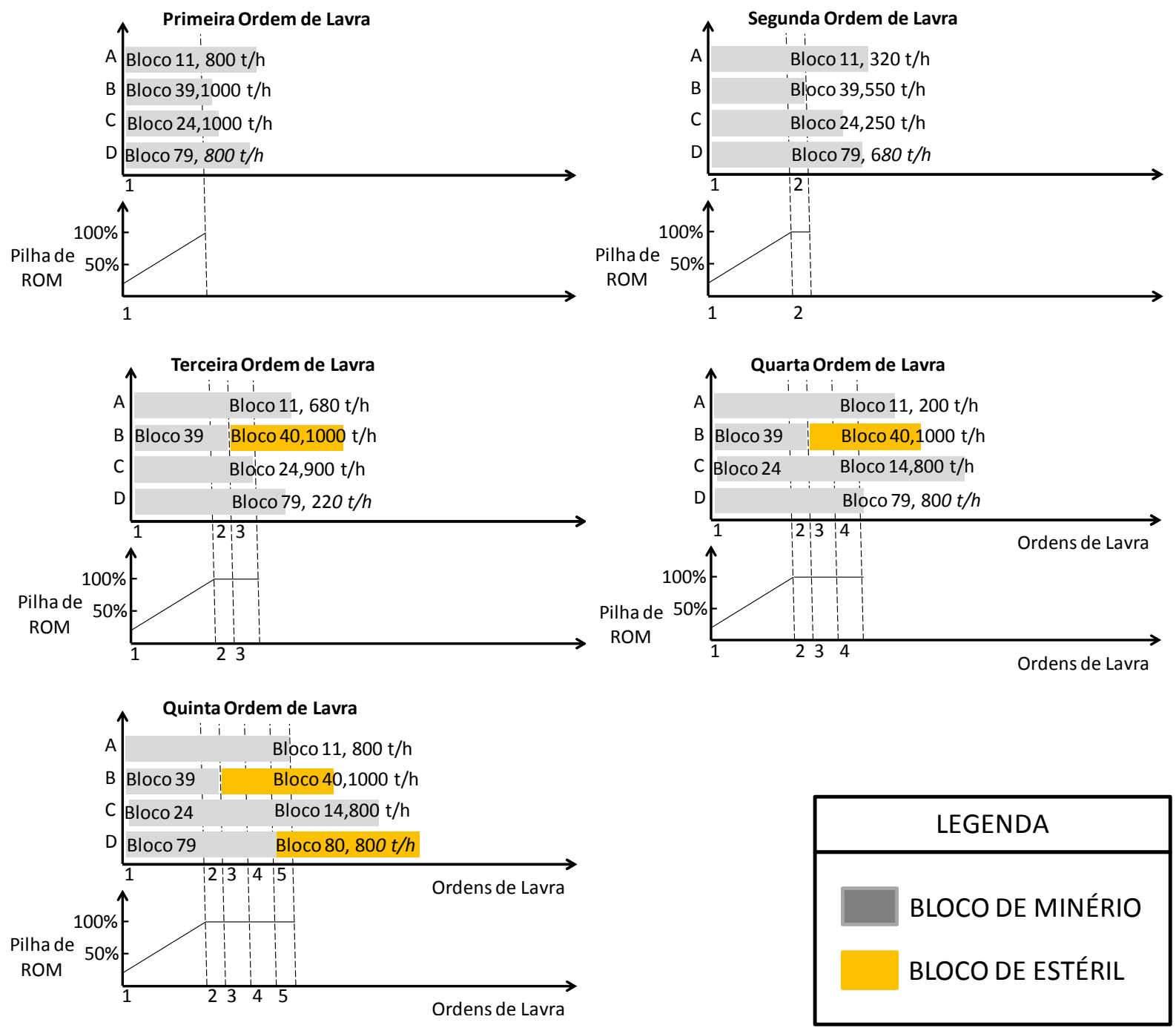

Figura 3.4 - Gráficos de Gantt representando uma sequência de ordens de lavra

Na primeira ordem de lavra, os equipamentos de carga são alocados aos blocos de minério 11, 39, 24 e 79 e o nível abaixo do nível de pedido da pilha de ROM possibilita que todos os equipamentos operem com capacidade máxima de extração (100\%), acarretando no acréscimo de material na pilha ao longo do tempo, pois nesse exemplo hipotético tal produtividade dos equipamentos de carga supera a capacidade atribuída a usina e consequentemente à demanda horária.

A segunda ordem de lavra foi gerada, pois a pilha de ROM atingiu sua capacidade máxima, requerendo um novo ritmo de lavra dos equipamentos capaz de igualar a produção de ROM dos equipamentos à uma demanda hipotética mantendo o nível da pilha, pois não existe à necessidade de consumi-la. Nota-se que o ritmo de lavra menor imposto na ordem aos equipamentos ( $A, B, C$ e $D)$ comparados à primeira 
ordem, aumenta o prazo de duração da lavra no bloco alocado pelos mesmos.

A terceira ordem de lavra foi gerada quando o equipamento A terminou a lavra do bloco 39, sendo redirecionado ao bloco de estéril 40 operando em plena capacidade, o ritmo de lavra dos demais equipamentos são redefinidos e atendem à demanda ponderando a qualidade a ser atingida na mistura do ROM.

A quarta ordem de lavra foi gerada, pois o equipamento $C$ terminou a lavra do bloco de minério 24 e foi direcionado para o bloco de minério 14. A ordem também redefine o ritmo de lavra dos demais equipamentos frente à nova realidade.

Na quinta ordem de lavra o Equipamento D terminou de lavrar o bloco 79 e é alocado ao bloco 80 , ressalta-se que nessa combinação todos os equipamentos operam em ritmo máximo de produção.

A Tabela 3.2 apresenta as ordens de lavra em seu formato reduzido padronizado, desenvolvido nessa pesquisa detalhando, a produção resultante de ROM, estéril, o tamanho da pilha, a hora de início e o fim, resultante da duração definida em cada ordem de lavra como o tempo resultante entre o início de uma ordem de lavra considerando a situação do sistema como a massa restante dos blocos, o consumo da pilha ou o enchimento da pilha e a solução gerada pelo modelo (alocação e produção) é possível calcular a duração da ordem de lavra.

Tabela 3.2 - Exemplo de ordens de lavrarem formato reduzido

\begin{tabular}{|c|c|c|c|c|c|c|c|c|c|c|c|c|c|}
\hline \multirow{2}{*}{$\begin{array}{c}\text { ORDEM } \\
\text { DE } \\
\text { LAVRA }\end{array}$} & \multicolumn{4}{|c|}{ ALOCAÇÂO } & \multicolumn{4}{|c|}{ RITMO (t/h) } & \multirow{2}{*}{$\begin{array}{c}R O M \\
(t / h)\end{array}$} & \multirow{2}{*}{$\begin{array}{l}\text { EST } \\
(\mathrm{t} / \mathrm{h})\end{array}$} & \multirow{2}{*}{$\begin{array}{c}\text { PILHA } \\
\text { (ton) }\end{array}$} & \multirow{2}{*}{$\begin{array}{c}\text { INÍCIO } \\
\text { (h) }\end{array}$} & \multirow{2}{*}{$\begin{array}{c}\text { FIM } \\
\text { (h) }\end{array}$} \\
\hline & A & B & C & D & A & B & C & D & & & & & \\
\hline 1 & 11 & 39 & 14 & 79 & 800 & 1000 & 1000 & 800 & 3600 & 0 & 20000 & 0 & 16.7 \\
\hline 2 & 11 & 39 & 14 & 79 & 320 & 550 & 250 & 680 & 1800 & 0 & 50000 & 16.7 & 21.3 \\
\hline 3 & 11 & 40 & 14 & 79 & 680 & 1000 & 900 & 220 & 1800 & 1000 & 50000 & 21.3 & 27.6 \\
\hline 4 & 11 & 40 & 24 & 79 & 200 & 1000 & 800 & 800 & 1800 & 1000 & 50000 & 27.6 & 33.7 \\
\hline 5 & 11 & 40 & 24 & 80 & 800 & 1000 & 1000 & 800 & 1800 & 1800 & 50000 & 33.7 & 38.5 \\
\hline
\end{tabular}

Em todas essas ordens de lavra hipotéticas a cada iteração e consequente geração 
de ordem de lavra, o modelo pondera entre a importância de lavrar ROM e a qualidade formada pela mistura do mesmo.

Por último, a Figura 3.5 apresenta uma representação dos movimentos realizados pelos equipamentos de carga ao longo das ordens de lavra. Nessa representação, os equipamentos são alocados a blocos pertencentes a um modelo de blocos com a superfície inicialmente plana. Nota-se que a partir da terceira ordem de lavra, os blocos exauridos ficam indisponíveis e sua localidade na superfície é aprofundada.

Embora nos exemplos apresentados não se observe nenhum caso em que, ao se terminar uma ordem de lavra, equipamentos de carga sejam deslocados de blocos que ainda não foram totalmente lavrados para outros blocos, essa situação é possível e pode ocorrer em função de requisitos de qualidade e quantidade de ROM. Por outro lado, na presente pesquisa, quanto maior a penalidade atribuída ao deslocamento do recurso entre os blocos menor o benefício alcançado por qualquer troca. 


\begin{tabular}{|c|c|}
\hline 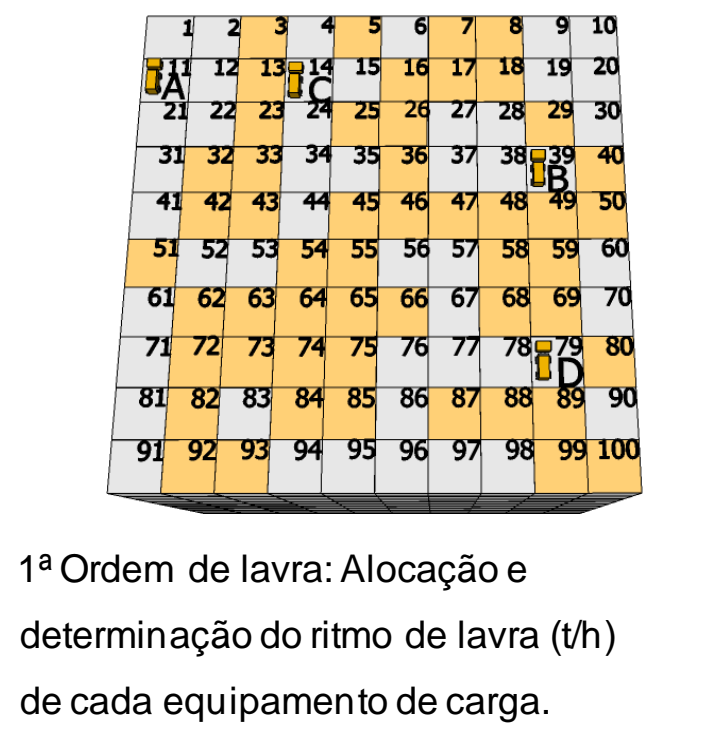 & 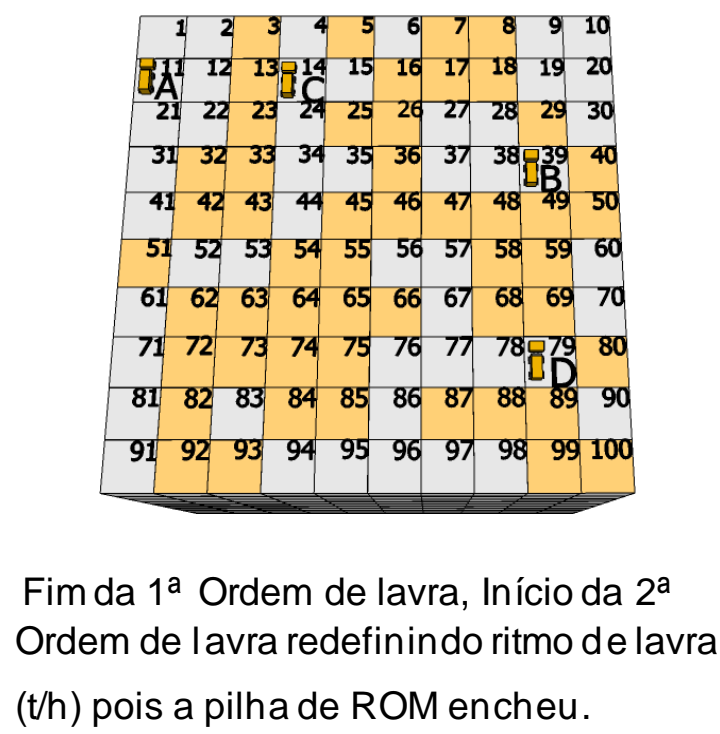 \\
\hline 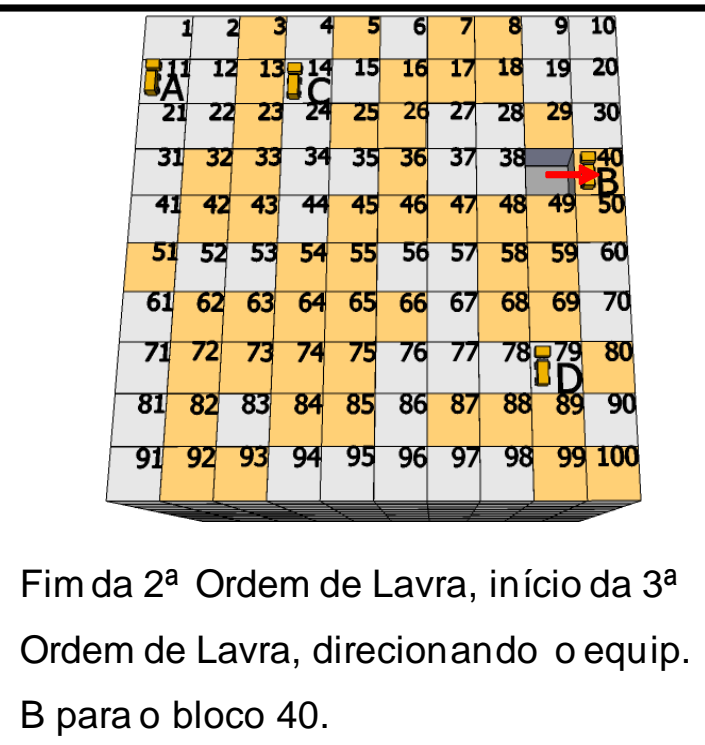 & 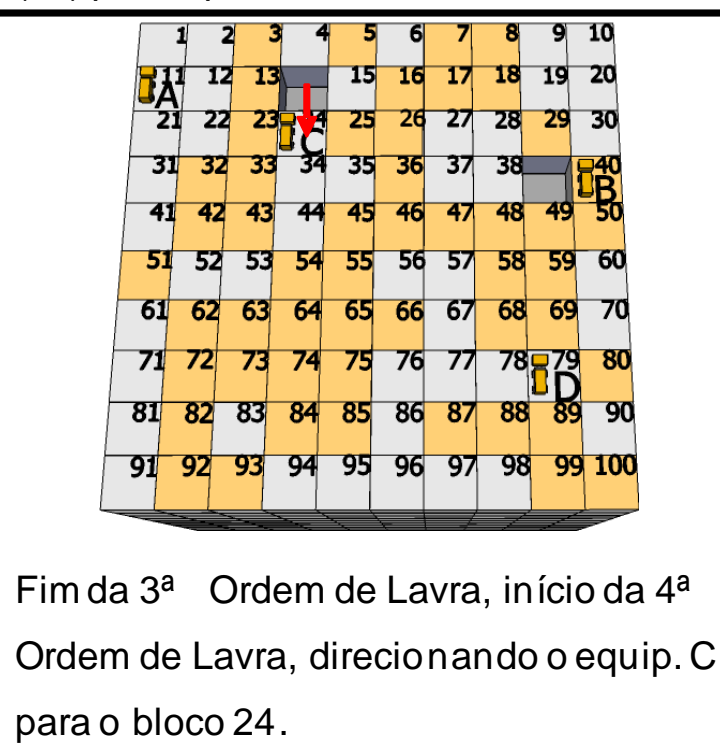 \\
\hline 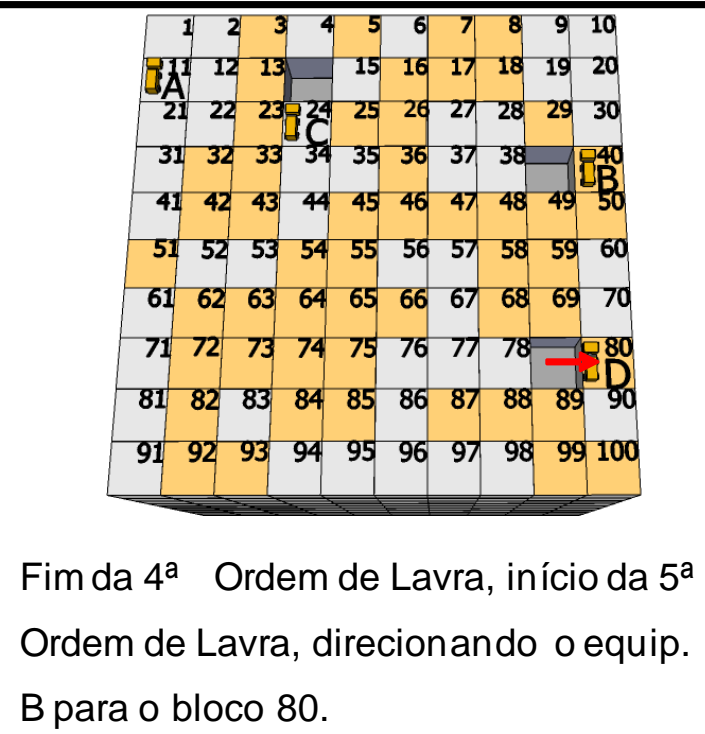 & $\begin{array}{l}\text { BLOCO DE MINÉRIO } \\
\text { BLOCO DE ESTÉRIL }\end{array}$ \\
\hline
\end{tabular}

Figura 3.5 - Movimentação dos equipamentos de carga 


\section{REVISÃO}

Este capítulo apresenta uma revisão de alguns dos trabalhos pesquisados para essa dissertação, distintos em três partes.

$\mathrm{Na}$ primeira parte, serão revisados os principais trabalhos encontrados, abordando diferentes técnicas de Pesquisa Operacional, relacionados ao problema de planejamento operacional de lavra em minas a céu aberto com objetivo de elucidar o estado da arte assim como os desafios encontrados.

Na segunda parte foi dada uma atenção especial a artigos que contemplam decisões de médio e curto prazos que se assemelham ao objetivo do presente trabalho ressaltando o trabalho de Amaral (2008) que contribuiu com o método desenvolvido nessa dissertação ao propor uma heurística e modelos para otimização sequencial para o problema do planejamento de operações de lavra em minas a céu aberto, como denominado pelo autor(a).

$\mathrm{Na}$ última parte, como o método de solução adotado para o problema é análogo a problemas da classe de problemas de sequenciamento e a programação de máquinas paralelas, será caracterizado o problema de sequenciamento e a programação (scheduling) de máquinas paralelas.

\subsection{PLANEJAMENTO DE LAVRA}

Os métodos de lavra referentes ao presente trabalho e a revisão bibliográfica são aplicáveis a diferentes minerais cuja jazida pode ser representada por blocos sólidos e lavrada bloco a bloco, tais como:

- Metálicos, como minério de ferro, ouro e cobre;

- Não Metálicos, como cimento;

- Fósseis, como carvão mineral. 
As pesquisas encontradas na literatura quanto ao planejamento de lavra, especificamente relacionada ao planejamento da extração de minério e estéril, podem ser divididas em sequenciamento de lavra e planejamento operacional de lavra de curto prazo. Os métodos para elaboração de sequenciamento são aplicados de forma geral em horizontes de longo e médio prazo, agregam metas de extração e visam, nos trabalhos pesquisados à maximização do VPL.

Por outro lado, nos trabalhos pesquisados que estudam o planejamento operacional de lavra de curto prazo, é gerada uma ordem de lavra alocando equipamentos de carga e em alguns trabalhos equipamentos de transporte, com intuito de atingir metas de produção e controle da qualidade e maximização da utilização dos recursos.

Essa ordem pode apoiar o planejamento e controle de lavra durante o período de tempo que suas premissas forem válidas, após alguma mudança como fim de um bloco ou quebra de equipamentos é necessária geração de uma nova ordem de lavra.

Poucos são os trabalhos que relacionam características de médio prazo e curto prazo, detalhando a operação para cada recurso. Os trabalhos pesquisados na presente dissertação que apresentam essa abordagem são: Amaral, 2008; Amaral \& Pinto, 2009. Segundo Amaral \& Pinto (2009), apesar de diferirem no horizonte de planejamento, esses problemas não resultam necessariamente em uma relação hierárquica de solução.

\subsubsection{Sequenciamento de lavra}

Espinoza et al. (2012a) apresentam três modelos matemáticos em programação inteira utilizados para definir cava ótima (denominado pelos autores como UPIT), sequenciamento de lavra onde um bloco é lavrado em apenas um período (denominado pelos autores como CPIT) e outro onde um bloco pode ser lavrado em vários períodos (denominado pelos autores como PCPSP). Desses três modelos destaca-se o CPIT cuja solução gerada pode ser útil ao SPLAEC, pois definem os blocos que serão considerados pelo modelo matemático, blocos esses que a princípio maximizam o lucro da operação, restando ao SPLAEC obedecer a restrições e 
requisitos operacionais a cada ordem de lavra. Dado um modelo de blocos, o CPIT define os blocos que serão lavrados em cada ano de operação limitados a uma capacidade de beneficiamento de minério com objetivo de maximizar o valor presente líquido da operação.

A seguir será descrito o modelo matemático CPIT conforme Espinoza et al. (2012a)

\section{Conjuntos:}

$T \quad$ : Conjunto de períodos $t$ em um horizonte.

$B \quad$ : Conjunto de blocos $b$.

$B_{b} \quad$ : Conjunto de blocos $b^{\prime}$ que são precedentes de $b$.

$R \quad$ : Conjunto de recursos operacionais $r$.

\section{Parâmetros:}

$p_{b t} \quad$ : Lucro obtido a partir da extração (e transformação) do bloco $b$ (no período de tempo $t$ ).

$q_{b r} \quad: \quad$ Quantidade do recurso operacional $r$ usado para extrair o bloco $b$.

$\underline{R}_{r t} \quad$ : Disponibilidade mínima do recurso operacional $r$ no período de tempo $t$.

$\bar{R}_{t t} \quad$ : Disponibilidade máxima do recurso operacional $r$ no período de tempo $t$.

\section{Variáveis:}

$x_{b t}:\left\{\begin{array}{l}1-\text { se o bloco bé processado no período } t \\ 0 \text {-caso contrário. }\end{array}\right.$

$$
\max \sum_{b \in B} \sum_{t \in T} p_{b t} x_{b t}
$$

Sujeito a:

$$
\begin{array}{cl}
\sum_{\tau \leq t} x_{b \tau} \leq \sum_{\tau \leq t} x_{b^{\prime} \tau} & \forall b \in B, b^{\prime} \in B_{b}, t \in T \\
\sum_{t \in T} x_{b t} \leq 1 & \forall b \in B
\end{array}
$$




$$
\begin{array}{rr}
\underline{R}_{r t} \leq \sum_{b \leq B} q_{b r} \times x_{b t} \leq \bar{R}_{r t} & \forall t \in T, r \in R \\
x_{b t} \in\{0,1\} & \forall b \in B, t \in T
\end{array}
$$

O CPIT visa a maximizar o valor presente líquido dos blocos extraídos durante a vida útil da mina. A restrição (4.2) impõe a precedência de cada bloco. Ou seja, o bloco b' deve ser lavrado antes ou no mesmo período do bloco $b$. A restrição (4.3) impõe que cada bloco deve ser extraído no máximo uma vez. A restrição (4.4) limita a quantidade de material extraída entre um mínimo e máximo a ser processado por ano. Os autores avaliam que restringir um mínimo de extração implica em diminuição do tempo computacional para solução do problema. Por último, todas as variáveis são binárias.

Cacceta \& Hill (2003) apresentam um método de branch\&cut para solucionar um modelo de programação linear inteira mista de sequenciamento de lavra definindo, entre outros, em qual período de tempo o bloco será extraído, considerando capacidade de processamento e formação de pilhas de minério. Esses e os demais autores na pesquisa realizada optaram por contemplar no sequenciamento apenas blocos contidos na cava final ótima obtida através da implementação do algoritmo de Lerchs \& Grossmann. Os resultados obtidos considerando 10 períodos de tempo e 250.000 blocos apontam que o método pode ser utilizado em problemas práticos. Porém, alegando sigilos comerciais, o autor não apresentou maiores detalhes.

Newman et al., (2010) fizeram uma revisão da literatura abordando modelos relacionados ao planejamento estratégico e tático de minas a céu aberto e mina subterrânea. Segundo os autores, modelos de sequenciamento de lavra, ao contrário dos modelos de cava ótima que consideram apenas as restrições de precedência, consideram também em qual sequência extrair o bloco e capacidades operacionais como de carregamento e processamento. Devido à natureza combinatória do problema, é comum a formação de agregação de blocos para diminuir sua complexidade. Afirmam que diversos autores publicaram diferentes formas de gerálas, porém elas não permitem capturar a questão da precedência para todos os blocos contidos na agregação. A direção apontada pelos autores nas pesquisas recentes é a maior atenção a detalhes, tornando as respostas dos modelos mais realísticas e aplicando-os a problemas maiores com tempo computacional aceitável e sem comprometer significativamente a resposta. 
O trabalho de Epstein et al. (2012) apresenta um sistema composto por um relaxação de variáveis inteiras em um modelo programação linear e utilizando heurísticas de arredondamento para encontrar uma solução viável inteira. Responsável por gerar o sequenciamento de lavra onde blocos são agregados sempre que possível através de bancadas de lavra e sua solução representa quais bancadas serão extraídas a cada período de tempo capaz de atender restrições de produção máxima por período entre outras. Os autores consideram a existência de diferentes produtos lavrados em múltiplas minas.

Segundo Bley et al. (2012), a formação de pilhas de estoque vem sendo desconsiderada em estudos sobre sequenciamento de lavra e sua importância para manter a capacidade produtiva da usina de beneficiamento e a homogeneização do material, os autores apontam que a consideração de mais de uma pilha de estoque aumenta consideravelmente a complexidade do problema. Consideram no modelo em programação inteira mista (mixed integer program) três destinos distintos para os materiais extraídos:(1) o minério pode ser direcionado diretamente à usina de beneficiamento ou (2) estocado para futura utilização em uma pilha, (3) caso o material seja estéril, será enviado à pilha de estéril.

Kozan \& Liu (2012) propõem um framework composto por ferramentas de otimização da cava ótima, sequenciamento da produção e do transporte do material. Segundo os autores, tal estrutura seria capaz de maximizar o VPL e eficiência do empreendimento. É proposto um modelo inteiro misto de sequenciamento utilizando uma abordagem de máquina única contemplando informações como:

- J: conjunto dos $\mathrm{n}$ jobs (blocos) a serem processados;

- $r_{j}$, data de liberação do job $j \in J$, equivalente ao primeiro horário disponível do job j, determinado pela relação de precedência;

- $d_{j}$, data de vencimento do job $j \in J$, sendo considerado que o britador solicita o bloco em certa data para seu processamento;

- $w_{j}$, peso ou importância do job $j \in J$.

O modelo contempla as seguintes variáveis de decisão: 
- $S_{j}$, data de início do processamento do job $j \in J$;

- $C_{j}$, data na qual o job $j \in J$ foi processado;

- $\quad F_{j}$, tempo de permanência do job $j \in J$;

- $T_{j}$, tempo de atraso ao job $j \in J$.

- $x_{i j}$, uma variável binária onde é 1 se o job $j$ precede o job $i, 0$ caso contrário.

Formulação matemática:

O objetivo na função (4.6) é minimizar o custo total, considerando o máximo horizonte total para realizar as tarefas, o tempo de permanência ponderado e o tempo de atraso ponderado.

$$
\min \left(f\left(\operatorname{Crax}, \frac{1}{n} \sum_{j=1}^{n} w_{j} F_{j}, \frac{1}{n} \sum_{j=1}^{n} w_{j} T_{j}\right)\right)
$$

A equação (4.7) define $C \max$ como o término do último job a ser processado.

$$
C \max \geq S_{j}+p_{j}, \forall j \in J
$$

A equação (4.8) impõe que um job só pode ser processado após sua data de liberação.

$$
r_{j} \leq S_{j}, \forall j \in J
$$

As equações (4.9) e (4.10) definem a relação de precedência entre jobs $i$ e $j$.

$$
\begin{aligned}
& S_{i} \geq S_{j}+p_{j}+L\left(x_{i j}-1\right), \forall i, j \in J, i \neq j \\
& S_{j} \geq S_{i}+p_{i}+L\left(x_{j i}-1\right), \forall i, j \in J, i \neq j
\end{aligned}
$$


Segundo os autores, a proposta diferencia-se das demais por tratar o problema de sequenciamento baseado em programação de máquina única e consideram a abordagem mais flexível aos demais trabalhos relacionados ao sequenciamento da lavra, porém não demonstram como foram definidos os parâmetros essenciais no modelo como $r_{j}$ e $d_{j}$.

\subsubsection{Planejamento operacional de lavra de curto prazo}

COSTA (2005) estudou o problema do planejamento operacional de lavra de curto prazo, distinguindo-o em problema da mistura de minério (PMM), problema de alocação estática de caminhões (PAEC) ou problema de alocação dinâmica de caminhões (PAED). Foi realizada uma pesquisa sobre diferentes modelos de programação lineares e não lineares aplicados aos três problemas. O autor propõe a criação de novos modelos que buscam, entre outros, minimizar desvios de produção e qualidade de ROM atribuindo-os à classe de programação por metas, goal programming:

- O Problema da Mistura de Minérios (PMM) caracteriza-se pela escolha de frentes de lavra a serem alocadas a um equipamento de carga que realizará $n$ caçambadas. O termo caçambada refere-se a cada movimento, dos $n$ movimentos necessários para encher um caminhão. O somatório das caçambadas realizadas multiplicadas pela capacidade atribuída à caçamba de cada equipamento de carga em cada frente de lavra busca atender as metas de produção e minimizar os desvios. Deseja-se atender a mínima extração de estéril requerida, minimizar os desvios de qualidade de minério assim como impor limites mínimos e máximos para a qualidade do minério gerada pela mistura e que cada equipamento de carga opere produzindo valores entre o mínimo e máximo de toneladas definidos;

- O Problema de Alocação Estática de Caminhões (PAEC) contempla as regras impostas ao PMM, acrescentando a necessidade da disponibilidade de caminhões para transporte de minério e estéril. Nesse sistema, a alocação de cada caminhão restringiu-se a apenas uma frente de lavra em operação. O objetivo é acrescido 
em minimizar o número de caminhões necessários;

- O Problema de Alocação Dinâmica de Caminhões (PAED) contempla as regras impostas ao PMM, acrescentando a necessidade da disponibilidade de caminhões para transporte de minério e estéril. Ao contrário da alocação estática, na alocação dinâmica, considera-se que existe um sistema computadorizado capaz de orientar o operador do caminhão quanto à próxima frente de lavra a seguir, visando à maior produtividade dos equipamentos de carga e transporte.

Os três modelos sugeridos pelo autor foram implementados no otimizador LINGO e em diferentes heurísticas e metaheurísticas. O autor destaca que as três abordagens podem ser atribuídas à classe do Problema da Mochila Inteira Múltipla, a qual pertence à classe de problemas NP-difícil. Devida à maior complexidade do PAED quando comparado com os demais, PMM e PAEC, pesquisas recentes vêm buscando aproximar os resultados obtidos ao ótimo e torná-los mais rápidos através de procedimentos heurísticos (SOUZA et al., 2010; ARAÚJO \& SOUZA, 2010; PANTUZA JÙNIOR, 2011).

\subsection{PROBLEMA DO PLANEJAMENTO DE OPERAÇÕES DE LAVRA EM MINAS À CÉU ABERTO}

Amaral (2008) apresentou novos modelos para auxílio ao planejamento da produção, úteis especialmente para decisões de médio prazo, mas que consideram também fatores operacionais, como os custos de deslocamentos dos equipamentos de carga.

Dois modelos on-line, que podem aproveitar informações atualizadas provenientes de tecnologia de localização remota e sistemas embarcados disponibilizando a localização dos equipamentos de carga e de alguns dados de produção disponibilizados, um modelo é aliado a algoritmos de otimização sequencial, com a finalidade de reduzir o número de variáveis e de dados do problema real, denominado POLAEC (Planejamento das Operações de Lavra com Alocação de Equipamentos de Carga) e o outro modelo, multiperíodo, possui complexidade de resolução 
consideravelmente superior por considerar um número maior de combinação por objetivar o melhor resultado em mais de um período de tempo.

Segundo o autor(a) os testes, realizados com instâncias hipotéticas, verificam a coerência dos métodos de otimização sequencial propostos e mostram que bons resultados podem ser obtidos em tempo computacional considerado aceitável para aplicações práticas (AMARAL, 2008).

Os modelos apresentados por Amaral (2008) consideram as atividades de carregamento assim como são apresentadas restrições que contribuem para considerar a atividade de transporte a ser realizado por caminhões. Porém serão apresentadas a seguir somente as restrições ligadas ao carregamento por assemelhar-se à proposta do presente trabalho.

\subsubsection{Heurística e modelo matemático (AMARAL, 2008)}

Amaral (2008) desenvolveu um sistema composto por um modelo matemático em programação inteira mista e uma heurística que apoia a otimização sequencial por meio de sucessivas ordens de lavra. A heurística representada na Figura 4.1 realiza as atividades descritas por sete passos com intuito de gerar planos viáveis a serem definidos por um modelo matemático resolvido com otimalidade por um software de otimização. As iterações são repetidas até o fim do horizonte a ser estudado. O autor(a) aponta resultados satisfatórios tanto em qualidade da solução como em tempo de execução em instâncias estimadas pelos mesmos contendo 10.800 blocos.

O sistema contribui para uma lacuna prática e teórica existente em modelos de operações de lavra entre os horizontes de longo e curto prazos, apontando a falta de capacidade de relacionar fatores operacionais importantes em modelos com horizontes mais longos e a incapacidade dos modelos de curto prazo em considerar informações do modelo geológico (AMARAL, 2008).

No primeiro passo são lidos todos os dados de entrada do problema, associados ao modelo de blocos, aos equipamentos de carga, as metas e requisitos de operação, ao 
acompanhamento da produção e penalidades.

No passo seguinte (passo 2) é definido os blocos disponíveis a serem lavrados, somente blocos da superfície e aqueles que não possuem precedentes lavrados podem ser considerados disponíveis.

Executa-se no passo 3 o modelo on-line implementados utilizando-se a linguagem AMPL 11.0 e resolvidos com o CPLEX.

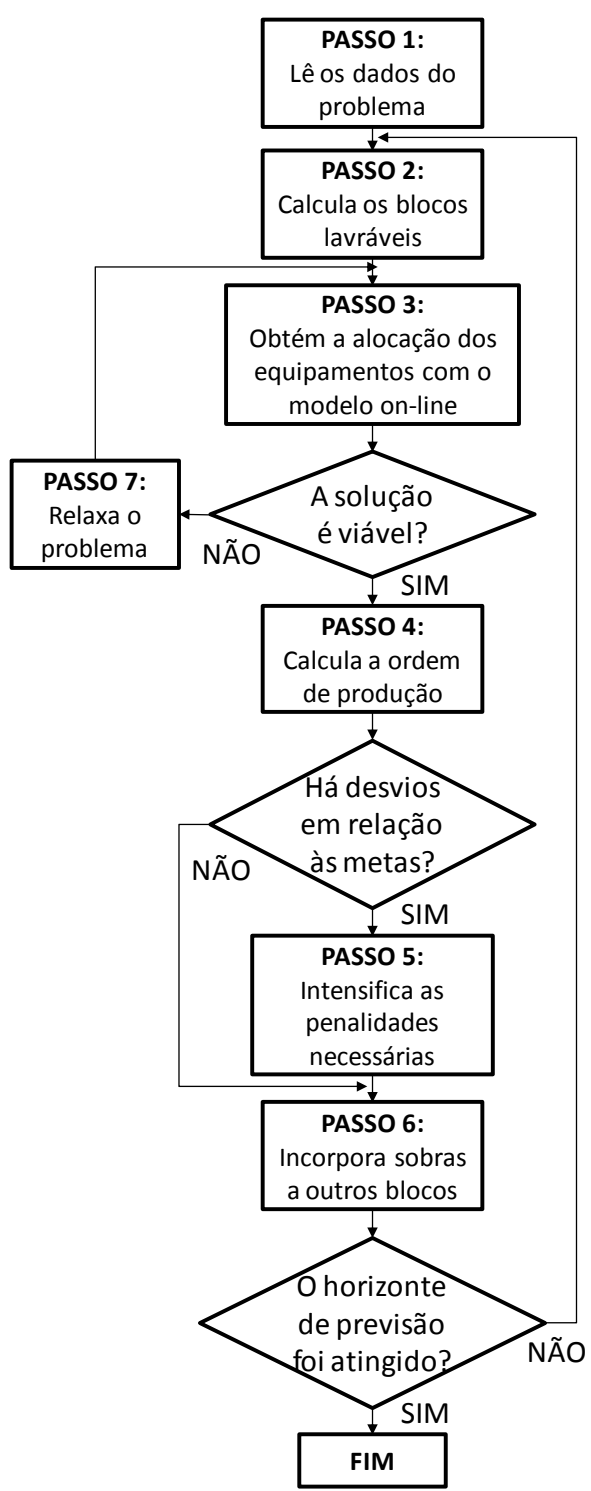

Figura 4.1 - Heurística para otimização sequencial.

FONTE: AMARAL (2008) 
A seguir serão apresentados os parâmetros de entrada, as variáveis e o modelo matemático proposto por Amaral (2008), POLAEC (Planejamento das Operações de Lavra com Alocação de Equipamentos de Carga).

\section{Dados da Mina:}

$B^{\prime} \quad$ : Conjunto de índices para os blocos disponíveis.

$R \quad$ : Conjunto de coordenadas para representação do modelo de blocos formados por (L, C e H).

$V \quad$ : Conjunto das variáveis físico-químicas.

$p_{r}^{b} \quad$ : Posição do bloco $b$ em relação à coordenada $r$.

$T_{v b} \quad$ : Teor da variável físico-química $v$ no bloco $_{b}$.

\section{Dados dos Equipamentos de Carga:}

I : Conjunto dos equipamentos de carga disponíveis.

$p o_{r}^{i} \quad$ : Posição inicial do equipamento de carga $i$ em relação à coordenada $r$.

$P \min _{i}$ : Produção horária mínima para operação do equipamento de carga $i$.

$P \max _{i}$ : Produção horária máxima para operação do equipamento de carga $i$.

\section{Conjunto de Metas e Requisitos de Operação:}

TC : Teor de corte (\%).

$\operatorname{Pr} \quad$ : Produção mínima de minério requerida (t/h)

$T \min _{v} \quad:$ Teor mínimo na blendagem do ROM da variável físico-química $v$.

$T \max _{v}$ : Teor máximo na blendagem do ROM da variável físico-química $v$.

REM : REM requerida. $d \max _{r}: \begin{aligned} & \text { Número máximo de deslocamentos permitidos para os equipamentos } \\ & \text { de carga em relação à coordenada } r \text {. }\end{aligned}$ 
NNLS : Número máximo de níveis da mina que podem ser lavrados. simultaneamente.

\section{Dados de Acompanhamento de Produção:}

$P M \quad$ : Produção de minério acumulada ( $\mathrm{t}$ ).

PE : Produção de estéril acumulada (t)

DTA : Desvio de teor acumulado para a variável química de controle (\%) $v$.

\section{Conjunto de Penalidades a Serem Aplicadas:}

$\alpha_{v}^{-} \quad$ : Penalidade por desvio inferior da físico-química $v$.

$\alpha_{v}^{+} \quad$ : Penalidade por desvio superior da físico-química $v$.

$\beta^{-} \quad$ : Penalidade por desvio negativo em relação à REM.

$\beta^{+} \quad$ : Penalidade por desvio positivo em relação à REM .

$\gamma_{r} \quad$ : Custo de deslocamento para os equipamentos de carga em relação à coordenada $r$.

\section{Variáveis de decisão:}

$P_{b} \quad$ : Produção horária no bloco $b(\mathrm{t} / \mathrm{h})$.

$y_{b}^{i}:\left\{\begin{array}{l}1-\text { se o recurso ié alocado ao bloco } b \\ 0-\text { caso contrário. }\end{array}\right.$

$d_{r}^{i} \quad$ : Deslocamento realizado pelo recurso $i$ na coordenada $r$.

Nmin : Número do menor nível com recurso alocado.

Nmax : Número do maior nível com recurso alocado.

$d N \quad$ : Diferença entre o maior e o menor nível com recurso alocado.

$d T_{v}^{-} \quad$ : Desvio negativo em relação ao teor máximo recomendado para a 
variável v.

$d T_{v}^{+} \quad$ : Desvio positivo em relação ao teor máximo recomendado para a variável v.

$f T_{v}^{-} \quad$ : Folga de qualidade em relação ao teor mínimo recomendado para a variável $v$.

$f T_{v}^{+} \quad$ : Folga de qualidade em relação ao teor máximo recomendado para a variável $v$.

$d R E M$

: Desvio negativo em relação à REM requerida.

$d R E M^{+} \quad$ : Desvio positivo em relação à REM requerida.

\section{Modelo Matemático:}

$$
\begin{gathered}
\operatorname{Max} z=\sum_{b \in B^{\prime}} P_{b}- \\
-\sum_{r \in R} \gamma_{r} \sum_{i \in I} d_{r}^{i}-\beta^{-} \times d R E M^{-}-\beta^{+} \times d R E M^{+} \\
-\sum_{v \in V}\left(\alpha_{v}^{-} \times d T_{v}^{-}+\alpha_{v}^{+} \times d T_{v}^{+}\right)
\end{gathered}
$$

Sujeito a:

$$
\begin{gathered}
\sum_{b \in B^{\prime}} y_{b}^{i}=1 \quad \forall i \in I \\
\sum_{i \in I} y_{b}^{i} \leq 1 \quad \forall b \in B^{\prime} \\
d_{r}^{i}=\left|\sum_{b \in B^{\prime}} p_{b r} y_{b}^{i}-p o_{r}^{i}\right| \quad \forall i \in l, r \in R \\
d_{r}^{i} \leq d \max _{r} \quad \forall i \in I, r \in R \\
P_{b}-\sum_{i \in I} y_{b}^{i} P \min ^{i} \geq 0 \quad \forall b \in B^{\prime}
\end{gathered}
$$




$$
P_{b}-\sum_{i \in I} y_{b}^{i} P \max ^{i} \geq 0 \quad \forall b \in B^{\prime}
$$

$$
\sum_{\substack{b \in B^{\prime} \\ T_{F e} \geq t c}} P_{b} \geq P r
$$

$$
\sum_{\substack{b \in B^{\prime}, T_{F e} \geq t c}} T_{v b} P_{b}-\operatorname{Tmin}_{v} \sum_{\substack{b \in B^{\prime} \\ T_{F e} \geq t c}} P_{b}+D T A_{v}+d T^{-}-f T^{-}=0 \quad \forall v \in V
$$

$$
\operatorname{Tmax}_{v} \sum_{\substack{b \in B^{\prime} \\ T_{F e} \geq t c}} P_{b}-\sum_{\substack{b \in B^{\prime} \\ T_{F e} \geq t c}} T_{v b} P_{b}+D T A_{v}+d T^{+}-f T^{+}=0 \quad \forall v \in V
$$

$$
\begin{array}{r}
\left(P E+\sum_{\substack{b \in B^{\prime} \\
T_{F e}<t c}} P_{b}\right)-R E M\left(P M+\sum_{\substack{b \in B^{\prime} \\
T_{F e} \geq t c}} P_{b}\right)+d R E M^{-}-d R E M^{+}=0 \\
n M i n=\min \left(\sum_{b \in B^{\prime}} p_{b r} y_{b}^{i}\right) \quad \forall i \in I, r=H \\
n M a x=\max \left(\sum_{b \in B^{\prime}} p_{b r} y_{b}^{i}\right) \quad \forall i \in I, r=H
\end{array}
$$

$$
d N=n M a x-n M i n
$$

$$
d N \leq N N L S
$$

$$
P_{b} \geq 0 \quad \forall b \in B^{\prime}
$$$$
y_{b}^{i} \in\{0,1\} \quad \forall b \in B^{\prime}, i \in I
$$$$
d_{r}^{i} \geq 0 \quad \forall i \in l, r \in R
$$

$$
n \operatorname{Min} \geq 0, n \operatorname{Max} \geq 0
$$

$$
d N \geq 0
$$

$$
d R E M^{-} \geq 0, d R E M^{+} \geq 0
$$

$$
d T_{v}^{-} \geq 0, d T_{v}^{+} \geq 0, f T_{v}^{-} \geq 0, f T_{v}^{+} \geq 0 \quad \forall v \in V
$$

Assim, a função objetivo (4.11) visa à maximização da produção horária e à 
minimização dos deslocamentos dos equipamentos de carga, além dos desvios em relação às metas de qualidade e REM. A REM (relação estéril/minério) normalmente encontrada ao dividir o ritmo de lavra de estéril pelo ritmo de lavra de minério tem sua importância ligada a impedir que somente minério seja lavrado, possibilitando a liberação de novas frentes de minério ou a implantação de obras necessárias para viabilizar as operações na mina.

Nas restrições (4.12) - (4.13) se referem à alocação dos equipamentos de carga e em (4.14) - (4.15) são impostos os números máximos de deslocamentos permitidos em cada direção. Em (4.16)- (4.17), têm-se os limites de operação horária para os equipamentos de carga. Em (4.18), impõe-se a meta mínima de produção de minério. As restrições de (4.19) - (4.20) calculam os desvios de qualidade em relação ao mínimo e máximo requerido. A restrição (4.21) calcula em uma forma linearizada se existem desvios na REM considerando a produção atual e a produção acumulada de estéril e minério. As restrições (4.22) - (4.24) referem ao número máximo de níveis que podem lavrados simultaneamente. De (4.25) - (4.32), têm-se os domínios das variáveis, sendo $y_{b}^{i}$ binárias de alocação dos equipamentos de carga, enquanto as demais são não negativas.

No Passo 4, os resultados do modelo são usados no cálculo das seguintes variáveis da ordem $k$ : duração da ordem $t^{k}(\min )$; quantidade de material lavrado em cada bloco $x_{b}^{k}(\mathrm{t})$; e massa restante no bloco após a execução da ordem $M_{b}^{k}(\mathrm{t})$, por meio das equações (4.33) - (4.35). Se forem apurados desvios de qualidade, ocorre a potencialização de penalidades no Passo 5. Nessa etapa, os parâmetros $\mu_{\beta}^{f}, f \in F$ multiplicam as penalidades originais. Devido às faixas $f \in F$, quanto maior o desvio, maior a intensificação aplicada. Uma vez que os desvios sejam corrigidos, as penalidades voltam as valores fornecidos originalmente. Senão, a heurística segue diretamente para o Passo 6.

$$
\begin{array}{r}
t^{k}=\left\{\begin{array}{r}
\min \left(M_{b} / P_{b}^{k}\right), \text { se } k=1 \\
\min \left(M_{b} / P_{b}^{k}\right), \text { se } k>1
\end{array} \quad \forall b \in B^{\prime} \mid y_{b}^{i}=1\right. \\
x_{b}^{k}=P_{b}^{k} t^{k} \quad \forall b \in B^{\prime} \mid y_{b}^{i}=1
\end{array}
$$




$$
M_{b}^{k}=\left\{\begin{array}{l}
M_{b}-x_{b}^{k}, \text { se } k=1 \\
M_{b}^{k-1}-x_{b}^{k}, \text { se } k>1
\end{array} \quad \forall b \in B^{\prime} \mid y_{b}^{i}=1\right.
$$

Onde:

$$
\begin{array}{ll}
M_{b} & : \quad \text { Massa final do bloco } \mathrm{b}(\mathrm{t}) . \\
x_{b}^{k} & : \quad \text { Quantidade lavrada do bloco } b \text { no plano de lavra } k .
\end{array}
$$

No passo 6, caso ao final da ordem, algum dos equipamentos de carga está muito próximo de exaurir um bloco e essa sobra for insuficiente para gerar uma ordem com duração $d m$, essa sobra é incorporada a um bloco adjacente. Prioriza-se, nessas situações, a união de blocos de mesmo material, minério com minério e estéril com estéril. O Passo 7 é executado quando a solução do modelo é inviável, quando por exemplo, ocorre o estrangulamento da mina, isto é, todo o minério está coberto por blocos de estéril ou por restrições sobre o aprofundamento. Caso a mina esteja estrangulada, retira-se a restrição (4.18) e a penalidade para os desvios de REM positivos $\left(\beta^{+}=0\right)$. Se isso não for suficiente, aumenta-se o espaço de soluções, de forma progressiva nas restrições (4.15), primeiramente aprofundando e depois alargando a cava.

\subsubsection{Modelo multiperíodo (AMARAL, 2008)}

A seguir serão apresentados os parâmetros de entrada que diferem do modelo on-line apresentado por Amaral (2008):

\section{Dados da Mina:}

B : Conjunto de todos os blocos da mina. 
$M_{b} \quad$ : Massa atual do bloco $b$.

K : Conjunto de índices de todos os períodos de planejamento.

Matriz binária que indica a precedência para retirada dos blocos de

$g_{a b} \quad$ : material na mina, mantendo-se ângulos de talude adequados (o bloco $q$ deve ser retirado antes de $b$ ).

$G$

: Massa do número máximo de blocos q que devem ser retirados antes de b para manutenção dos ângulos de talude adequados (t).

A matriz binária $g_{q b}$, é uma matriz de adjacências, que representa as regras para a manutenção de ângulos de talude seguros, a partir de imposições determinadas pelo estudo geológico do terreno da mina. Como o número de vizinhos precedentes para cada bloco varia com os ângulos de talude requeridos, a densidade da matriz também varia com esse dado de entrada. Outro fator impactante é o nível que bloco $b$ se encontra, onde, quanto mais profundo menor o número de precedentes.

Outra variável importante acrescentada, $v_{b}^{k}$, armazena toda a massa inicial de cada bloco precedente do bloco $b$. Se essa massa for igual a zero, significa que não existem precedentes a serem lavrados liberando o bloco. Assim, o bloco está liberado e a variável $w_{b}^{k}$ correspondente também terá valor igual a zero. Caso contrário, o bloco está impedido e a variável $w_{b}^{k}$ assume valor igual a um.

Para o modelo multiperíodo passam a serem consideradas as variáveis multiperíodo descritas a seguir:

$$
\begin{array}{ll}
v_{b}^{k} & :\left\{\begin{array}{l}
0, \text { se o bloco } b \text { pode ser lavrado no período } k \\
>0, \text { caso contrário }
\end{array}\right. \\
\omega_{b}^{k} \quad:\left\{\begin{array}{l}
0, \text { se o bloco } b \text { pode ser lavrado no período } k \\
1, \text { caso contrário }
\end{array}\right. \\
t^{k} \quad: \text { Duração do período } k \\
x_{b}^{k} \quad: \text { Quantidade de minério retirado do bloco b no período } k(\mathrm{t})
\end{array}
$$


$M_{b}^{k} \quad:$ Massa atual do bloco $b$ no período $k(t)$

$P_{b}^{k} \quad:$ Produção horária no bloco $b$ no período $k(\mathrm{t} / \mathrm{h})$ $y_{b}^{i k}:\left\{\begin{array}{l}1, \text { se o equipamento de carga } i \text { está alocado ao bloco b no período } k \\ >0 \text {, caso contrário }\end{array}\right.$

$d_{r}^{i k} \quad:$ Deslocamento do equipamento $i$ em relação à coordenada $r$ no período k

$n \operatorname{Min}^{k} \quad$ : Número do menor nível com equipamento de carga alocado no período $k$

$n \operatorname{Max}^{k} \quad$ : Número do maior nível com equipamento de carga alocado no período $\mathrm{k}$

$d N^{k} \quad$ : Diferença entre o maior e o menor nível com equipamento de carga alocado no período $k$

$d T_{v}^{k-} \quad$ : Desvio negativo em relação ao teor mínimo recomendado para a variável $v$ no período $k$

$d T_{v}^{k+} \quad$ : Desvio positivo em relação ao teor mínimo recomendado para a variável $v$ no período $k$

$f T_{v}^{k-} \quad: \quad$ Folga da qualidade em relação ao teor mínimo recomendado para a variável $v$ no período $k$

$f T_{v}^{k+} \quad:$ Folga da qualidade em relação ao teor maior recomendado para a variável $v$ no período $k$

$d R E M^{-} \quad$ : Desvio negativo em relação à relação estéril-minério requerida

$d R E M^{+} \quad$ : Desvio positivo em relação à relação estéril-minério requerida

\section{Modelo Matemático:}

$$
\begin{gathered}
\operatorname{Max} z=\sum_{k \in K} \sum_{b \in \mathrm{B}} x_{b}^{k}-\sum_{k \in K} \sum_{v \in V} \alpha^{-} \times d T_{v}^{k-}-\sum_{k \in K} \sum_{v \in V} \alpha^{+} \times d T_{v}^{k+}- \\
\beta^{-} \times d R E M^{-}-\beta^{+} \times d R E M^{+}-\gamma_{r} \sum_{k \in K} \sum_{i \in l} \sum_{r \in R} d_{r}^{i k}
\end{gathered}
$$


Sujeito a:

$$
\begin{aligned}
& \sum_{b \in B} y_{b}^{i k}=1 \quad \forall i \in l, \forall k \in K \\
& \sum_{i \in I} y_{b}^{i k} \leq 1 \quad \forall b \in B, \forall k \in K \\
& d_{r}^{i k}=\left|\sum_{b \in B} p_{b r} \times y_{b}^{i k}-p o_{r}^{i}\right| \quad \forall i \in I, k=1 \\
& d_{r}^{i k}=\left|\sum_{b \in B} p_{b r} \times y_{b}^{i k}-\sum_{b \in B} p_{b r} \times y_{b}^{i k-1}\right| \quad \forall i \in I, k>1 \\
& \begin{array}{ll}
d_{r}^{i k} \leq \operatorname{dmax}_{r} \quad & \forall i \in l, \forall r \in R, \\
& \forall k \in K
\end{array} \\
& v_{b}^{k}-\sum_{q \in B} g_{q b} \times M_{q}=0 \quad \forall b \in B, k=1 \\
& v_{b}^{k}-\sum_{q \in B} g_{q b} \times M_{q}^{k-1}=0 \quad \forall b \in B, k>1 \\
& v_{b}^{k} \geq \omega_{b}^{k} \quad \forall b \in B, \forall k \in K \\
& v_{b}^{k} \leq G \times \omega_{b}^{k} \quad \forall b \in B, \forall k \in K \\
& \sum_{s \in K / s \leq K} x_{b}^{s} \leq M_{b} \times\left(1-\omega_{b}^{k}\right) \quad \forall b \in B, \forall k \in K \\
& P_{b}^{k} \geq \sum_{i \in l} y_{b}^{i k} \times P \min ^{i} \quad \forall b \in B, \forall k \in K \\
& P_{b}^{k} \leq \sum_{i \in l} y_{b}^{i k} \times P \max ^{i} \quad \forall b \in B, \forall k \in K \\
& \sum_{\substack{b \in B \\
T_{F e} \geq t c}} P_{b}^{k} \geq \operatorname{Pr} \quad \forall k \in K \\
& t^{k}=\min \left(\frac{M_{b}}{P_{b}^{k}}\right) \quad \forall b \in B, k=1
\end{aligned}
$$




$$
\begin{aligned}
& t^{k}=\min \left(\frac{M_{b}}{P_{b}^{k}}\right) \quad \forall b \in B, k>1 \\
& x_{b}^{k}=P_{b}^{k} \times t^{k} \quad \forall b \in B, \forall k \in K \\
& M_{b}^{k}=M_{b}-x_{b}^{k} \quad \forall b \in B, k=1 \\
& M_{b}^{k}=M_{b}^{k-1}-x_{b}^{k} \quad \forall b \in B, k>1 \\
& \sum_{\substack{b \in B^{\prime} \\
T_{F e} \geq t c}} T_{v b} P_{b}^{k}-\operatorname{Tmin}_{v} \sum_{\substack{b \in B^{\prime} \\
T_{F e} \geq t c}} P_{b}^{k}+D T A_{v}+d T_{v}^{k-}-f T_{v}^{k-}=0 \quad v \in V, \forall k \in K \\
& T \max _{v} \sum_{\substack{b \in B \\
T_{F e} \geq t c}} P_{b}^{k}-\sum_{\substack{b \in B \\
T_{F e} \geq t c}} T_{v b} P_{b}^{k}+D T A_{v}+d T_{v}^{k+}-f T_{v}^{k+}=0 \quad v \in V, \forall k \in K \\
& \sum_{k \in K} \sum_{\substack{b \in B, T_{F e}<t c}} P_{b}^{k}-R E M \times \sum_{k \in K} \sum_{\substack{b \in B, T_{F e} \geq t c}} P_{b}^{k}+d R E M^{-}-d R E M^{+}=0 \\
& N \min ^{k}=\min \left(H^{i k}\right) \quad i \in l, \forall k \in K \\
& N \max ^{k}=\max \left(H^{i k}\right) \quad i \in I, \forall k \in K \\
& d N^{k}=N \max ^{k}-N \min ^{k} \quad k \in K \\
& d N^{k} \leq N N L S \quad k \in K \\
& v_{b}^{k} \geq 0 \quad \forall b \in B, \forall k \in K \\
& \omega_{b}^{k} \in\{0,1\} \quad \forall b \in B, \forall k \in K \\
& t^{k} \in \square^{+} \quad \forall k \in K \\
& x_{b}^{k} \geq 0 \quad \forall b \in B, \forall k \in K \\
& M_{b}^{k} \geq 0 \quad \forall b \in B, \forall k \in K \\
& P_{b} \geq 0 \quad \forall b \in B
\end{aligned}
$$




$$
\begin{aligned}
y_{b}^{i k} \in\{0,1\} & \forall b \in B, \forall i \in I \\
& \forall k \in K \\
d_{r}^{i k} \geq 0 & \forall r \in R, \forall i \in I \\
& \forall k \in K \\
n M i n^{k} \geq 0 & \forall k \in K \\
n M a x^{k} \geq 0 & \forall k \in K \\
d N^{k} \geq 0 & \forall k \in K \\
d T_{v}^{k-} \geq 0 & \forall v \in V, \forall k \in K \\
d T_{v}^{k+} \geq 0 & \forall v \in V, \forall k \in K \\
f T_{v}^{k-} \geq 0 & \forall v \in V, \forall k \in K \\
d R E M^{+} \geq 0 & \\
f T_{v}^{k+} \geq 0 & \forall v \in V, \forall k \in K \\
d R E M^{-} \geq 0 & \\
d R &
\end{aligned}
$$

Para esse modelo multiperíodo, serão comentadas as restrições novas, isto é, que diferenciam o modelo da abordagem on-line, apresentada na seção anterior. As demais restrições sofreram pequenas adaptações e por isso não serão mencionadas novamente. Ressalta-se este modelo também objetiva a geração de ordens de lavra em cada período, porém é capaz de gerar soluções em mais de um período de tempo.

As equações (4.42) a (4.46), representam as relações de precedência para a retirada de cada bloco da mina. Nas equações (4.42) e (4.43), a variável $v_{b}^{k}$ armazena a massa, em cada ordem de produção, de todos os blocos precedentes ao bloco $b$ no período $k$, segundo as regras contidas na matriz $g_{b}^{k}$. As restrições (4.44) e (4.45) relacionam a variável contínua $v_{b}^{k}$ em uma variável binária $\omega_{b}^{k}$, que significa que 0 bloco $b$ está liberado para lavra no período $k$ se não estiver impedido $\left(\omega_{b}^{k}=0\right)$. 0 autor(a) sugere que a constante $G$ deve ser ajustada como um número grande, 
podendo-se utilizar como referência a maior massa que deve ser retirada para liberação de qualquer bloco da mina.

As restrições (4.46) geram limites de produção para a produção dos equipamentos de carga em cada bloco, definidos como zero para os blocos impedidos ou iguais à massa do bloco, caso estes estejam liberados.

As restrições (4.50) e (4.51), calculam a duração de cada período do planejamento, isto é, a duração de uma ordem de produção. Nota-se que, para o segundo período de planejamento em diante, ou seja, equações (4.51), essas restrições são nãolineares, pois estabelecem uma relação entre duas variáveis, a massa dos blocos no período anterior $\left(M_{q}^{k-1}\right)$ e a produção horária dos equipamentos de carga no período atual $\left(P_{b}^{k}\right)$.

As equações definidas em (4.52), também são não-lineares, calculam a quantidade de material retirado de cada bloco que, por sua vez, são utilizadas para o cálculo das massas restantes nos blocos utilizando-se as equações (4.53) e (4.54), fechando o ciclo. Os domínios das novas variáveis são definidos nas equações (4.62) a (4.78).

Quando se compara o modelo multiperíodo ao modelo on-line apoiado pela heurística ao modelo é possível ressaltar:

- Presença de restrições não lineares, que impedem a resolução do modelo utilizando os principais softwares de otimização;

- Aumento da escala do problema pela inclusão dos índices referentes ao período de planejamento k;

- Passa a considerar todo o conjunto $B$ que é consideravelmente maior que $B^{\prime}$ visto que $B^{\prime}$ representa apenas os blocos da superfície da cava disponíveis na ordem de lavra $k$ e $B$ representa todos os blocos da mina, além de deixar implícitas as decisões de quando é necessário que cada bloco esteja liberado e quando lavrar cada bloco de minério a fim de buscar atender requisitos ao longo dos períodos $k$, a fim de possibilitar melhorias na função objetivo multiperíodo;

- Outro fator que aumenta a complexidade do modelo multiperíodo está ligado à 
manutenção REM para todo o horizonte de planejamento, aumentando a dependência entre as decisões de alocação dos equipamentos de carga e da determinação do ritmo de lavra em todos os períodos $k$ do horizonte estabelecido.

Apesar da simplificação da abordagem do modelo on-line apoiado pela heurística quando compara-se o número de combinações de soluções avaliadas pelo modelo muitiperíodo, o modelo POLAEC possibilita a obtenção de soluções aproximadas para o problema e contribui consideravelmente para agilidade do tempo computacional requerido para gerar o planejamento de lavra.

\subsection{SEQUENCIAMENTO E PROGRAMAÇÃO DE MÁQUINAS PARALELAS}

O modelo desenvolvido nesta dissertação se baseia na analogia ao problema de máquinas em paralelo (equipamentos de carregamento) e pode ser classificado segundo a metodologia proposta por Graham et al. (1979), como Qm|s $s_{i j k}$, prec $/ C_{\text {max }}$. A seguir serão descritos algumas classificações de problemas de máquinas em paralelos como as descritas entre outras.

Segundo Pinedo (2008), uma estrutura composta por máquinas paralelas tem importância tanto do ponto de vista teórico como prático. Do ponto de vista teórico, máquinas em paralelo é uma generalização de estrutura composta por máquina única e, do ponto de vista prático, máquinas paralelas são encontradas em muitos casos reais. Podem-se considerar simultaneamente sequenciamento e programação da produção, em algumas heurísticas, tratam os problemas separadamente. No primeiro, escolhem-se quais jobs serão atribuídos a cada máquina e, no último, determinam-se em qual ordem serão executadas as tarefas nas máquinas.

Graham et al. (1979) elaboraram uma classificação para problemas de sequenciamento e programação expressa por três campos $\alpha|\beta| \gamma$.

- $\quad \alpha$ : Ambiente de máquinas, Machine Environment.

- $\quad \beta$ : Características das tarefas, Jobs Characteristics. 
- $\quad \gamma$ : Critério de otimalidade, Optimality Criterion.

O parâmetro $\alpha$ pode assumir os seguintes valores:

- P: Homogêneas, máquinas idênticas em paralelo.

- Q: Proporcionais, máquinas com velocidades proporcionais.

- R: Não relacionadas, máquinas com velocidades dependentes da máquina e da tarefa.

A classificação homogênea é atribuída a máquinas que possuem a mesma velocidade de processamento, máquinas proporcionais possuem velocidades independentes entre si e por último máquinas não relacionadas possuem velocidades de processamento dependente tanto da tarela a ser executada quanto da máquina. (ALLAHVERDI et al., 2008).

Segundo Pinedo (2008), o parâmetro $\beta$ aplicado a máquinas paralelas pode assumir, por exemplo, as seguintes restrições:

- $\quad r_{j}$ (Release dates): Impõe que o job j só pode começar a ser executado após o tempo atual exceder o valor de $r_{j}$. Ou seja, se não houver a restrição $r_{j}$, o job $j$ pode ser executado a qualquer momento.

- $\quad$ rmp (Preemptions): Permite que seja interrompido a processamento de um job, voltando a processá-lo posteriormente.

- prec (Precedence constraints): Requer que um ou mais Jobs sejam processados antes de um determinado job. Caso o campo $\beta$ não possua essa restrição, então não existe restrição de precedência.

- $s_{j k}$ (Sequence dependent setup times): Atribui-se ao tempo de preparação de determinado job $\mathrm{k}$ após o término do job j. Caso cada máquina possua um tempo distinto entre a troca do job je o job $k$, então é atribuído i a $s_{i j k}$, ou seja, existe um tempo de troca distinto a cada máquina $i$.

- fmls (Job Families): Os jobs são divididos conforme sua semelhança em 
famílias. Nesse caso, tempos de setup ocorrem somente quando existe diferença de famílias entre o fim de um processo de um job j e a alocação do job $k$.

- batch(b) (Batch processing): Nesse caso, máquinas são habilitadas a processarem um número de jobs $b$ simultaneamente. $O$ tempo de processamento do lote é determinado pelo job de maior tempo para conclusão; após concluídos os jobs do lote, são alocados novos jobs ao lote a ser processado.

- $\quad b r k d w n$ (Breakdowns): Máquinas com breakdowns indicam períodos de tempo nos quais cada máquina não estará disponível.

- $\quad M_{i j}$ (Machine eligibility restrictions): Determinados jobs $j$ não podem ser processados por todas as máquinas $i$.

Quanto às funções objetivo, são encontradas diferentes abordagens na literatura (PINEDO, 2008):

- $C_{\max }$ (Makespan): Minimizar o tempo total para processar todas as tarefas. A minimização do makespan pode ser obtida através da maximização da utilização dos recursos limitantes e redução no tempo de setup entre as tarefas.

- $L_{\max }$ (Maximum Lateness): Minimizar o atraso máximo gerado pela maior violação entre a data que o job $j$ foi processado, $C_{j}$, e sua data de entrega, $d_{j}$. Ou seja, lateness é igual a $L_{j}=C_{j}-d_{j}$ e deseja-se reduzir a maior diferença gerada por $L_{j}$ para cada $j \in J$.

- $\sum w_{j} T_{j}$ (Total weighted tardiness): Minimizar o custo gerado pelo somatório do atraso de cada job $j$ multiplicado pelo peso atribuído ao atraso do job $j$.

- $\sum w_{j} U_{j} \quad$ (Weighted number of tardy jobs): Minimizar o custo gerado pela ocorrência de atraso do job $j$ multiplicado pelo peso atribuído ao atraso do mesmo.

Tendo em vista as classificações descritas, o problema estudado será tratado como 
um conjunto de máquinas $m$ (equipamentos de carga) que processarão jobs $j$ (blocos de minério ou estéril). Nesse trabalho, permite-se que cada máquina possa operar com velocidades distintas durante o processo de um mesmo job. Essa velocidade dependerá das condições da operação, distinguindo-se da abordagem tradicional para problemas caracterizados como $\mathrm{Q} m\left|s_{i j k}, \operatorname{prec}\right| C_{\max }$, na qual cada máquina possui apenas uma velocidade de operação independente da tarefa.

No sistema proposto, similar a modelos que têm como objetivo a otimização do makespan $\left(C_{\max }\right)$, deseja-se que as máquinas operem em sua velocidade máxima e que sejam minimizados tempos de setup. Porém, máquinas alocadas a blocos de minério devem ponderar entre quantidade produzida e a qualidade da mistura da produção das diferentes frentes de lavra de minério. Em certas ocasiões, para que a blendagem de minério realizada não se distancie demais das metas de qualidade de variáveis físico-químicas, faz-se necessário a redução da velocidade de uma ou mais máquinas alocadas a blocos diferentes de minério para serem capazes de gerar uma mistura que minimiza os desvios da meta dos parâmetros de qualidade.

Para que cada máquina $i$ tenha uma "liberdade" de velocidade, é identificado um mínimo e um máximo de capacidade. Por outro lado, máquinas que estejam alocadas a blocos de estéril sempre operarão em plena capacidade por não haver metas de mistura relacionada à sua extração. 


\section{MÉTODO MATEMÁTICO PARA O PROBLEMA}

O Sequenciamento e Programação de Lavra com Alocação de Equipamentos de Carga (SPLAEC) proposto no presente trabalho é composto por um novo modelo matemático para alocação de equipamentos de carga e um algoritmo composto por sete passos que apoia sucessivas iterações utilizando a técnica de horizonte móvel para gerar ordens de lavra que criarão o sequenciamento e programação da lavra.

O propósito do SPLAEC é fornecer a sequência ótima de lavra da mina, indicando a localização e o ritmo de lavra ( $t / h$ ) dos equipamentos de carga no modelo geológico, a cada ordem de lavra. A alocação e a produção horária dos equipamentos estão sujeitas a diversas restrições impostas, como:

- As capacidades horárias mínimas e máximas de produção dos equipamentos de carga, definidas em função de custos de operação economicamente viáveis e de restrições técnicas de uso recomendadas pelos fabricantes, respectivamente;

- A lavra de ROM é limitada à capacidade do britador;

- A lavra de ROM é limitada à capacidade da usina de beneficiamento caso a pilha de ROM esteja acima do nível de pedido.

- Na presente pesquisa, a capacidade atribuída à usina é inicialmente a mesma da demanda horária de ROM, porém a capacidade pode ser reajustada em ordens de lavra futuras para repor perdas de produção acumuladas quando não houver produção suficiente das frentes e a pilha estiver vazia;

- Manutenção dos ângulos de talude adequados, uma restrição comumente encontrada em modelos que abordam o planejamento de longo e médio prazo;

- Distância máxima de níveis entre o equipamento de carga alocado em um nível mais elevado da cava e o equipamento de lavra alocado ao bloco no nível inferior da cava. Essa restrição visa contribuir para reduzir a possibilidade do estrangulamento de uma cava; 
- Quantidade de deslocamento máximo permitido aos equipamentos de carga para alocar um bloco;

- A retomada da pilha de ROM é permitida somente em situações onde a lavra proveniente das frentes de lavra de minério é insuficiente quando comparado com a demanda da usina de beneficiamento;

- A quantidade de ROM que pode ser retomada da pilha de ROM para atender a usina é limitada por uma capacidade operacional $(C r)$.

Os objetivos a serem atingidos:

- A maximização da produção horária dos equipamentos de carga;

- Sempre que possível, a lavra do ROM somado à retomada da pilha de ROM, deve atender a todos os requisitos de qualidade e atingir a capacidade da usina suprindo a demanda horária da usina de beneficiamento;

- A redução dos custos de deslocamentos dos equipamentos de carga, que visa a dois propósitos: minimizar os deslocamentos para ajuste da qualidade e produção de ROM e de minimizar a profundidade de lavra e seu estrangulamento.

\subsection{MODELO DO PROBLEMA DE ALOCAÇÃO DE EQUIPAMENTOS DE CARGA EM UMA MINA A CÉU ABERTO CONSIDERANDO A EXISTÊNCIA DA PILHA DE ROM}

O modelo matemático desenvolvido pertence à classe de programação linear inteira mista (PLIM), possuindo variáveis de decisão contínuas e inteiras. As variáveis inteiras estão ligadas à alocação de equipamentos e utilização da pilha.

O modelo, em aplicações reais, considera informações provenientes da mina e do controle de produção. Dessa forma, empresas que utilizam informações provenientes de comunicação remota e sistemas automatizados podem se beneficiar de sua 
utilização.

Destacam-se duas aplicabilidades, na primeira o modelo on-line, a cada período, direciona os equipamentos de carga em tempo real por meio de uma ordem de lavra, que considera a situação atual da mina sendo executado novamente ao fim da ordem ou caso existam desvios significativos ao esperado nas operações.

$\mathrm{Na}$ segunda aplicabilidade, o modelo on-line, que também utiliza informações em tempo real, apoiado por algoritmo, executa um sequenciamento e programação da lavra levando em consideração o posicionamento dos equipamentos e demais controles de qualidade. Desse modo, considera mais de um período de tempo contribuindo para o planejamento e o controle da lavra a ser executada.

A seguir serão apresentados os parâmetros de entrada, variáveis de decisão e modelo matemático proposto.

\section{Dados da Mina:}

$B^{\prime} \quad$ : Conjunto de índices para os blocos disponíveis.

$R \quad$. Conjunto de coordenadas para representação do modelo de blocos. : Sendo (L, C e H).

V $\quad$ : Conjunto das variáveis físico-químicas.

$p_{b r} \quad$ : Posição do bloco $b$ em relação à coordenada $r$.

$T_{v b} \quad$ : Teor da variável físico-química $v$ no bloco $_{b}$.

$s_{b}:\left\{\begin{array}{l}1, \text { se o bloco bé de minério } \\ 0, \text { se o bloco bé de estéril }\end{array}\right.$

Cb : Capacidade de processamento do britador (t/h).

\section{Dados da Pilha de ROM:}

MP : Capacidade atribuída à pilha de ROM

PercP : Nível de pedido para reposição da pilha de ROM (\% da capacidade). 
VolP : Tonelagem atual na pilha de ROM.

$\mathrm{Cr} \quad$ : Capacidade de retomada (t/h) do ROM contido na pilha.

\section{Conjunto de metas e requisitos:}

capUsina : Capacidade atribuída à usina (t/h).

$\operatorname{Tr}_{v} \quad: \quad$ Teor requerido na mistura do ROM da variável físico-química $v$.

$T u_{v} \quad$ : Teor máximo na mistura do ROM da variável físico-química $v$.

$T l_{v} \quad: \quad$ Teor mínimo na mistura do ROM da variável físico-química $v$.

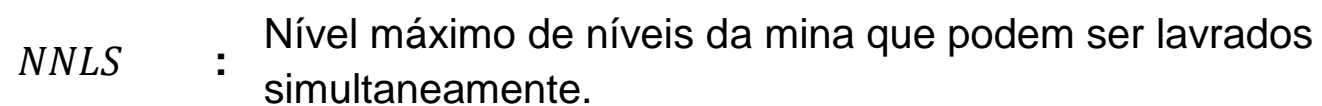

$\operatorname{dmax}_{r} \quad$ : Deslocamento máximo permitido na coordenada $r$.

$D T A_{v} \quad$ : Desvio de teor acumulado do teor $v$.

\section{Dados dos Equipamentos de Carga:}

I : Conjunto dos equipamentos de carga disponíveis.

$p o_{r}^{i} \quad$ : Posição inicial do equipamento de carga $i$ em relação à coordenada $r$.

$\operatorname{Pmin}_{i}$ : Produção horária mínima para operação do equipamento de carga $i$.

$\operatorname{Pmax}_{i}$ : Produção horária máxima para operação do equipamento de carga $i$.

\section{Benefícios:}

BM : Benefício atribuído à lavra de ROM.

BS : Benefício atribuído à lavra de estéril.

\section{Penalidades:}

$\alpha_{v}^{-} \quad$ : Penalidade por desvio inferior em relação à meta do parâmetro físicoquímico $v$. 
$\alpha_{v}^{+} \quad$ : Penalidade por desvio superior em relação à meta do parâmetro físicoquímico $v$.

$\gamma_{r}^{i} \quad$ : Penalidade pelo deslocamento do recurso $i$ na coordenada $r$.

$\delta^{-} \quad$ : Penalidade por desvio negativo da produção de ROM (t/h).

$\omega_{v}^{-} \quad$ : Desvio negativo em relação ao mínimo parâmetro físico-químico $v$ especificado.

$\omega_{v}^{+} \quad$ : Desvio positivo em relação ao máximo parâmetro físico-químico $v$ especificado.

Variáveis de decisão:

$P_{b} \quad$ : Produção horária no bloco $b(\mathrm{t} / \mathrm{h})$.

$D P^{-} \quad$ Desvio negativo do ritmo de lavra total $(\mathrm{t} / \mathrm{h})$ em relação à demanda de : ROM.

$D P^{+} \quad$ : ROM

$D M^{-} \quad$ : pilha em relação demanda de $\mathrm{ROM}(\mathrm{t} / \mathrm{h})$.

$D M^{+} \quad: \begin{aligned} & \text { Desvio positivo do total extraído }(\mathrm{t} / \mathrm{h}) \text { somad } \\ & \text { pilha em relação demanda de } \mathrm{ROM}(\mathrm{t} / \mathrm{h}) .\end{aligned}$

$R P \quad$ : Quantidade de ROM retirada da pilha para suprir a demanda (t/h).

$z \quad:\left\{\begin{array}{l}1-\text { se a pilha de ROM será consumida. } \\ 0 \text { - caso contrário. }\end{array}\right.$

$w: \quad\left\{\begin{array}{l}1-\text { se será lavrado ROM excedendo à demanda. } \\ 0 \text { - caso contrário. }\end{array}\right.$

$y_{b}^{i}:\left\{\begin{array}{l}1-\text { se o recurso ié alocado ao bloco } b . \\ 0-\text { caso contrário. }\end{array}\right.$

Nmin : Número do menor nível com recurso alocado. 
Nmax : Número do maior nível com recurso alocado.

$d T_{v}^{-} \quad: \begin{aligned} & \text { Desvio negativo em relação ao teor recomendado da variável físico- } \\ & \text { química } v .\end{aligned}$

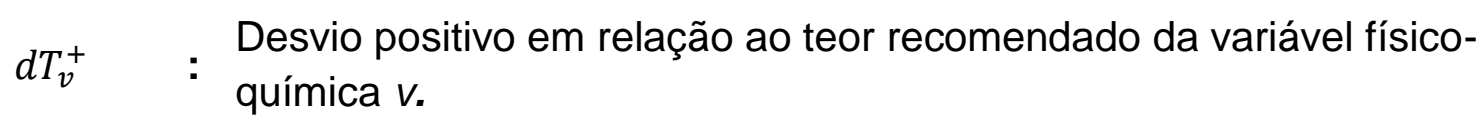

$d e_{v}^{-} \quad: \begin{aligned} & \text { Desvio negativo em relação ao mínimo teor especificado da variável } \\ & \text { fisico-química } v \text {. }\end{aligned}$

$d e_{v}^{+} \quad: \begin{aligned} & \text { Desvio positivo em relação ao máximo teor especificado da variável } \\ & \text { fisico-química } v \text {. }\end{aligned}$

$d_{r}^{i} \quad: \begin{aligned} & \text { Número de blocos deslocados pelo recurso } i \text { em relação à coordenada } \\ & r .\end{aligned}$

\section{MODELO MATEMÁTICO:}

A função objetivo (5.1) visa a:

- Maximizar produção de minério e de estéril.

- Minimizar deslocamentos entre blocos de origem e destino (podendo permanecer no bloco atual caso possua massa) desvios de qualidade e falta de ROM.

$$
\begin{aligned}
& \operatorname{Max} z^{\prime}=\sum_{b \in B^{\prime}} P_{b} \times B M \times s_{b}+\sum_{b \in B^{\prime}} P_{b} \times B S \times\left(1-s_{b}\right)-\sum_{i \in I} \sum_{r \in R} d_{r}^{i} \times \gamma_{r}^{i}- \\
& -\sum_{v \in V}\left(\alpha^{+} \times d T_{v}^{+}+\alpha^{-} \times d T_{v}^{-}+d e_{v}^{+} \times \omega_{v}^{+}+d e_{v}^{-} \times \omega_{v}^{-}\right)-D M^{-} \times \delta^{-}
\end{aligned}
$$

Sujeito as seguintes restrições:

As restrições (5.2-5.4) visam:

- Definir o desvio de qualidade da mistura proveniente da lavra de frentes de minério.

- Calcular a existência de desvio de qualidade em relação ao teor máximo e mínimo da mistura.

$$
\sum_{b \in B^{\prime}}\left(\left(T_{v b}-T r_{v}\right) \times P_{b} \times s_{b}\right)+\left(T P_{v}-T r_{v}\right) \times R P+D T A_{v}+d T_{v}^{-}-d T_{v}^{+}=0 \quad \forall v \in V
$$




$$
\begin{array}{ll}
\sum_{b \in B^{\prime}}\left(\left(T_{v b}-T u_{v}\right) \times P_{b} \times s_{b}\right)+\left(T P_{v}-T u_{v}\right) \times R P_{v}-d e_{v}^{+} \leq 0 & \forall v \in V \\
\sum_{b \in B^{\prime}}\left(\left(T_{v b}-T l_{v}\right) \times P_{b} \times s_{b}\right)+\left(T P_{v}-T l_{v}\right) \times R P_{v}+d e_{v}^{-} \geq 0 & \forall v \in V
\end{array}
$$

As restrições (5.5-5.8) visam:

- Todo equipamento de carga deve ser alocado a um bloco.

- Cada bloco lavrável pode ser alocado a no máximo um equipamento de carga.

- O ritmo de lavra aplicado no bloco $b$ pelo equipamento $i$ deve encontrar-se entre a produção mínima e máxima atribuída ao equipamento $i$.

$$
\begin{array}{rlrl}
\sum_{b \in B^{\prime}} y_{b}^{i} & =1 & & \forall i \in I \\
\sum_{i \in I} y_{b}^{i} \leq 1 & & \forall b \in B^{\prime} \\
\sum_{i \in I} y_{b}^{i} \times \operatorname{Pmin}_{i}-P_{b} \leq 0 & & \forall b \in B^{\prime} \\
\sum_{i \in I} y_{b}^{i} \times \operatorname{Pmax}_{i}-P_{b} & \geq 0 & & \forall b \in B^{\prime}
\end{array}
$$

As restrições (5.9-5.12) são adaptadas do modelo matemático proposto por Amaral (2008) e visam:

- Limitar a faixa vertical de operação da mina, ou seja, limitar a diferença entre o bloco alocado mais ao topo da mina e o bloco alocado mais profundo na mina.

- Limitar o deslocamento entre o bloco aonde encontra-se o equipamento de carga e o bloco a ser alocado.

$$
\begin{array}{rlrl}
N \min -\sum_{b \in B} y_{b}^{i} \times p_{b r} & \leq 0 & & \forall i \in I, r=H \\
N \operatorname{Nmax}-\sum_{b \in B} y_{b}^{i} \times p_{b r} & \geq 0 & & \forall i \in I, r=H \\
N \max -N \min -N N L S & \leq 0 & \\
\mathrm{a}\left|\sum_{b \in B^{\prime}} p_{b r} \times y_{b}^{i}-p o_{r}^{i}\right|-d \max _{r} \leq 0 & \forall i \in I, r \in R
\end{array}
$$

As restrições (5.13-5.16) visam:

- Limitar a lavra de minério (t/h) à capacidade do britador.

- Calcula desvio da quantidade de ROM lavrado em relação à capacidade da usina de beneficiamento. 
- Limita a quantidade de ROM lavrado caso a pilha de ROM esteja acima do nível de pedido.

$$
\begin{aligned}
\sum_{b \in B^{\prime}}\left(P_{b} \times s_{b}\right)-C b & \leq 0 \\
\sum_{b \in B^{\prime}}\left(P_{b} \times s_{b}\right)-\text { capUsina }+D P^{-}-D P^{+} & =0 \\
w \times V o l P-M P \times P e r c P & \leq 0 \\
w \times G-D P^{+} & \geq 0
\end{aligned}
$$

As restrições (5.17-5.22) visam:

- Definir se será necessário retomar da pilha de ROM, ou seja, se a produção de ROM nas frentes de lavra supre a demanda.

- Somente é permitida retomada da pilha caso haja material na mesma.

- Limitar o ritmo de retomada da pilha $(\mathrm{t} / \mathrm{h})$ à capacidade atribuída a operação de retirar material da pilha e enviar à usina.

- Ou a pilha recebe ROM (ritmo de lavra ( $\mathrm{t} / \mathrm{h}$ ) superior à capacidade da usina) ou fornece ROM (ritmo de lavra (t/h) menor que a capacidade da usina) ou ainda, quando o ritmo de lavra (t/h) for igual à demanda da usina a pilha não recebe e não envia material.

$$
\begin{aligned}
\sum_{b \in B^{\prime}}\left(P_{b} \times s_{b}\right)+R P-\text { capUsina }+D M^{-}-D M^{+} & =0 \\
R P-V o l P^{*} G & \leq 0 \\
R P-C r & \leq 0 \\
R P-D M^{-} & \leq 0 \\
R P-z \times G & \leq 0 \\
w+z & \leq 1
\end{aligned}
$$

No conjunto de restrições (5.23-5.25) são estabelecidos os domínios para as variáveis não negativas, em (5.26) atribui o conjunto real, positivo ou negativo, à variável e por último, (5.27) define as variáveis binárias.

$$
P_{b} \geq 0 \quad \forall b \in B^{\prime}
$$




$$
\begin{aligned}
D P^{-}, D P^{+}, D M^{-}, D M^{+}, R P, N \max , N \min & \geq 0 \\
d T_{v}^{-}, d T_{v}^{+} & \geq 0 \quad \forall v \in V \\
d_{i}^{r} & \in \square \quad \forall r \in R, i \in I \\
y_{b}^{i}, w, z & \in\{0,1\}
\end{aligned}
$$

A função objetivo (5.1) visa a maximizar a produção de minério (ROM) e estéril. São penalizados os deslocamentos realizados pelos equipamentos de carga para alcançarem os blocos de destino, os desvios de qualidade em relação aos teores requeridos e em relação ao mínimo e máximo desejado e o déficit de produção de ROM em relação à demanda.

A função objetivo distinguiu-se dos trabalhos pesquisados que possuem uma abordagem operacional principalmente por não englobar diretamente a relação estéril/minério. Na presente pesquisa considera-se que nos parâmetros de entrada existe uma proporcionalidade correta entre a capacidade de lavra dos equipamentos (t/h), a capacidade da usina (t/h) (cujo valor associado é igual à demanda de ROM $(\mathrm{t} / \mathrm{h})$ ) e a quantidade de minério e estéril proveniente da extensão de material a ser lavrada. Ou seja, na presente pesquisa, atribuir uma capacidade da usina ( $t / h)$ de ROM muito elevada considerando um avanço que possui poucos blocos de minério em relação à quantidade de blocos de estéril pode ao longo do tempo eliminar os blocos de minério restando apenas estéril a serem lavrado, acarretando em um longo período sem atividade da usina. Em situação oposta requerer pouco minério à usina de beneficiamento em um avanço com muito minério e poucos blocos de estéril pode eliminar os blocos de estéril causando a diminuição do ritmo de lavra dos equipamentos, onde, ao ser alocado somente a blocos de minério, a produção é limitada à capacidade da usina de beneficiamento.

Nos trabalhos pesquisados à relação estéril/minério visa a impedir que somente 0 minério seja lavrado, visto que do minério provem o lucro da operação, o que poderia causar um estrangulamento da cava causando longo período sem lavra de minério. $\mathrm{Na}$ presente pesquisa, optou-se pelos limitantes serem a capacidade de produção do britador primário, o nível da pilha de ROM e a capacidade atribuída à usina beneficiamento. Dessa forma, acredita-se que o sistema se comportará de forma 
coerente à realidade da operação, cujo objetivo é atender à usina de beneficiamento sem comprometer a vida útil da mina.

A restrição (5.2) atribui o desvio do teor de qualidade $v$ em relação à meta considerando a mistura gerada pela lavra nas frentes de lavra de minério e a retirada da pilha. A inserção do parâmetro DTA foi proposta em Amaral (2008) e tem como objetivo tentar compensar o desvio de qualidade dos teores ao longo do tempo.

$\mathrm{Na}$ restrição (5.3)-(5.4) identifica desvios de qualidade da mistura em uma faixa de adequação, considerando a mistura do minério proveniente das frentes de minério e da retirada de ROM da pilha para abastecer a usina. A equação (5.3) calcula se a qualidade da mistura esta acima do especificado, ou seja, se o teor proveniente da mistura de ROM das frentes lavradas e da pilha é superior ao requisito máximo exigido. A equação (5.4) calcula se o teor obtido na mistura está abaixo do especificado. Nota-se que a forma apresentada é uma adaptação da linearização proposta por Pinto \& Mershmann (2001):

$$
T l_{v} \leq \frac{\sum_{b \in B}\left(T_{v b} \times P_{b} \times s_{b}\right)}{\sum_{b \in B}\left(P_{b} \times s_{b}\right)} \leq T u_{v}
$$

Separadas nas seguintes equações:

$$
\begin{aligned}
& \sum_{b \in B^{\prime}}\left(\left(T_{v b}-T l_{v}\right) \times P_{b} \times s_{b}\right) \geq 0 \\
& \sum_{b \in B^{\prime}}\left(\left(T_{v b}-T u_{v}\right) \times P_{b} \times s_{b}\right) \leq 0
\end{aligned}
$$

As restrições (5.5)-(5.6) têm como objetivo alocar cada equipamento de carga a um bloco e que cada bloco seja alocado a no máximo um equipamento respectivamente.

As restrições (5.7)-(5.8) propostas por Pinto \& Mershmann (2001) limitam a produção de cada equipamento de carga entre uma faixa de operação $(t / h)$.

No conjunto de restrições (5.9) a (5.12) foram adaptados do modelo matemático 
apresentado em Amaral (2008) onde se computam os deslocamentos realizados pelos equipamentos de carga. Na restrição (5.9)-(5.11) limita a diferença de altura (Nível) entre o equipamento alocação na parte superior da cava e o equipamento alocado na parte mais inferior. A restrição (5.12) calcula os deslocamentos efetuados pelos equipamentos de carga e restringe os deslocamentos nas três direções consideradas, (Linha, Coluna e Nível).

A restrição (5.13) limita a produção horária de ROM proveniente das frentes de lavra de minério à capacidade do britador. Ressalta-se que a capacidade do britador deve ser suficientemente superior à demanda da usina, o excedente entre ( $C b$ - capUsina) é responsável por abastecer à pilha em um cenário com produção máxima de ROM.

As equações (5.14) a (5.22), desenvolvidas nesse trabalho, possuem relação direta à presença da pilha de ROM no sistema estudado.

$\mathrm{Na}$ restrição (5.14) é atribuído o desvio de quantidade da produção de ROM proveniente das frentes de lavra de minério em relação à demanda. Nesta equação, $D P^{+}>0$, implica que a pilha de ROM receberá material na presente ordem de lavra, em situação oposta, $D P^{-}>0$, significa que as frentes de lavra de ROM não atingem à demanda.

As restrições (5.15)-(5.16) permitem que a produção total de ROM exceda à demanda apenas se a pilha de ROM esteja com material abaixo do nível de pedido, ou seja, caso o volume atual de pilha (ton) seja menor ou igual ao percentual atribuído ao nível de pedido (\%) multiplicado pela capacidade da pilha (ton), nesse caso $w=1$. Em (5.16), w é multiplicado por $G$, um número suficientemente grande.

Nas restrições (5.17)-(5.18) permitem-se a retomada de ROM da pilha em um cenário onde a produção total de ROM não atende a capacidade da usina. A restrição (5.17) limita a quantidade horária que pode ser retirada da pilha para suprir à capacidade da usina atribuindo como valor máximo a diferença entre a produção de ROM e a capacidade (a variável $D M^{-}$).

Na restrição (5.18), a retirada de material da pilha ( $t / h)$ é permitida somente se a pilha não estiver completamente vazia. A restrição seguinte, (5.19), limita a retomada da pilha $(\mathrm{t} / \mathrm{h})$ a certa capacidade operacional de retirar o material da pilha e enviar à usina 
de beneficiamento $(C r)$. Em (5.20) calcula-se o desvio de ROM em relação à capacidade da usina considerando a produção nas frentes de lavra de minério e a possibilidade do ROM ser retirado da pilha para suprir à capacidade da usina. Ou seja, nessa restrição é calculada se a usina foi plenamente atendida ou não. Caso a demanda da usina seja atendida, a variável $D M^{+}$será nula, em situação oposta, caso a produção das frentes de lavra de ROM exceda à demanda, as variáveis $D M^{-}$e $R P$ serão nulas. ). Em (5.21) caso seja retirado material da pilha atribui-se $z=1$. Por último,

em (5.22) é apresentada uma restrição disjuntiva na qual ou é permitido o excesso de lavra de $\mathrm{ROM}$ em relação à demanda $(\mathrm{w}>0)$ ou é permitida à retirada da pilha $(z>0)$. Ou ainda, caso a produção de ROM das frentes se iguala a demanda ou for menor que à demanda e não houver material na pilha para ser retirado, $z=0$ e $w=0$.

No conjunto de restrições (5.23)-(5.25) são estabelecidos os domínios para as variáveis não negativas, em (5.26) atribui o conjunto real, positivo ou negativo, à variável $d_{i}^{r}$ e por último, (5.27) define as variáveis binárias.

\subsection{ALGORITMO PARA ABORDAGEM DO HORIZONTE MÓVEL}

O SPLAEC identifica as operações a serem realizadas por cada equipamento de carga em cada período não obrigatoriamente uniforme de planejamento até o fim do período total a ser estudado ou exaustão do material contido no avanço, formado por centenas ou milhares de blocos, a ser lavrado considerando requisitos tipicamente atendidos em trabalhos que abordam o planejamento de lavra considerando um cenário de curto prazo e os que abordam o médio prazo. O método proposto para elaboração do sequenciamento e programação de lavra pode ser descrito por sete passos. A Figura 5.1 apresenta uma representação dos passos contidos no sistema para geração das ordens de lavra até que o último bloco seja processado. 


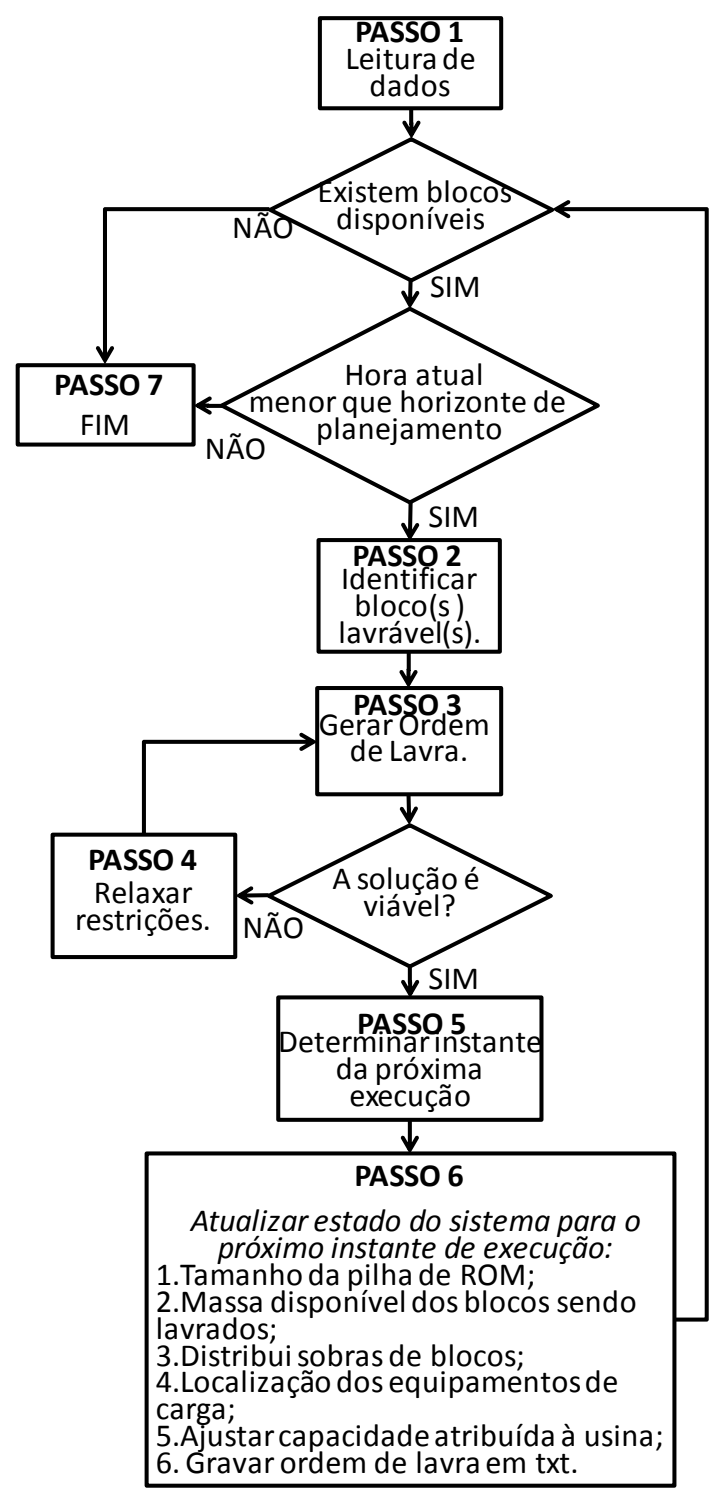

Figura 5.1 - Fluxograma das atividades executadas pelo algoritmo.

A seguir serão detalhados os passos executados pelo algoritmo:

No primeiro, é realizada a leitura dos dados necessários.

O passo 2 é responsável pela verificação da disponibilidade dos blocos lavráveis.

No passo 3, é executado o modelo de programação matemática descrito alocação de equipamentos de carga descrito visando alocar recursos disponíveis a blocos lavráveis.

Caso uma resposta seja infactível é executado o passo 4, onde, no modelo apresentado, uma resposta infactível está associada principalmente ao deslocamento dos recursos sendo relaxada a restrição associada o número de deslocamentos 
máximos gradativamente.

No passo 5 pondera-se a situação atual da mina e a resposta do modelo matemático para gerar uma nova ordem de lavra $k$ e definir sua duração.

O passo 6 atualiza parâmetros para uma nova execução do modelo matemático. Em especial esse trabalho permite que se ajuste a capacidade da usina de beneficiamento, tentando compensar nas próximas ordens déficits de produção acumulados em ordens de lavra anteriores tentando compensar a perda.

Caso não existam mais blocos a serem lavrados ou o somatório de $t_{k}$ exceda 0 horizonte de planejamento a ser definido pelo usuário $\left(t_{\text {plano }}\right)$ finaliza-se o algoritmo.

\subsubsection{Leitura dos dados de entrada}

Os dados são lidos a partir de arquivos no formato *.txt e estão agrupados conforme a organização apresentada no modelo matemático apresentado:

1. Dados da mina;

- Diferente do modelo matemático apresentado, onde, consideram-se apenas os blocos lavráveis, $B^{\prime}$, ou seja, blocos na superfície da mina cujos blocos precedentes foram lavrados, nesse passo computam-se todos os dados dos blocos da mina (Dados da Mina), acrescentando as seguintes informações:

$$
\begin{aligned}
& \text { massa }_{b} \quad \text { : Massa dos blocos do conjunto } B \text {. } \\
& \text { nColuna . Número de colunas consideradas no modelo de } \\
& \text { blocos (Figura 2.4); } \\
& \text { nLinha } \\
& \text { Número de linhas consideradas no modelo de blocos } \\
& \text { (Figura 2.4); }
\end{aligned}
$$


nNível

Número de níveis considerados no modelo de blocos (Figura 2.4);

Matriz de duas dimensões $(\mathrm{nL} \times \mathrm{nC})$ responsável por

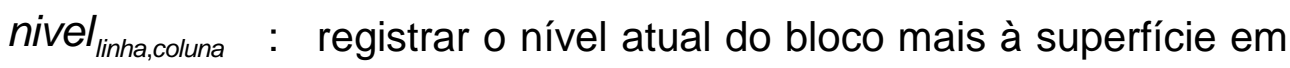
cada posição linha e coluna.

A Figura 5.2 apresenta duas matrizes nivel linha,coluna $_{\text {e representações }}$ resultantes dos blocos contidos na superfície de dimensão ( $\mathrm{nC}=4 \times \mathrm{nL}=4$ ) assim como modelos geológicos para ilustrar a superfície em formato tridimensional. Em "1 - a", é apresentado um exemplo de uma matriz

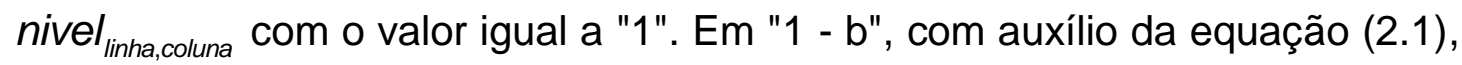
é convertida a matriz para o índice sequencial dos blocos da superfície da mina hipotética. Em "1 - c" é apresentado o modelo geológico associado à matriz nível. Em "2 - a" mostra uma matriz nivel ${ }_{\text {linha,coluna }}$ com alguns blocos removidos, em seguida apresenta-se os blocos da superfície em "2 - b" e por último demonstra-se o modelo geológico resultante.

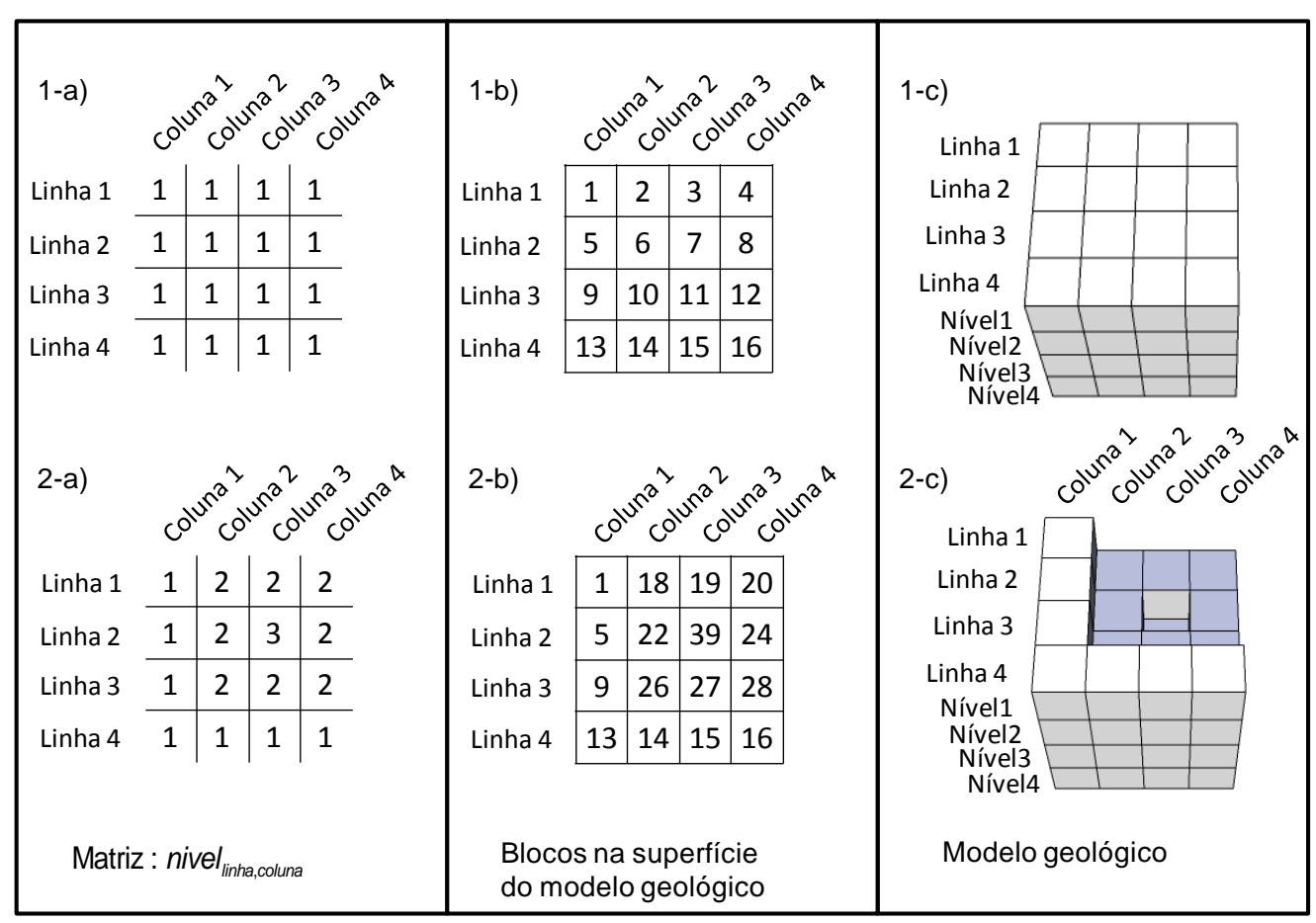

Figura 5.2 - Matriz nível e conversão para índice sequencial dos blocos da superfície 


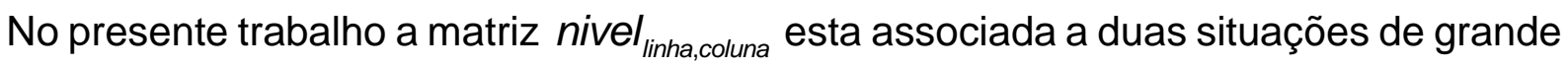
importância, na primeira, no Passo 1, se alguma posição nas coordenadas linha e coluna da matriz nível, fornecida pelo usuário em *.txt, receber valor maior do que "1", automaticamente, não serão considerados a lavra dos blocos representados por níveis de valores menor, ou seja, dos blocos acima.

Por exemplo, se no exemplo acima, nivel ${ }_{2,3}$ seja iniciada com o valor 3 (bloco 39), significa que os blocos nivel ${ }_{2,3}=2$ (bloco 23) e nivel ${ }_{2,3}=1$ (bloco 7) não serão considerados. Em muitos casos o avanço a ser estudado pode não ser possuir superfície plana, sendo assim a matriz é responsável por informar os blocos que não existem. Sua segunda importância está associada ao longo de todas as ordens de lavra, sempre que um bloco é lavrado, incrementa-se a matriz considerando a posição linha e coluna do bloco ( nivel $l_{\text {linha,coluna }}=$ nivel $\left._{\text {linha,coluna }}+1\right)$, essas informações são destinas à definição dos blocos disponíveis a ser demonstrada no Passo 2.

2. Dados da Pilha de ROM;

3. Conjunto de metas e requisitos;

4. Dados dos equipamentos de carga;

5. Benefícios;

6. Penalidades;

Outros parâmetros, em *.txt, considerados para geração das ordens de lavra são:

1. $t_{\text {plano }}:$ Horizonte total de tempo (h) a ser estudado;

2. $t_{\text {ordem }}$ : Duração mínima da lavra de um bloco em uma ordem de lavra;

3. talude : Angulo de segurança a ser considerado para definição de precedentes. $(1-5$ ou $1-9)$ 


\subsubsection{Definição de blocos disponíveis}

No Passo 2, as relações de precedência que permitem classificar um bloco como disponível ou não, estão relacionadas aos ângulos de talude requeridos e à retirada dos blocos precedentes em ordens de lavra executadas em períodos anteriores.

Além das regras apresentadas na Figura 2.7, a seguir são descritas as regras utilizadas para lidar com algumas exceções relacionadas:

- O algoritmo considera a lavra de um modelo de blocos de tamanho (nColuna $\mathrm{x}$ nLinha x nNível), porém, em muitos casos, blocos incluídos nesse "cubo" não pertencem ao avanço a ser lavrado, definido pelo planejamento de lavra de longo prazo. Nesses casos, ao atribuir um valor nulo à lavrar $_{b}$ um valor, será impedida sua lavra e consequentemente, de todos os blocos que dependem de sua liberação.

- Blocos da superfície no primeiro nível não possuem blocos precedentes e estão liberados já a partir do primeiro período de planejamento.

- Blocos das fronteiras laterais não possuem precedentes na direção do ponto cardeal da fronteira da qual faz parte, por exemplo, blocos localizados na ultima coluna, não possui precedentes na direção $C+1$, blocos localizados na primeira coluna não possuem precedentes na direção $C-1$, blocos localizados na ultima linha, não possui precedentes na direção $L+1$ e, blocos localizados na primeira linha não possuem precedentes na direção L-1.

Esse passo constitui uma etapa de pré-processamento de dados que reduz significativamente o tamanho da instância. Ressalta-se que em qualquer situação o número máximo de blocos disponíveis a ser considerado pelo modelo matemático é nColuna $x$ nLinha. 


\subsubsection{Execução do modelo matemático}

Para execução do modelo matemático monoperíodo, no passo 3, utiliza-se o software CPLEX, versão 12.51.

Os principais resultados gerados pelo modelo matemático apresentam informações destinadas às atividades dos equipamentos de carga considerando o sistema atual:

- Bloco alocado;

- Ritmo de lavra (t/h) a ser aplicado na frente de lavra;

- Deslocamentos em uma coordenada $(C, L$ e H) para alocar um novo bloco. $A$ Tabela 5.1 apresenta uma forma generalizada dos resultados relacionados a cada equipamento.

Tabela 5.1 - Principais resultados gerados pelo modelo matemático

\begin{tabular}{cccccc}
\hline RECURSO & $\begin{array}{c}\text { BLOCO } \\
\text { ATUAL }\end{array}$ & $\begin{array}{c}\text { RITMO DE } \\
\text { LAVRA (t/h) }\end{array}$ & $\begin{array}{c}\text { DESLOC. } \\
\text { COLUNA }\end{array}$ & $\begin{array}{c}\text { DESLOC. } \\
\text { LINHA }\end{array}$ & $\begin{array}{c}\text { DESLOC. } \\
\text { NIVEL }\end{array}$ \\
\hline Maq. 1 & aloca $_{1}$ & $v_{1 b}$ & $d_{1}^{C}$ & $d_{1}^{L}$ & $d_{1}^{H}$ \\
Maq 2 & aloca $_{2}$ & $v_{2 b}$ & $d_{2}^{C}$ & $d_{2}^{L}$ & $d_{2}^{H}$ \\
$\cdot$ & $\cdot$ & $\cdot$ & $\cdot$ & $\cdot$ & $\cdot$ \\
$\cdot$ & $\cdot$ & $\cdot$ & $\cdot$ & $\cdot$ & $\cdot$ \\
$\cdot$ & $\cdot$ & $\cdot$ & $\cdot$ & $\cdot$ & $\cdot$ \\
Maq N & aloca $_{n}$ & $v_{n b}$ & $d_{n}^{C}$ & $d_{n}^{L}$ & $d_{n}^{H}$ \\
\hline
\end{tabular}

\subsubsection{Relaxação de restrições}

Em alguns casos a execução do modelo pode se tornar inviável. Por exemplo, em algum ponto do sequenciamento e programação os blocos disponíveis podem estar distantes de equipamentos de carga ociosos, não permitindo uma alocação equipamento x bloco viável. Nesse caso aumenta-se progressivamente $d \max _{\text {Linha }} \mathrm{e}$ $d \max _{\text {coluna }}$, ou seja, acrescenta-se uma unidade no limite de deslocamento até 
$d \max _{\text {Coluna }}=$ nColuna e $d \max _{\text {Linha }}=$ nLinha. Permanecendo as soluções inviáveis, aumenta-se progressivamente $d \max _{\text {Nivel }}$ até nNivel.

Outras situações que poderiam provocar soluções inviáveis são número de blocos disponíveis menores que o número de equipamentos de carga e restrições ligadas à faixas verticais de operação para manter a segurança. Nesses casos o algoritmo descarta temporariamente equipamentos de carga que inviabilizam a solução.

\subsubsection{Determinar o instante da próxima execução do modelo}

No passo 5, considerando os ritmos de lavra (t/h) implementados por cada equipamento e a situação atual do sistema, ou seja, massa disponível em cada bloco que está sendo processado e o tamanho atual da pilha de $R O M$, calcula-se $t_{k}$, o tempo definido para a ordem de lavra $k$. A duração de uma ordem na presente pesquisa considera três eventos: 1) pilha de ROM encheu, 2) pilha de ROM exauriu e 3) fim de um bloco. A seguir, são definidas as equações para determinar $t_{k}$ :

A equação (5.31) define o tempo gasto para ultrapassar o limite da capacidade (ton) da pilha caso o ritmo de lavra total de $R O M$ exceda a demanda e permaneça tempo o suficiente, ou seja, caso não seja alterado no decorrer do tempo.

\section{Pilha de $R O M$ cheia:}

$$
t p c_{k}=\frac{(M P-V o l P)}{(R O M-\operatorname{cap} U \sin a)}
$$

Onde:

MP $\quad$ : $\quad$ Capacidade da pilha de ROM (t).

ROM : Produção total de minério (t/h) (soma da produção de equipamentos alocados a blocos de minério).

VolP : Quantidade atual de ROM na pilha (t).

capUsina : Capacidade atribuída à usina de beneficiamento (t/h). 
A equação (5.32) define o tempo gasto para exaurir a pilha de ROM caso o ritmo de lavra total de ROM seja inferior à demanda, e a pilha possua material.

\section{Fim da Pilha de ROM :}

$$
t \mathrm{pf}_{k}=\frac{V o l P}{R P}
$$

Onde:

RP : Material consumido da pilha para alimentar à usina de beneficiamento compensando o déficit de minério das frentes de lavra $(\mathrm{t} / \mathrm{h})$.

A equação (5.33) define o menor tempo gasto para exaurir um bloco, seja bloco de minério ou bloco de estéril. Esse tempo é determinado pela divisão da massa restante do bloco pelo ritmo de lavra $(\mathrm{t} / \mathrm{h})$ definido.

\section{Bloco Exauriu :}

$$
\mathrm{tb}_{\mathrm{k}}=\min _{\mathrm{k}}\left(\frac{\mathrm{M}_{\mathrm{b}}}{\mathrm{P}_{\mathrm{b}}}\right) \quad \forall b \in B
$$

Onde:

$\begin{array}{lll}\mathrm{M}_{\mathrm{b}} & : & \text { Massa atual do bloco b }(\mathrm{t}) . \\ \mathrm{P}_{\mathrm{b}} & : & \text { Ritmo de lavra no bloco }(\mathrm{t} / \mathrm{h}) .\end{array}$

O menor tempo entre $\operatorname{tpc}_{\mathrm{k}}, \operatorname{tpf}_{\mathrm{k}}$ e tb $\mathrm{b}_{\mathrm{k}}$ define a duração da ordem de lavra $\mathrm{t}_{\mathrm{k}}$.

\subsubsection{Atualizar dados}

Após a geração dos resultados do modelo matemático, o algoritmo desenvolvido realiza as seguintes atualizações para a próxima ordem de lavra $(k+1)$ :

1. Atualizar o tamanho da pilha de ROM: o volume da pilha varia ao final do período $t_{k}$ conforme o desvio da produção (t/h) de ROM provenientes das frentes de lavra de minério.

- Caso a produção das frentes de minério exceda à demanda, o valor 
atualizado da pilha será:

$$
\text { VolP }=\text { VolP } P_{0}\left(D P^{+} \times t_{k}\right)
$$

Onde:

VolP $P_{0}$ Volume da pilha no início da ordem de lavra $k$.

- Caso a produção das frentes de minério seja inferior à demanda, e a pilha possua material para suprir à usina, o valor atualizado da pilha será:

$$
\text { VolP }=\text { VolP } P_{0}-\left(R P \times t_{k}\right)
$$

- Caso a produção das frentes de minério iguale à demanda, o valor atualizado da pilha será:

$$
\text { VolP }=V_{0} P_{0}
$$

2. Atualizar a massa do bloco $_{b}$ : Cada equipamento de carga opera alocado a um bloco com ritmo de lavra aplicado ao bloco b $\left(\mathrm{P}_{\mathrm{b}}\right)$.

$$
M_{b}=M_{b_{0}}-\left(P_{b} \times t_{k}\right)
$$

Onde:

$M_{b_{0}}$ : Massa inicial do bloco $b$ no início da ordem de lavra $k$.

3. Distribuir sobras da massa do $b / o c o_{b}$ : Após atualizar a massa dos blocos verifica-se se existem blocos com pouca massa disponível para próxima ordem, ou seja, caso a massa do bloco $_{b}$ dividido pelo ritmo de lavra máximo do recurso i seja menor que $t_{\text {ordem }}$ será distribuída a massa do bloco a um bloco vizinho conforme a seguinte prioridade:

- Bloco do mesmo material (minério ou estéril) no nível inferior $(h+1)$;

- Bloco do mesmo material (minério ou estéril) ao leste $(c+1)$; 
- Bloco do mesmo material (minério ou estéril) ao oeste (c-1);

- Bloco do mesmo material (minério ou estéril) ao norte $(l+1)$;

- Bloco do mesmo material (minério ou estéril) ao sul (I-1);

Caso não estejam disponíveis blocos de mesmo material, segue-se a mesma ordem apresentada para distribuir a massa do bloco a um bloco de outro material.

Distribuir a massa de um bloco alocado pode contribuir em duas situações, evita-se que a próxima ordem tenha um tempo de duração $t_{k}$ muito reduzido e por propiciar melhores soluções ao possibilitar um maior número de escolhas de alocação na próxima ordem.

4. Alocar equipamentos de carga: Atualiza a localização de cada equipamento de carga alocado ao bloco, atribuindo a posição do bloco no modelo geológico ao equipamento de carga. Conforme descrito anteriormente, o modelo matemático desenvolvido nessa pesquisa penaliza o deslocamento com intuito de reduzir o tempo de setup entre o fim de um bloco e alocação do próximo, porém para o modelo essa alocação ocorre de forma imediata. Com intuito de permitir que a resposta do modelo seja mais coerente com a realidade da operação de lavra, o algoritmo desenvolvido desconsidera a produção do equipamento, equivalente ao período de tempo calculado para o deslocamento e o impacto resultante na mistura de minério. $O$ tempo de setup considera a distância entre os blocos em termos das posições dos blocos no modelo geológico, obtidas pelo método euclidiano. Essa premissa é importante, pois não considera restrições de formação de vias de acesso na mina, que são extremamente complexas.

5. Com intuito de tentar tornar constante à alimentação da usina, este trabalho propõe que a capacidade atribuída à usina de beneficiamento de minério esteja associada à meta de produção horária de minério. A meta pode ser definida, por exemplo, nos blocos a serem lavrados no próximo ano do planejamento escolhidos por um modelo matemático para definição dos avanços, dividindo a massa de minério total pelas horas de operação. Porém, em alguns momentos 
da operação, essa meta horária pode não ser atendida, o ritmo de minério que chega à usina é menor que sua capacidade, nesses casos o algoritmo registra o déficit acumulado e aumenta a capacidade da usina, a um dado valor preestabelecido e coerente com a realidade operacional da usina em uma situação prática, para a próxima ordem até que a perda acumulada das ordens anteriores seja compensada. Ao aumentar a capacidade atribuída à usina no presente modelo, permite-se que as frentes de lavra produzam mais minério mesmo em uma situação em que a pilha de ROM esteja cheia.

6. O relatório para cada uma das ordens de produção (Figura 5.3) apresenta as seguintes informações em * .txt:

- $\quad$ número da ordem e sua duração $t_{k}$;

- A produção de ROM oriunda dos blocos de minério e a produção de estéril. Calcula-se o desvio positivo (superior à demanda) ou negativo (inferior à demanda).

- Informações referentes à pilha de ROM, descrevendo o volume inicial da pilha (antes da ordem começar) e o volume após $t_{k}$. Também são informados os parâmetros de qualidade antes e após $t_{k}$. Os parâmetros são influenciados pela mistura de ROM e quantidade enviada provenientes das frentes de lavra de minério ponderados pelos parâmetros atuais da pilha e sua quantidade $(t)$.

- A alocação de cada equipamento, o bloco e ritmo de lavra atribuído, a massa de cada bloco alocado, antes e após o período de lavra $t_{k}$. Assim como os deslocamentos necessários para alocar o bloco, caso o bloco da ordem atual $\mathrm{k}$, seja diferente do bloco de k-1;

- Teores resultantes da mistura de ROM gerada e o desvio em relação aos parâmetros requeridos. 


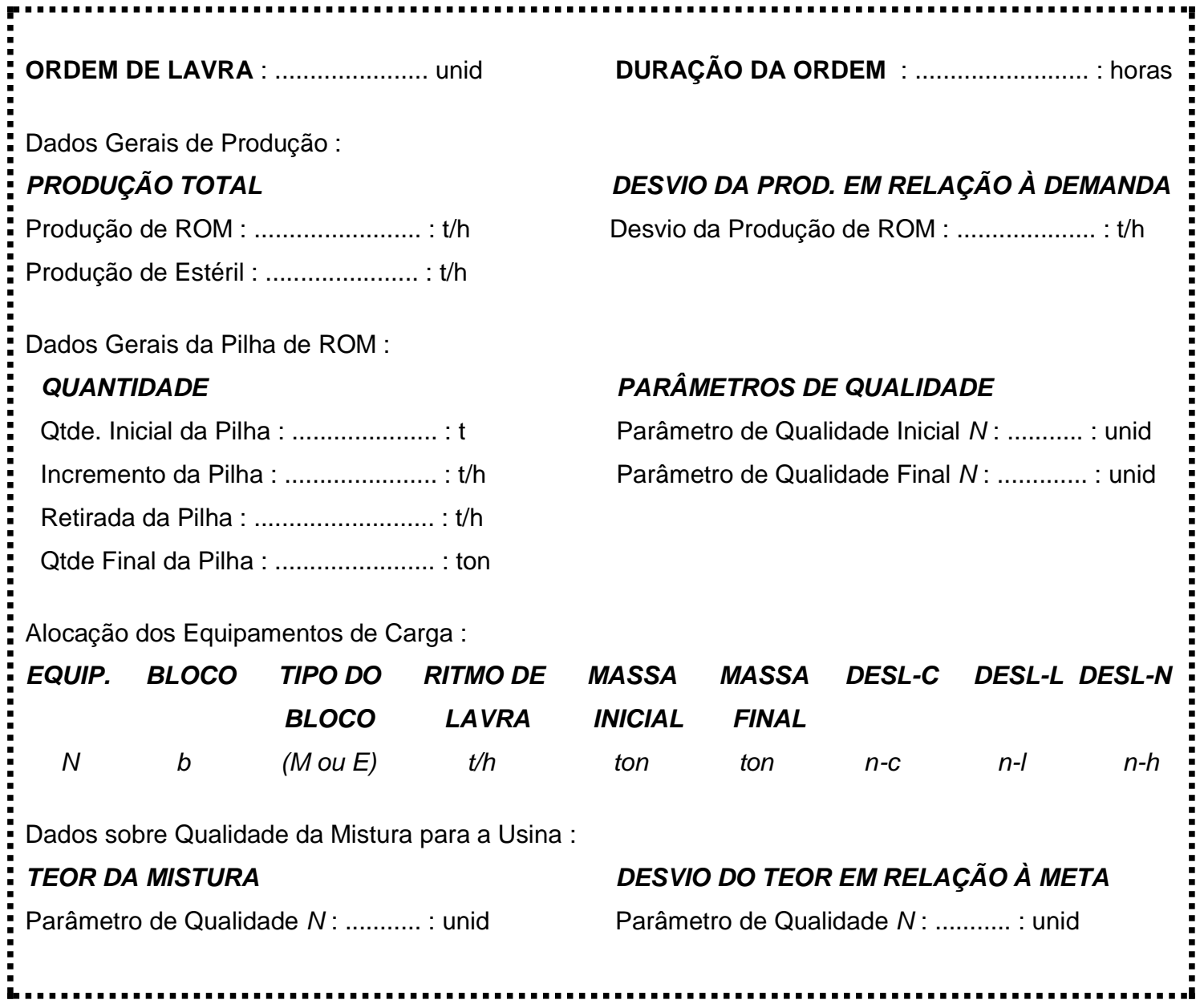

Figura 5.3 - Ordem de lavra completa

\subsubsection{Fim}

No sistema desenvolvido, duas situações acarretam no fim do sequenciamento e programação da lavra. Caso não existam blocos lavráveis para geração de uma nova ordem, o sistema automaticamente é finalizado. Outra situação prevista é atribuída caso o usuário deseje estudar certo horizonte de tempo definido em horas $\left(t_{\text {plano }}\right)$, nesse caso, quando a soma dos tempos das ordens $\left(t_{0}+t_{1}+\cdots t_{n}\right)$ for maior do que $t_{\text {plano }}$, finaliza-se o sistema. 


\section{RESULTADOS COMPUTACIONAIS}

Neste capítulo, são apresentadas as instâncias e os resultados computacionais alcançados de forma a avaliar o desempenho do modelo matemático proposto e do algoritmo. O modelo matemático foi implementado em linguagem $\mathrm{C} / \mathrm{C}++$ através do ILOG 12.51 Concert Technology.

Os experimentos foram realizados em um notebook com processador Intel, Core I 52430 M, 8 Gb de memória RAM, com sistema operacional Linux versão Ubuntu 13.1.

\subsection{INSTÂNCIA DE TESTE}

Para realização de testes foi utilizado um site que disponibiliza instâncias reais e criadas por autores (ESPINOZA et al., 2012b) descritas em Espinoza, et al. (2012a). Dentre as instâncias foi escolhida a "Arizona's Copper Deposit (KD)", uma mina a céu aberto que contém cobre. A Figura 6.1 apresenta a forma tridimensional da jazida.

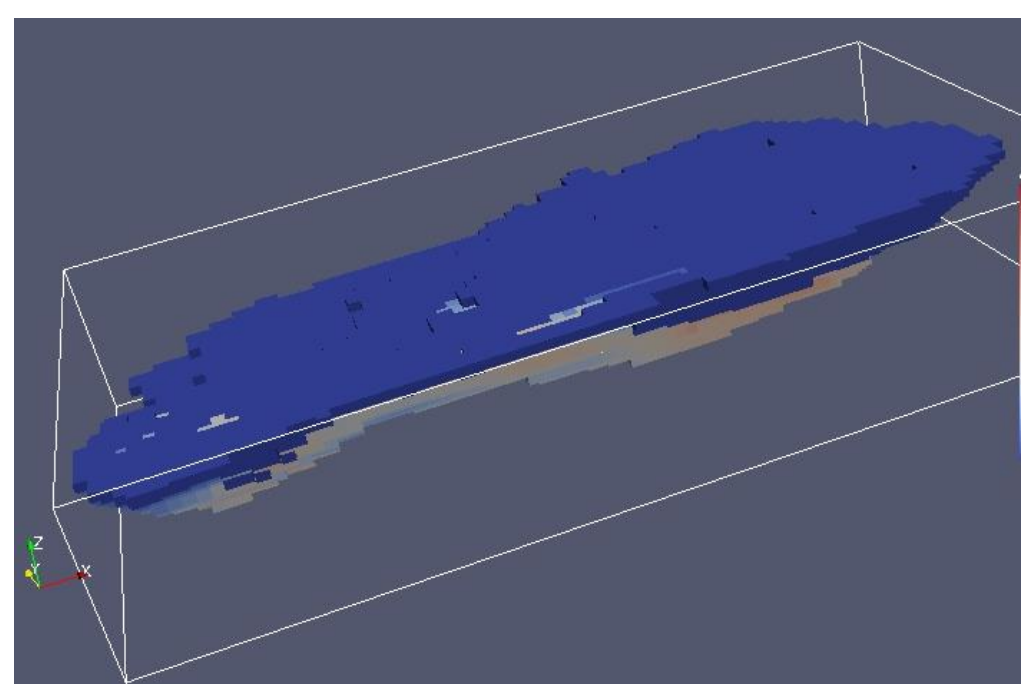

Figura 6.1 - Imagem tridimensional da mina utilizada.

Fonte: ESPINOZA, et. al (2009b) 
A mina contém 14.153 blocos, de dimensão 20x20×15 m, cada bloco possui diversas características, entre elas foram selecionadas por serem necessárias na presente pesquisa:

- ID: identificação numérica;

- Coordenadas (linha, coluna e nível);

- Tonelagem;

- Tipo: minério ou estéril;

- \% de Cu.

Dessa forma, nessa instância será controlado apenas "um" parâmetro de qualidade do minério lavrado, cobre $(\mathrm{Cu})$.

Dos dados obtidos na instância, houve a necessidade de alterar a coordenada "H" (nível) para ajustar-se ao algoritmo desenvolvido. Na instância original blocos com níveis menores são os mais profundos e no sistema desenvolvido nesse trabalho, blocos com menores estão mais à superfície da jazida. Dessa forma, a instância foi adaptada invertendo os valores atribuídos à coordenada nível. Ressalta-se que essa alteração não modificou a localização do bloco na jazida, apenas qual a coordenada Nível é atribuída a cada bloco.

A Figura 6.2 apresenta uma imagem da jazida vista de cima. As cores representam o nível de cada bloco, variando conforme profundidade da cava, sendo que, blocos mais "elevados" (valores de níveis menores) estão mais claros comparados aos blocos mais profundos (valores de níveis maiores).

Foi definida nessa pesquisa, a capacidade de recursos analisando todos os blocos selecionados para serem lavrados em um ano e os requisitos de qualidade analisando somente os blocos de minério desse avanço. Essa escolha tem como objetivo facilitar as análises dos resultados gerados, pois de outra maneira, desvios acentuados poderiam ser consequência de uma não conformidade do avanço selecionado comparada com os demais avanços a serem lavrados nos anos seguintes. 


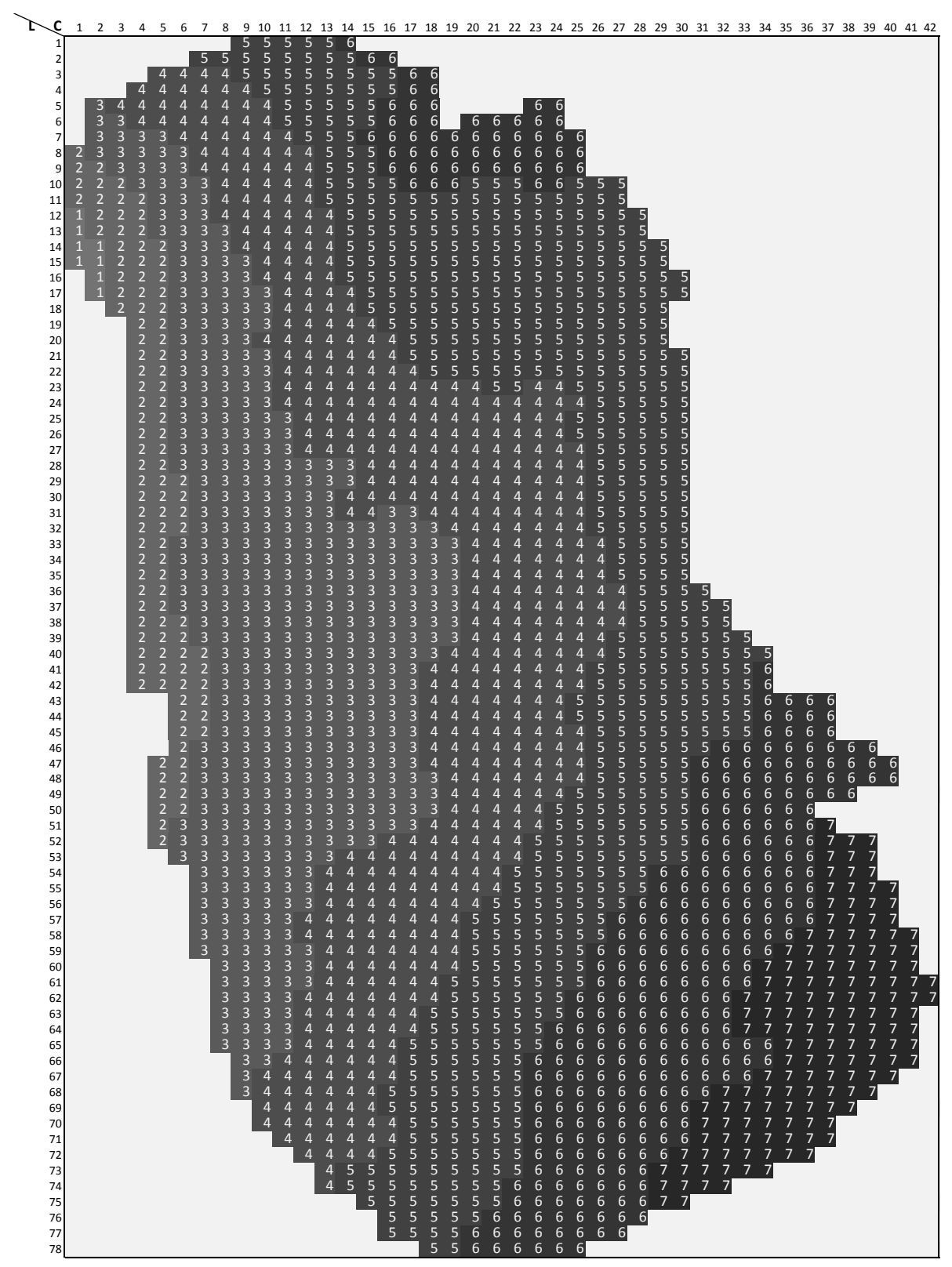

Figura 6.2 - Vista superior da jazida KD.

Os níveis mínimos, ou seja, nível do bloco mais à superfície de cada posição (linha x coluna), apresentados pertence à matriz nivel linha,coluna é elaborada através do algoritmo apresentado através de um pseudocódigo na Figura 6.3. O algoritmo implementado possui como parâmetros: G (um número suficientemente grande), nb (número de blocos), nColuna (número de colunas), nLinha (número de linhas), nNivel (número de níveis), $\mathrm{pb}($ ).L, pb().C e pb.().H (representa a linha, a coluna e o nível atribuídos a cada bloco respectivamente). 


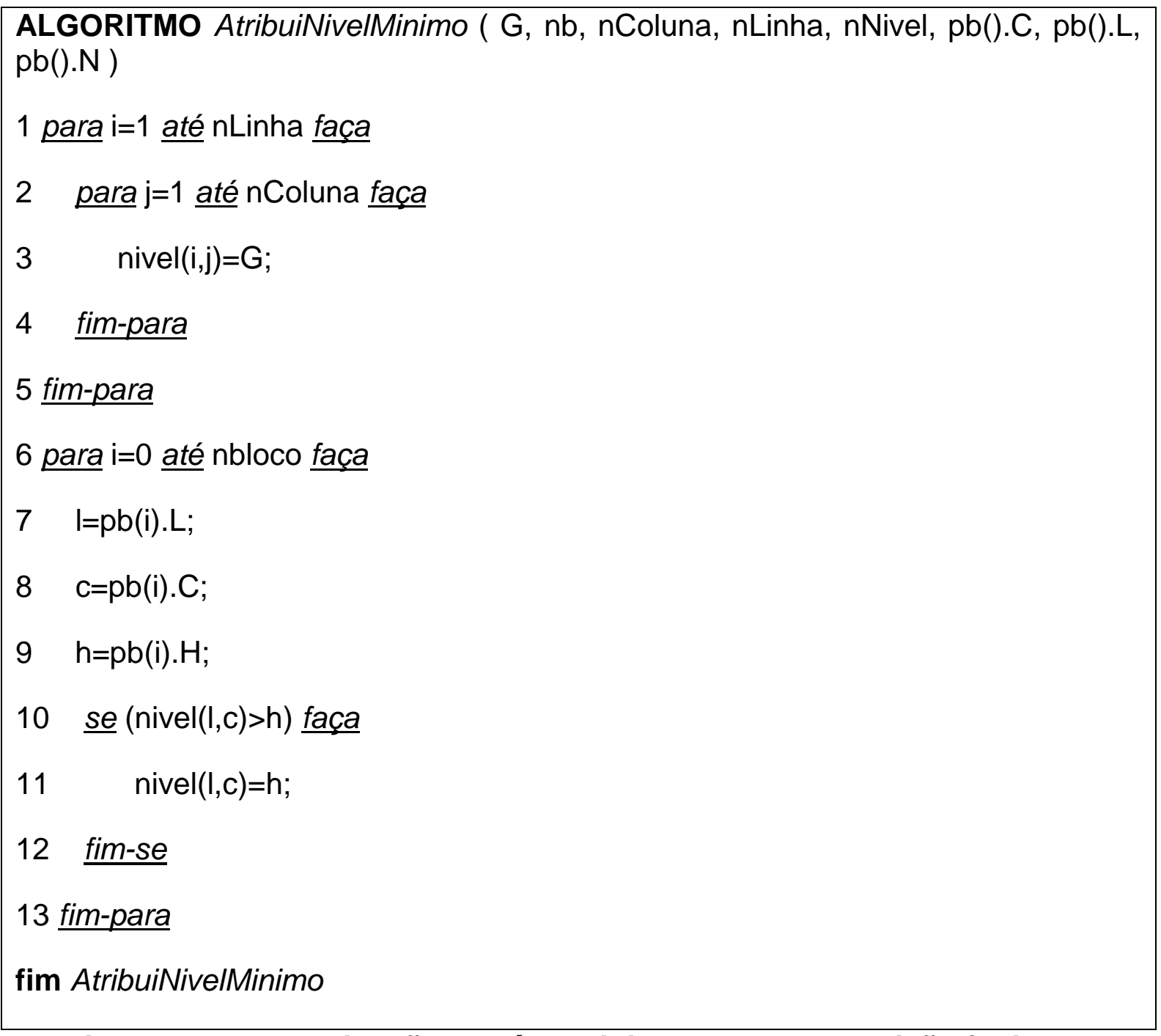

Figura 6.3 - Determinação do nível minimo para cada posição (nLinha $x$ nColuna).

Para a instância estudada nbloco $=14.153, \mathrm{nLinha}=72, \mathrm{nColuna}=42, \mathrm{nNivel}=18 \mathrm{e}$ $\mathrm{G}=19$. Assim como outras características de cada bloco e pb().L, pb().C e pb().H são "lidas" da instância fornecida. As posições da matriz nivel linha,coluna $_{\text {que obtiverem }}$ valor correspondente à "G" ao final da execução do algoritmo descrito acima automaticamente não possuem blocos a serem lavrados.

\subsubsection{BLOCOS SELECIONADOS}

Espinoza, et al. (2012b) disponibiliza soluções denominadas comumente em trabalhos que abordam a otimização da lavra em um horizonte de médio e longo prazo como 
"Problema de Sequenciamento em Minas a Céu Aberto" (open pit production scheduling problem), definindo quais blocos serão lavrados em cada ano de operação, limitados no caso de jazida KD à capacidade da usina de 10 milhões de toneladas de minério e sem limite para lavra dos blocos de estéril que sejam precedentes dos de cada bloco de minério selecionado, de forma a maximizar o lucro na retirada dos blocos de minério (blocos de minério possuem valores positivos e os blocos de estéril possuem valores negativos).

Nos resultados apresentados, cada ano de operação possui cerca de mil blocos de minério e estéril. Com intuito de tornar o problema mais complexo, demandando um número maior de recursos, foram selecionados 1.795 blocos contidos nos dois primeiros anos de lavra como um avanço. A área correspondente aos blocos está identificada na Figura 6.4.

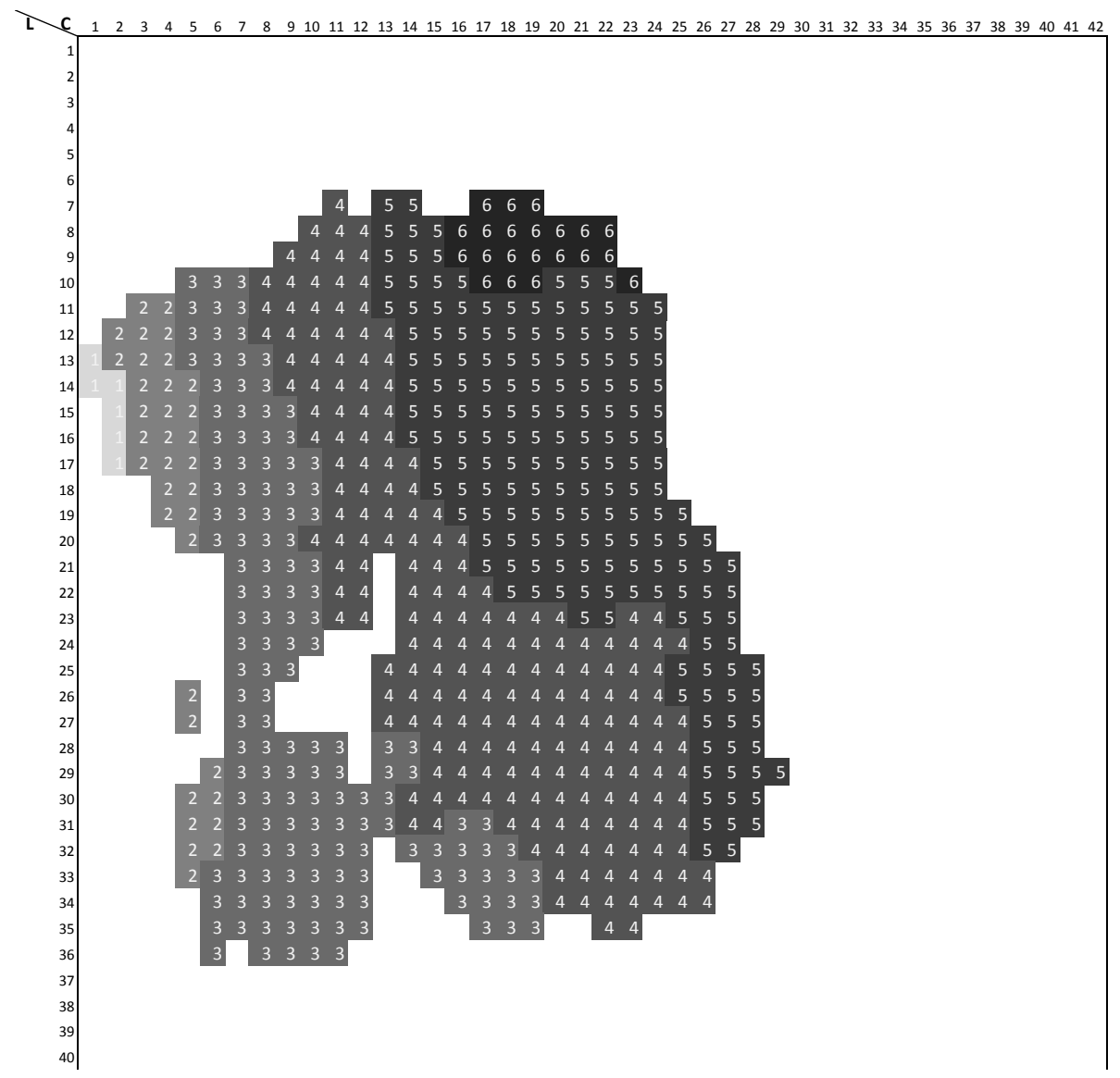

Figura 6.4 - Área selecionada como avanço

Nessa instância, ressalta-se a boa relação estéril/minério, REM, aproximadamente $66 \%$, contendo mais minério do que estéril. Foi levantado o número de blocos de 
minério que cada posição Linha $\times$ Coluna possui, ou seja, em cada posição, quantos blocos empilhados um em cima do outro são de minério o resultado é mostrado na Figura 6.5. Posições com cores mais "avermelhadas" possuem mais blocos de minério empilhados abaixo da superfície.

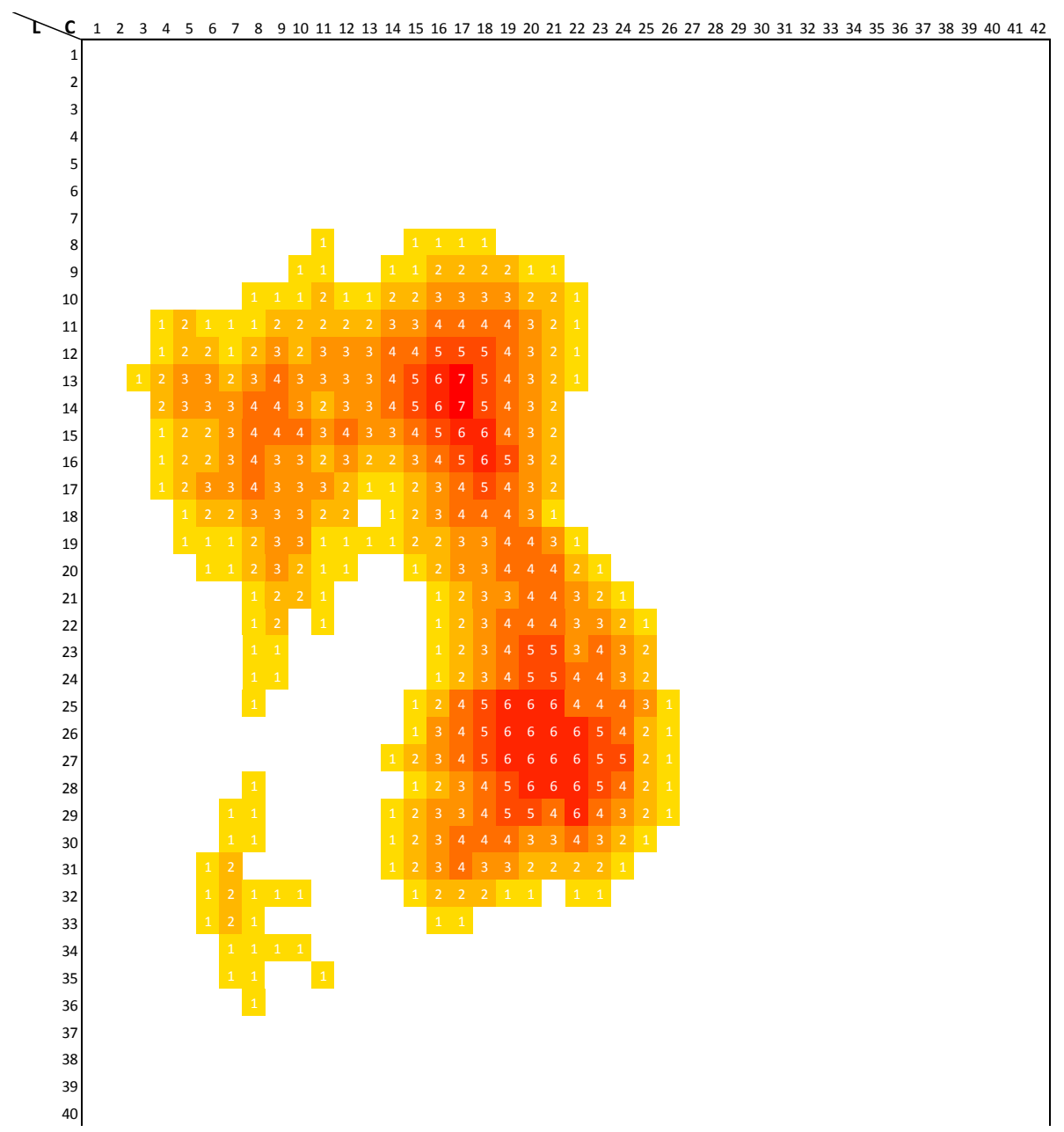

Figura 6.5 - Número de blocos de minério contidos em cada posição

\section{LinhaxColuna}

A Tabela 6.1 apresenta dados gerais dos blocos selecionados para a validação do sistema proposto para gerar o Sequenciamento e a Programação da Lavra com Alocação de Equipamentos de Carga. Dentre as informações destaca-se a produção média por hora, resultante da divisão da massa do material (minério e estéril) por um ano, 8.760 horas (365 dias $\times 24$ horas). Somando-se o ritmo de lavra calculado para minério e o ritmo para estéril obteve-se 3.140 t/h. 
Tabela 6.1 - Dados gerais dos blocos selecionados

\begin{tabular}{cccc}
\hline Tipo & Unidades & $\begin{array}{c}\text { Somatório da } \\
\text { tonelagem }\end{array}$ & $\begin{array}{c}\text { Produção } \\
\text { média por } \\
\text { hora }\end{array}$ \\
\hline MINÉRIO & 1.021 & 16.531 .140 & $\cong 1.890$ \\
ESTÉRIL & 774 & 10.921 .200 & $\cong 1.250$ \\
\hline TOTAL & 1.795 & 27.452 .340 & $\cong 3.140$ \\
\hline
\end{tabular}

\subsubsection{PARÂMETROS DO MODELO}

Foram utilizados os seguintes pesos associados à função objetivo:

$B M=100, B S=40$ : (Benefício por tonelada na extração do minério e do estéril).

$\alpha_{v}^{+}=10, \alpha_{v}^{-}=10, v \in V:$ (Penalidade atribuída ao desvio positivo e negativo do parâmetro de qualidade $\mathrm{CU})$.

$\delta^{-}=100:$ (Penalidade por tonelada a menos que à capacidade atribuída à usina).

$\gamma_{\text {linha }}^{i}=1000, \gamma_{\text {coluna }}^{i}=1000, \gamma_{\text {nivel }}^{i}=2000, \forall i \in I:$ (Penalidade pelo deslocamento dos equipamentos de carga em cada coordenada).

Essas penalidades foram ajustadas com base em testes preliminares e a qualidade da solução é dependente desse ajuste.

A seguir, são mostradas as restrições operacionais adotadas:

capUsina = $1.890(\mathrm{t} / \mathrm{h})$ (Ritmo ideal), $2.080(\mathrm{t} / \mathrm{h})$ (Ritmo para recuperar perdas);

$C b=2.540(\mathrm{t} / \mathrm{h}):$ Capacidade do britador.

$C r=1.890(\mathrm{t} / \mathrm{h}):$ Capacidade de retomada do minério na pilha para a usina. 
O tamanho máximo da pilha de ROM é 600.000 toneladas, e o nível de pedido é de $95 \%$.

Foram utilizados os seguintes parâmetros de qualidade em todas as ordens de lavra:

$T I=0,6, T r=0,92, T u=1,4:$ (Teor mínimo, requerido e máximo obtido na mistura de minério enviado à usina).

Considerou-se uma frota constituída por até seis equipamentos de carga, com produção descrita na Tabela 6.2.

Tabela 6.2 - Dados dos equipamentos de carga.

\begin{tabular}{ccc}
\hline $\begin{array}{c}\text { Equipamento } \\
\text { de Carga }\end{array}$ & $\begin{array}{c}\text { Produção Horária } \\
\text { Mínima (t/h) }\end{array}$ & $\begin{array}{c}\text { Produção Horária } \\
\text { Máxima (t/h) }\end{array}$ \\
\hline EQUIP A & 300 & 600 \\
EQUIP B & 325 & 650 \\
EQUIP C & 350 & 700 \\
EQUIP D & 275 & 550 \\
EQUIP E & 320 & 640 \\
EQUIP F & 300 & 600 \\
\hline
\end{tabular}

\subsubsection{CENÁRIOS}

Com intuito de estudar o comportamento do Sequenciamento e Programação da Lavra com Alocação de Equipamentos de Carga, foram estudados cenários com diferentes capacidades operacionais descritos na Tabela 6.3.

Nos cenários $A$, B e $C$, são utilizados os cinco primeiros equipamentos de carga descritos na Tabela 6.2 (Equip. A à Equip. E) distintos que juntos possuem capacidade suficiente para lavrar todo o material do avanço em um ano, se operar em plena capacidade. 
Os cenários $D$, E e F, são utilizados os seis equipamentos de cargas descritos na Tabela 6.2 e possuem o objetivo de estudar o comportamento do modelo proposto quando a capacidade de lavra é superior à demanda anual observando se essa situação pode ser prejudicial à relação estéril/minério, ou seja, se haveria lavra predatória de minério prejudicando as operações futuras.

Em todos os cenários, o valor atribuído ao volume inicial da pilha (VolP) é inicializado como zero. Está medida objetiva não criar minério que não esteja na jazida, facilitando as análises e sendo condizente com início da operação da lavra (primeiro ano).

Tabela 6.3 - Cenários analisados

\begin{tabular}{cccc}
\hline Cenário & $\begin{array}{c}\text { Capacidade } \\
\text { total de lavra } \\
(\mathbf{t} / \mathbf{h})\end{array}$ & $\begin{array}{c}\text { Capacidade } \\
\text { da Pilha (t) }\end{array}$ & $\begin{array}{c}\text { Capacidade da } \\
\text { usina flexível }\end{array}$ \\
\hline A & 3140 & Não & Não \\
B & 3140 & Sim & Não \\
C & 3140 & Sim & Sim \\
D & 3740 & Não & Não \\
E & 3740 & Sim & Não \\
F & 3740 & Sim & Sim \\
\hline
\end{tabular}

Além das diferentes capacidades operacionais, será estuda a existência da pilha e o seu resultado na operação.

Por último, dependendo de como os blocos de minério estão disponíveis em uma mina, em alguns períodos de tempo pode não ser processado nenhum ROM na usina, com intuito de repor essa perda, serão consideradas dois ritmos de beneficiamento (capUsina), 1890 e 2080, o primeiro um ritmo o ideal e o segundo uma capacidade extra mantida até que seja reposta a perda de produção. Sugere-se que o ritmo "ideal" seja definido pela demanda horária de ROM e o segundo, por exemplo, seja a capacidade real de beneficiamento da usina.

Os cenários descritos as figuras a seguir (Figura 6.6 a Figura 6.11), adaptadas da Figura 3.1, demonstram numericamente as características de cada cenário descrito 
pela Tabela 6.3 apresentando as capacidades de cada fluxo, em especial o fluxo do minério (ROM) das frentes de lavra até a usina.

Na Figura 6.6 os cinco equipamentos de carga, quando operam em ritmo de lavra máximo, produzem 3.140 t/h. Desse valor, apesar da capacidade atribuída ao britador ser $2.540 \mathrm{t} / \mathrm{h}$, somente poderia ser lavrado no máximo $1.890 \mathrm{t} / \mathrm{h}$ que são processadas pelo britador e são enviadas diretamente à usina.

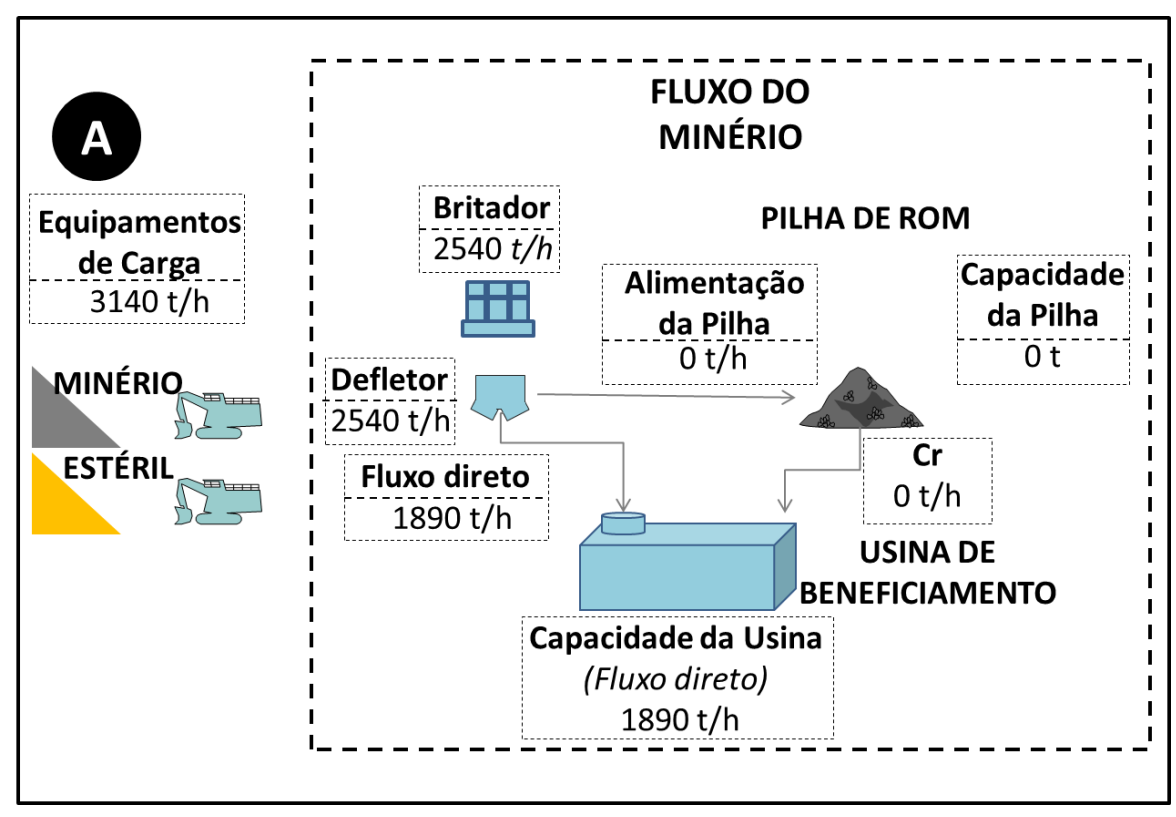

Figura 6.6 - Cenário A

A Figura 6.7 mostra um cenário onde é permitido o acumulo de ROM em uma pilha de capacidade 600.000 t. A mudança que essa pilha implica no sistema é significativa, estando abaixo do nível de pedido, permite-se que os equipamentos de carga alocados a blocos de minério enviem no máximo $2.540 \mathrm{t} / \mathrm{h}$ de ROM ao britador. Em dado instante em que os equipamentos de lavra alocados lavrem 2.540 de ROM, $1.890 \mathrm{t} / \mathrm{h}$ são enviadas diretamente à usina, o restante, $650 \mathrm{t} / \mathrm{h}$ (2.540-1.890), é enviado à pilha. Em situação oposta, podem existir poucos blocos de minério disponível e a lavra de minério não alcance a capacidade da usina, nessa situação, e havendo material na pilha, a diferença entre a capacidade da usina e a quantidade horária de ROM enviado pelo britador é atribuído à Cr para compensar uma possível perda de produção. Ou seja, $\mathrm{Cr}$, somente é maior do que zero, em situações onde falte minério proveniente das frentes de lavra suficiente para suprir a capacidade da usina. 


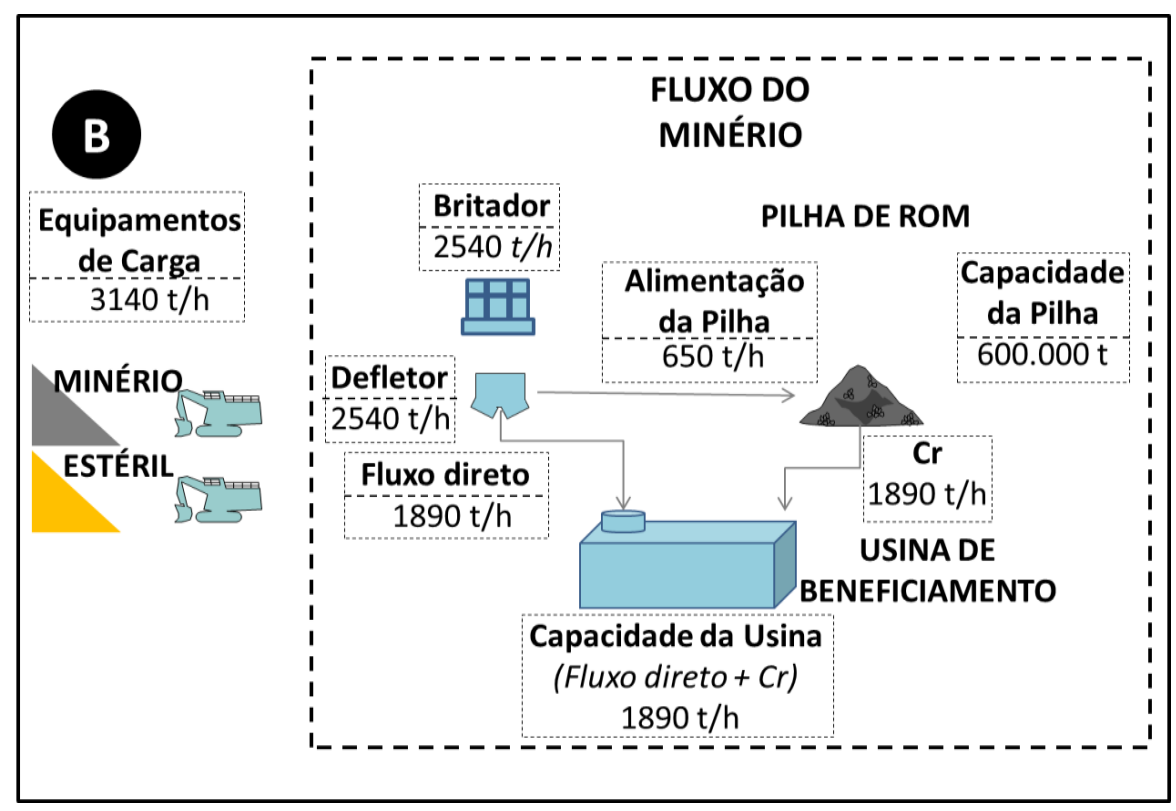

Figura 6.7 - Cenário B

A Figura 6.8 mostra um cenário semelhante ao descrito anteriormente. Porém, nesse cenário foi habilitada a opção de incrementar a capacidade atribuída à usina quando a meta de produção de ROM não foi atingida em ordens de lavra anteriores. Ou seja, nas próximas ordens de lavra a capacidade da usina será incrementada, podendo receber mais minério, de 1.890 para $2.080 \mathrm{t} / \mathrm{h}$, até que as perdas acumuladas sejam compensadas.

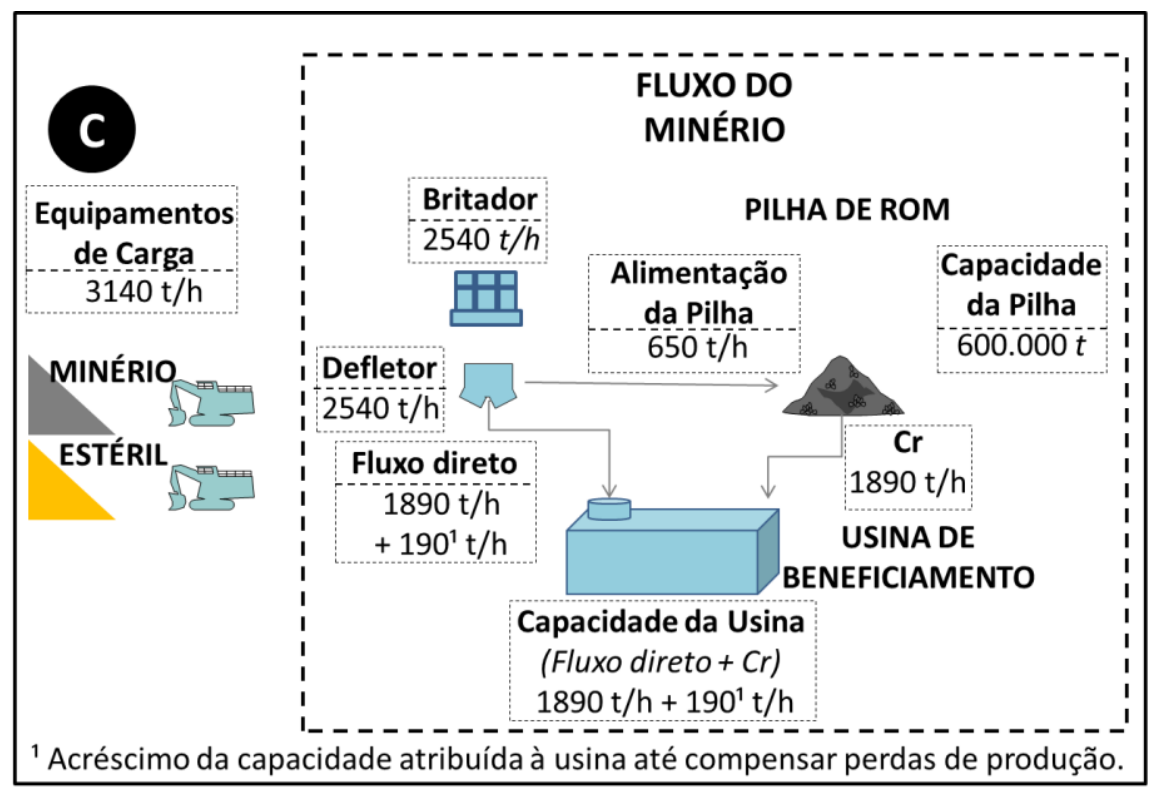

Figura 6.8 - Cenário C 
A Figura 6.9 mostra um cenário semelhante ao descrito na figura Figura 6.6. Porém, nesse cenário foram considerados seis equipamentos de carga. Se todos os equipamentos operarem em plena capacidade, o ritmo de lavra total será de 3.740 t/h.

É importante observar que nos cenários descritos a seguir, mesmo tendo mais capacidade de lavra, todo material da mina só será processado em no mínimo um ano, pois a usina restringe a lavra de minério independente da disponibilidade dos equipamentos de carga ser maior.

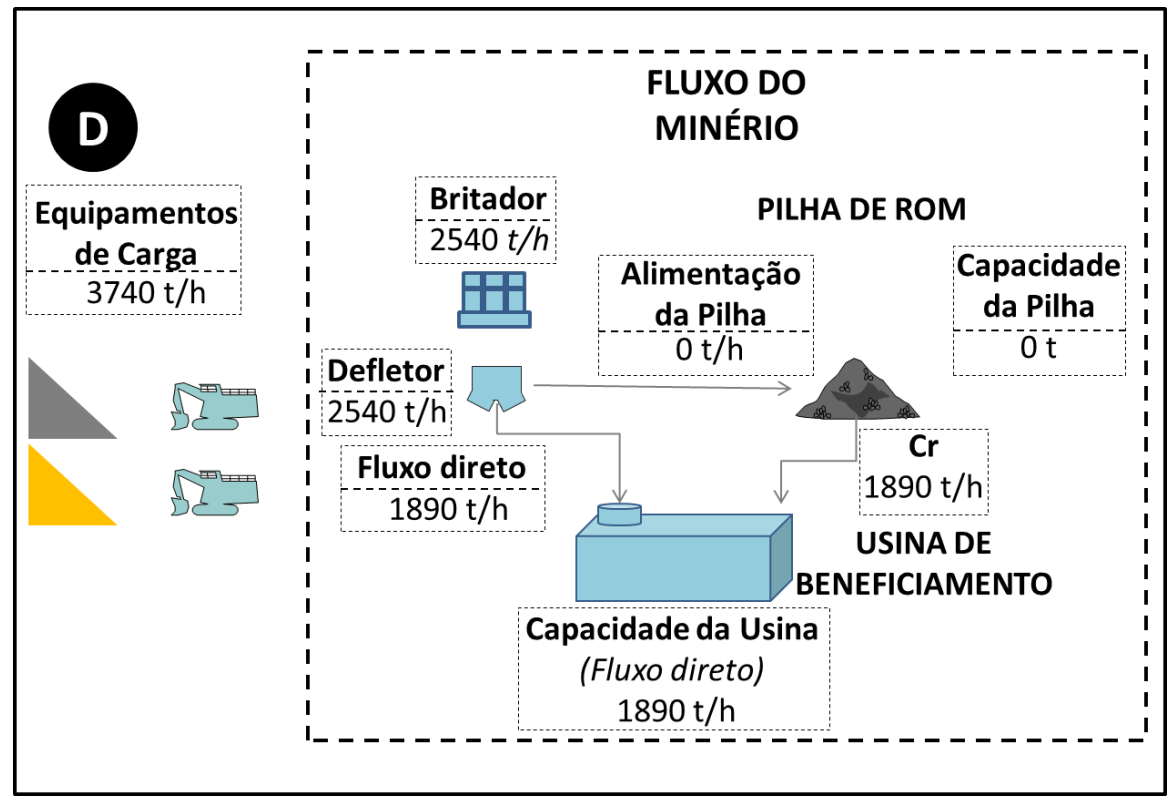

Figura 6.9 - Cenário D

A Figura 6.10 mostra um cenário semelhante ao descrito na figura Figura 6.7. Porém, nesse cenário foram considerados seis equipamentos de carga. Se todos os equipamentos operarem em plena capacidade, o ritmo de lavra total será de 3.740 t/h. 


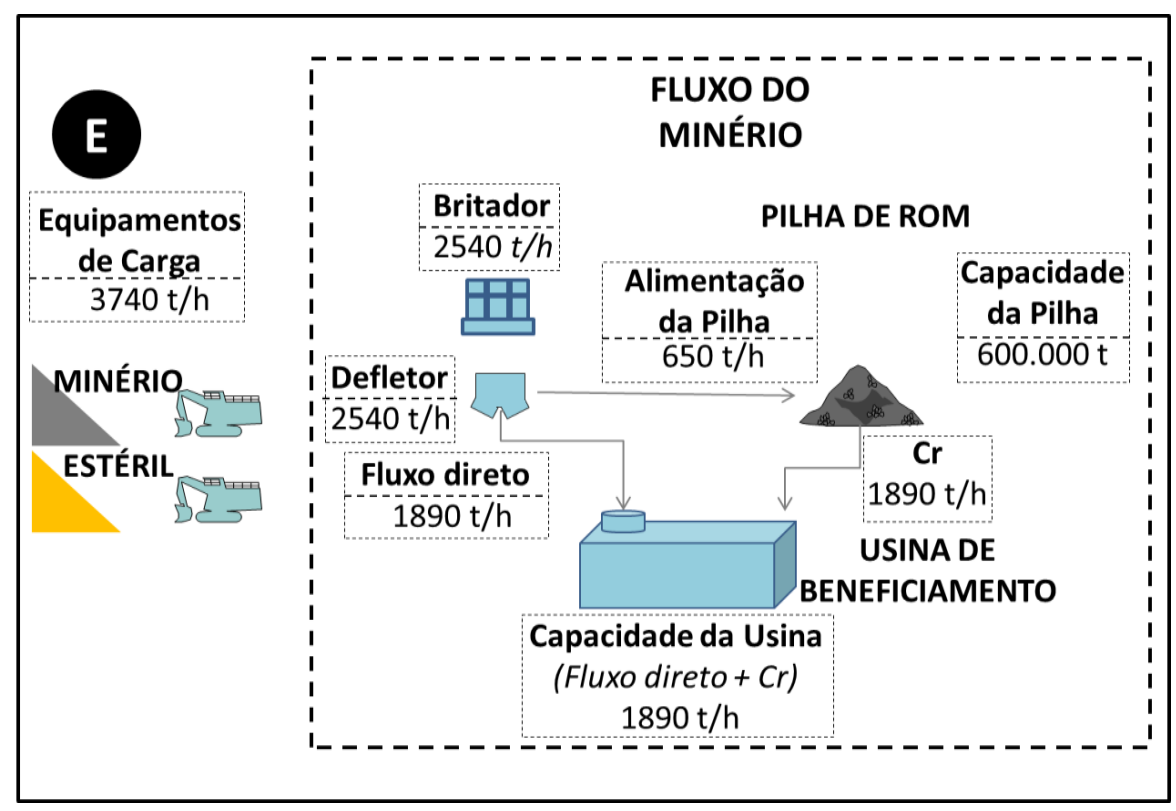

Figura 6.10 - Cenário E

A Figura 6.11 mostra um cenário semelhante ao descrito na figura Figura 6.8. Porém, nesse cenário, foram considerados seis equipamentos de carga. Se todos os equipamentos operarem em plena capacidade, o ritmo de lavra total será de 3.740 t/h.

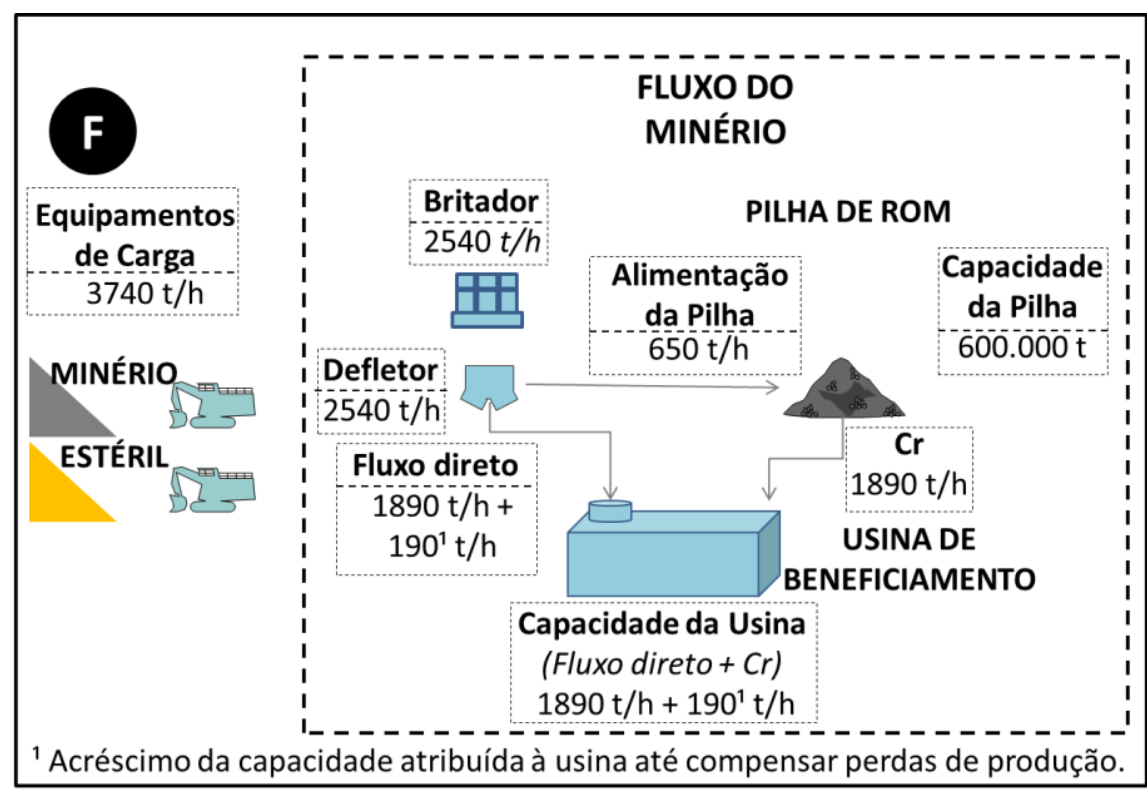

Figura 6.11 - Cenário F 


\subsection{SOLUÇÕES GERADAS}

Serão descritos os seis cenários mostrados na Tabela 6.3 gerados pelo Sequenciamento e Programação da Lavra com Alocação de Equipamentos de Carga (SPLAEC). É importante lembrar que alguns dados são específicos de cada mina, no caso da mina KD, a regra de precedência 1-5 (cinco blocos acima) e foi adotado no presente trabalho como ângulo de segurança.

Em todos os cenários, $t_{\text {plano }}$ (horizonte de planejamento) é um número suficientemente grande, dessa forma são geradas sucessivas ordens até que todos os blocos sejam completamente lavrados. $O$ valor atribuído a $t_{\text {ordem }}$ (duração mínima de cada ordem de lavra) é de 30 minutos.

Os resultados gerais que apresentam a qualidade das soluções são mostrados na Tabela 6.4. A tabela apresenta o tempo computacional requerido para gerar as soluções e imprimir os resultados, a quantidade de material contido na pilha no final da lavra dos blocos, os dias necessários para lavrar todo o avanço e na coluna "USINA" informam-se os dias necessários para processar todo o ROM. O tempo atribuído à usina é composto pelo tempo necessário para lavrar todo o minério acrescido com o tempo necessário para processar o minério contido na pilha.

Tabela 6.4 - Resumo dos resultados obtidos

\begin{tabular}{ccccc}
\hline Cenário & $\begin{array}{c}\text { Tempo de } \\
\text { Execução (s) }\end{array}$ & $\begin{array}{c}\text { Tamanho Final } \\
\text { da Pilha }\end{array}$ & $\begin{array}{c}\text { LAVRA } \\
\text { (dias) }\end{array}$ & $\begin{array}{c}\text { USINA } \\
\text { (dias) }\end{array}$ \\
\hline A & 78 & 0 & 427,6 & 427,6 \\
B & 119 & 530.503 & 391,5 & 403,2 \\
C & 99 & 571120 & 386,5 & 398,0 \\
D & 69 & 0 & 397,5 & 397,5 \\
E & 85 & 556.348 & 384,3 & 396,5 \\
F & 102 & 560.901 & 355,9 & 366,8 \\
\hline
\end{tabular}


Nos seis cenários, em conformidade com o dimensionamento de recursos adotado, que considera o minério contido no avanço para calcular à meta horária da usina (1.890 t/h), objetivando lavrar o minério do avanço em um ano (365 dias), se os dias necessários para processar o ROM forem maiores que 365 dias, implica que a usina não operou em plena capacidade durante todo o ano.

A existência da pilha possibilitou um aumento na lavra de minério controlado até que a mesma encha, contribuindo para suprir em alguns períodos de falta de minério nas frentes de lavra. A existência da pilha contribuiu em todos os cenários para reduzir o horizonte de tempo necessário para lavrar o avanço, pois déficit na usina implica acréscimo de tempo para processar o minério a ser lavrado no futuro.

O tempo computacional obtido em todos os cenários é bastante promissor, menos que dois minutos, viabilizando, por exemplo, que um profissional responsável pelo planejamento de lavra execute diversas execuções do SPLAEC estudando a mudança nos resultados obtidos ao alterar parâmetros de entrada com intuito de obter uma melhor qualidade nas respostas.

A título de ilustração, a seguir serão descritas maiores informações a respeito do Cenário F que apresentou a melhor resposta com utilização de 99,5\% da usina, sendo necessária a elaboração de 1.615 ordens de lavra para lavrar os 1.795 blocos:

\subsubsection{Descrição do Cenário F}

A Figura 6.12 mostra a duração de cada ordem de lavra. Cada ordem de lavra possui em média 5,5 horas de duração, mas, como pode ser observado, existe uma grande variação entre as ordens. No presente exemplo, apesar de um equipamento poder permanecer lavrando um mesmo bloco em plena capacidade por até vinte e nove horas, a iteração entre os eventos acarreta na oscilação da duração das ordens. Durante a lavra de cada bloco, demais blocos alocados aos outros equipamentos de carga exaurem, a pilha pode encher, e a pilha pode esvaziar, exigindo que uma nova ordem seja executada. 


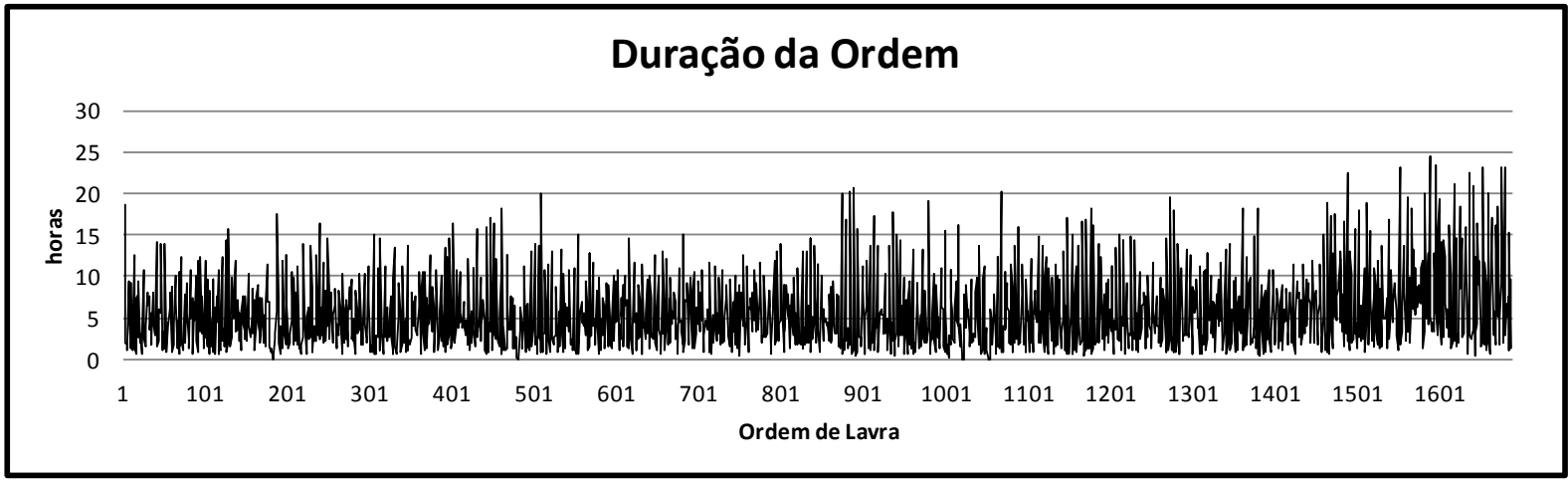

Figura 6.12 - Duração de cada ordem de lavra (horas)

A Figura 6.13 mostra um dado interessante sobre a instância, apesar de os blocos de minério serem maioria no avanço a ser lavrado, eles são cobertos em sua maior parte por blocos de estéril. Isso pode dificultar a disponibilidade de blocos de minério sobre tudo no início da lavra, pois obriga os equipamentos a lavrarem o estéril para liberar o minério. Como os blocos de estéril estão principalmente nas camadas da superfície, ao longo das ordens, blocos de minério são gradativamente liberados, e a disponibilidade dos blocos de estéril fica reduzida.

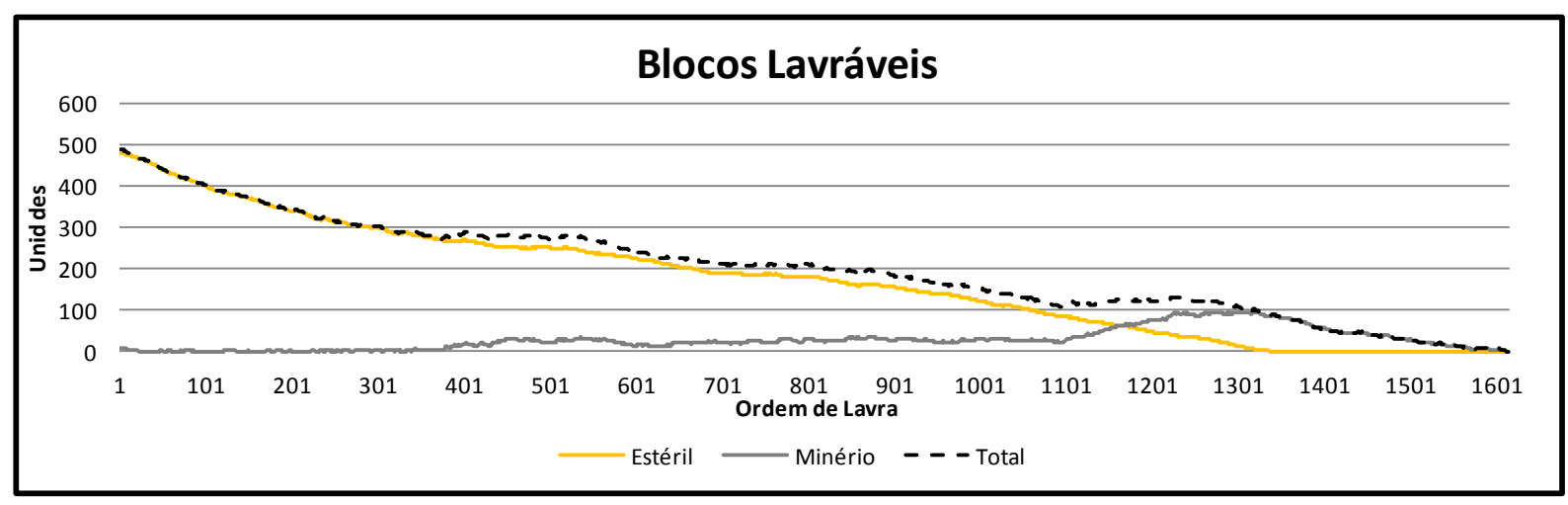

Figura 6.13 - Blocos de minério e estéril disponíveis

A Figura 6.14 mostra o ritmo de lavra calculado em cada ordem de lavra. Nota-se que a produção horária de minério e estéril obtida até a ordem 350 oscila consideravelmente. Isso pode ser atribuído à falta de disponibilidade de blocos de minério nesse período, o que implica a lavra ostensiva de estéril com intuito de liberar blocos de minério. Essa prática impactou principalmente após a ordem 1.350, onde foi exaurido todo o estéril, obrigando os equipamentos de carga a operarem à capacidade atribuída à usina com acréscimo (2.080), pois a usina perdeu produtividade no início da operação e ainda não recuperou a perda. 
Nessa situação, os seis equipamentos de carga estão trabalhando com baixa capacidade com intuito de não ultrapassar a capacidade atribuída à usina, em uma situação prática, um ou mais equipamentos poderiam ser disponibilizados para outras atividades como auxiliar na construção de vias de acesso ou iniciar a lavra do próximo avanço (pushback). No presente trabalho, por exemplo, ao chegar na ordem 1.350, poderia reduzir os equipamentos de carga disponíveis para nova situação o que permitiria maior produtividade dos recursos.

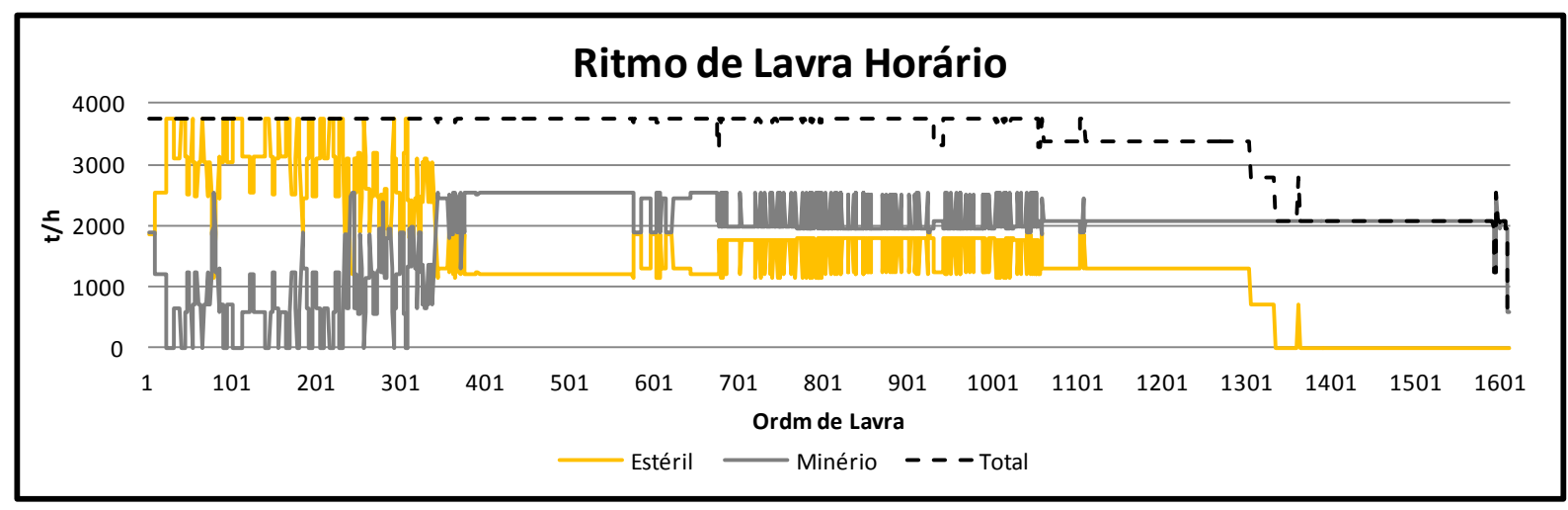

Figura 6.14 - Ritmo de lavra total dos equipamentos de carga.

A Figura 6.15 mostra a produção horária enviada para a usina em cada ordem de lavra. Como descrito anteriormente, a falta de blocos de minério disponíveis no início da operação implica a oscilação da lavra de minério e caso não haja material na pilha, registra-se perda de produção. A perda de produção desse período inicial resulta em acréscimo da capacidade atribuída à usina até o final da operação.

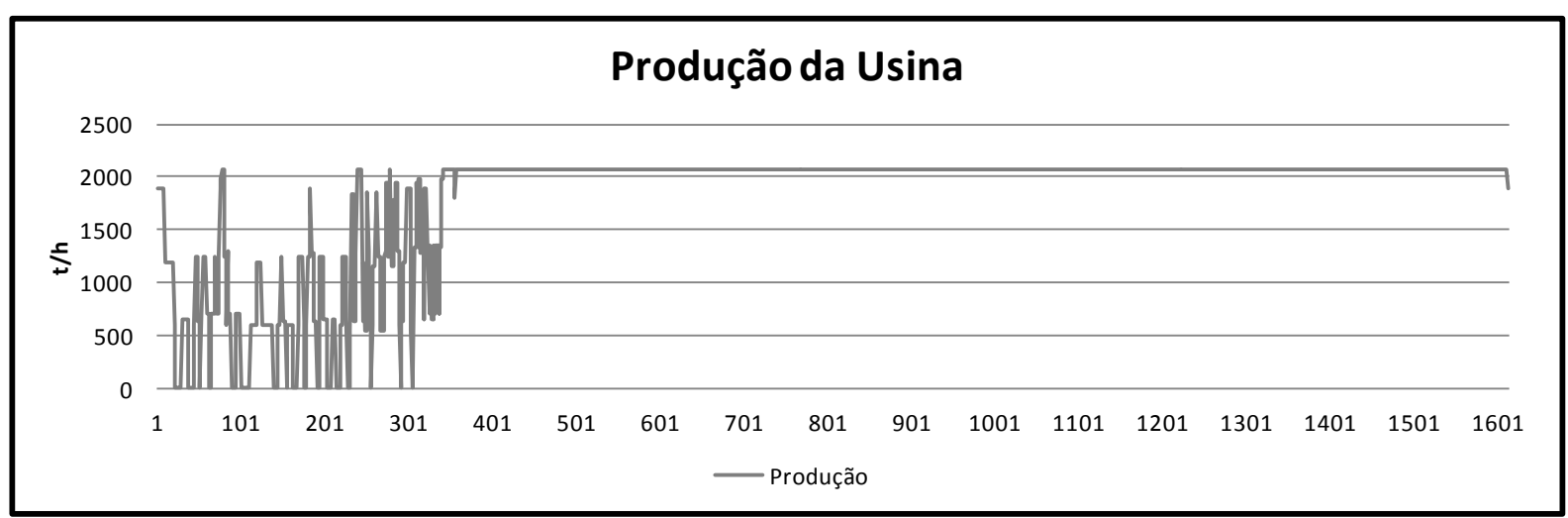

Figura 6.15 - Produção horária da usina 
A Figura 6.16 mostra o comportamento da pilha ao longo de cada ordem de lavra. Até a ordem de lavra 350, poucas vezes a pilha recebeu material, ou seja, durante esse período não foi possível uma lavra de minério tão efetiva capaz de superar a capacidade da usina e encher a pilha. Porém, após esse período, a pilha enche gradativamente e após a ordem 700 não são observadas variações significativas de sua tonelagem. É importante notar que a acumulação da pilha para o próximo avanço pode vir a ser muito benéfica para facilitar o alcance da demanda requerida de minério do próximo avanço desde o início da operação.

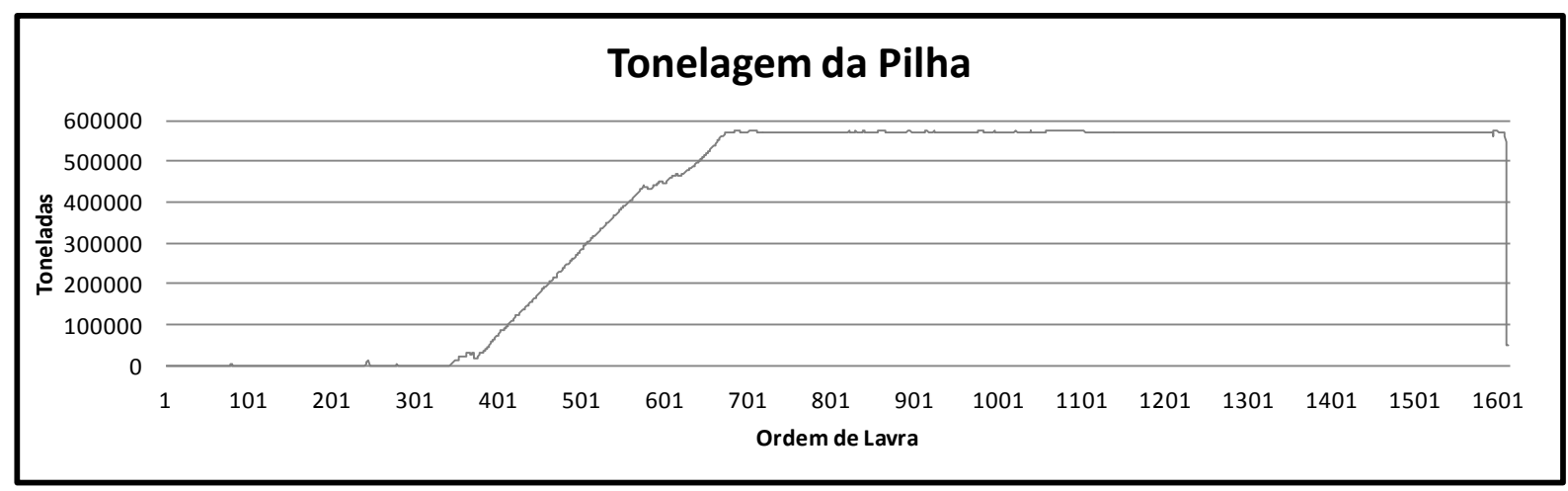

Figura 6.16 - Evolução do tamanho da pilha

A Figura 6.17 mostra a retomada do ROM em cada ordem de lavra. Ou seja, um pico nesse gráfico significa que existia material na pilha, e a produção de minério pelos equipamentos de carga foi inferior à capacidade da usina.

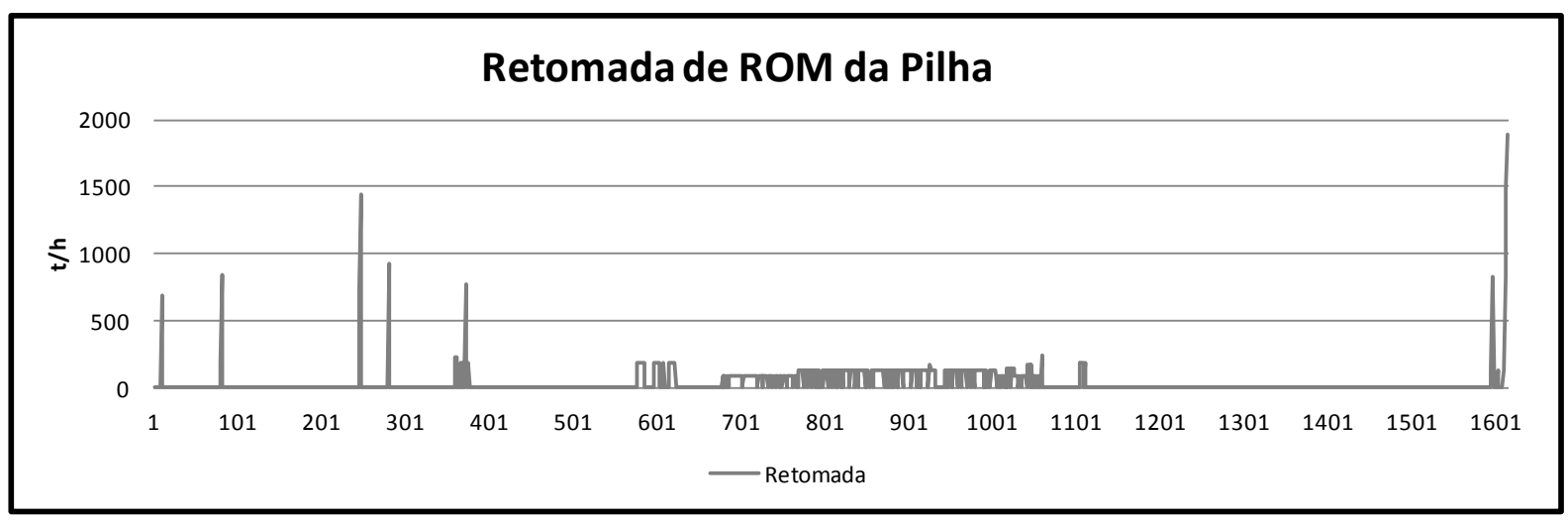

Figura 6.17 - Retomada da pilha de ROM

A Figura 6.18 mostra o teor de cobre formado pela mistura do minério enviada à usina em cada ordem de lavra. Esse teor pondera as características do ROM provenientes das frentes de lavra de minério e o teor do ROM contido na pilha quando essa é 
retomada. Nota-se que no princípio existem pontos onde o teor é zero, provocando picos; isso se deve a períodos sem produção alguma de minério, o que acarreta em teor igual a zero. Notou-se que ao longo da jazida existe grande variação dos teores dos blocos, o que dificultou uma mistura mais homogênea quanto ao teor requerido, por outro lado, na maioria das ordens de lavra, obteve-se uma mistura compatível com a faixa desejada de qualidade.

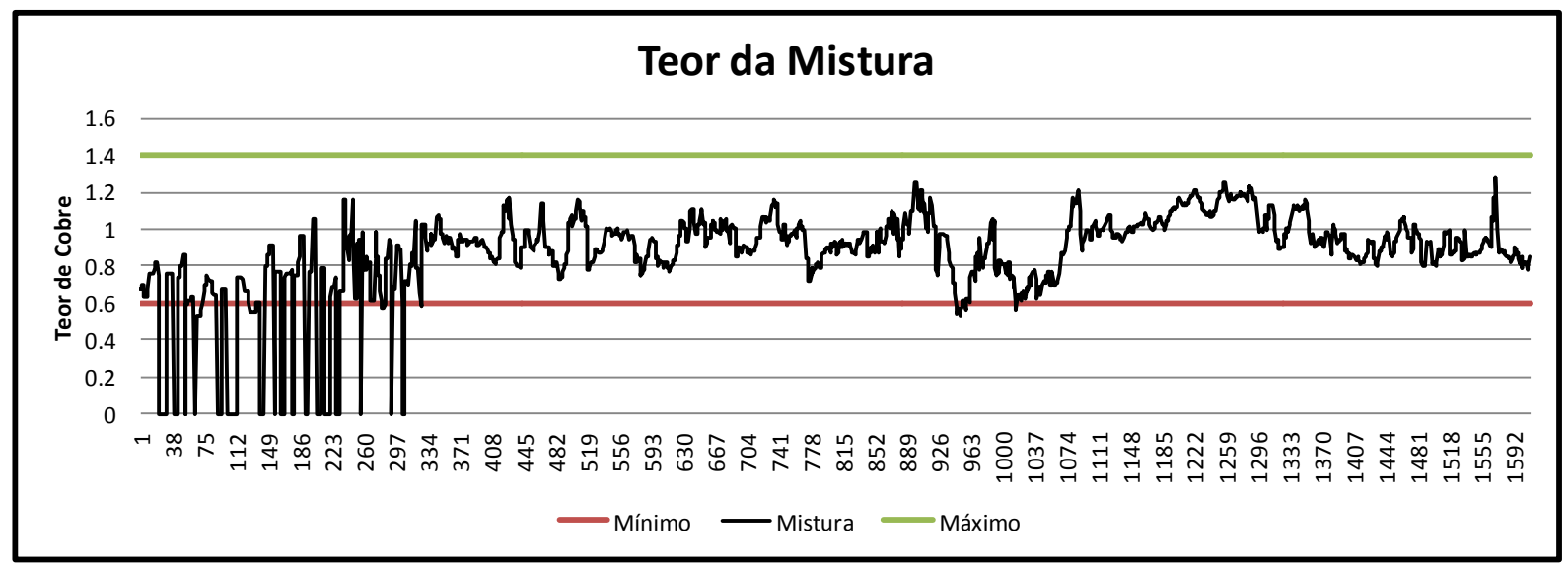

Figura 6.18 - Teor da mistura enviado a usina a cada ordem de lavra 


\section{CONCLUSÃO}

Este trabalho tratou o Sequenciamento e Programação da Lavra com Alocação de Equipamentos de Carga (SPLAEC). O objetivo nesse problema é o de maximizar a produtividade dos equipamentos de carga e da usina de beneficiamento, durante toda a operação de lavra de uma dada extensão de blocos por meio de sucessivas ordens de lavra, penalizando desvios dos parâmetros de qualidade, deslocamentos dos equipamentos e o não atendimento da demanda de minério da usina.

Diferentemente dos trabalhos encontrados na literatura e procurando desenvolver modelos que se aproximem mais da realidade nas minas, foi considerado além dos equipamentos de carga, um britador, uma pilha de ROM (estoque) e uma capacidade atribuída à usina de beneficiamento. No presente trabalho, a capacidade da usina foi dimensionada inicialmente conforme a demanda horária de ROM calculada ao analisar o avanço a ser lavrado em um ano.

Um diferencial do modelo matemático apresentado caracteriza-se pela independência da lavra de minério e a lavra de estéril. Entendendo que o objeto-fim da mineração é a lavra do minério, em contra partida, lavrar somente minério causa problemas futuros como estrangulamento da cava e falta de minério adiante, foi observado que a correta extração de minério e estéril pode ser controlada pelo dimensionamento da produção horária da usina, à capacidade horária do britador e dos equipamentos de carga.

A existência da pilha de ROM e a capacidade do britador contribuíram de forma direta para que o modelo matemático proposto trate a retirada de minério e do estéril sem considerar uma restrição de REM (relação estéril/minério) comumente adotada em trabalhos de curto prazo para evitar que somente minério seja lavrado caracterizando lavra predatória. É permitida uma lavra de minério efetiva caso a pilha esteja abaixo do nível de pedido, porém a lavra de minério é limitada pela capacidade atribuída ao britador. Ao atingir o nível de pedido da pilha, a lavra de minério é reduzida para ajustar-se à capacidade da usina.

Para testar o SPLAEC proposto, buscou-se um modelo de blocos real, disponibilizado na internet, e dimensionaram-se recursos coerentes com a jazida e a meta de 
produção desejada. Foram comparadas diferentes capacidades de carga, existir ou não uma pilha de ROM e permitir acréscimo na produção de minério para superar perdas acumuladas quando a lavra é inferior à meta de produção. Os experimentos realizados mostraram que a consideração da existência da pilha de ROM e atribuir uma capacidade de produção da usina variável contribuiu de maneira significativa para a qualidade da solução.

Este trabalho contribuiu, assim, com o desenvolvimento de um novo modelo matemático e algoritmo, que possui uma abordagem diferenciada da literatura pesquisada para a otimização do planejamento operacional de lavra na indústria mineral. Conforme os resultados, observou-se que o SPLAEC é capaz de gerar soluções mais próximas da realidade operacional, lidando com problemas de falta de espaço físico para depositar o minério extra, momentos com falta de minério e outros com falta de estéril sem gerar soluções infactíveis.

O SPLAEC proposto gera ordens de lavra apoiado por um algoritmo para rolar o tempo entre cada ordem, fazendo uso do modelo on-line para otimizar as alocações dos equipamentos de carga em cada período do horizonte de planejamento.

Ressalta-se que a geração de ordens de produção, comuns em meios fabris, pode contribuir de maneira significativa para o planejamento e o controle das operações de lavra e beneficiamento em mineradoras que possuem como método de lavra mineração a céu aberto.

Dessa forma, o modelo e algoritmo propostos podem ser utilizados nas seguintes situações:

a) No planejamento de curto prazo (executando uma vez o modelo matemático), utilizando informações disponíveis em tempo real apoiado por modernas tecnologias de localização e comunicação existentes em muitas minas, como a situação atualizada em relação ao cumprimento das metas de produção e de qualidade e ainda a localização dos equipamentos de carga.

b) Devido à velocidade de processamento do algoritmo e modelo matemático, o SPLAEC mostrou-se especialmente propício para o apoio ao planejamento de médio prazo. Nesses casos, sua utilidade está principalmente relacionada à possibilidade de teste de cenários, respondendo a questões relativas à 
quantidade de equipamentos necessários para se atingir uma determinada meta de produção anual, comportamento da pilha de ROM ao longo do tempo e períodos de falta de minério.

Como trabalhos futuros, aponta-se:

a) Considerar um número flexível de avanços simultâneos, britador, pilha de ROM e usina de beneficiamento em conformidade com operações de indústrias minerais de maior porte e consequente complexidade.

b) Considerar a existência de mais de um tipo de minério definindo demandas e requisitos de parâmetros de qualidade de cada tipo de minério.

c) Ainda no intuito de deixar as soluções do SPLAEC mais coerentes com a realidade da operação, propõe-se flexibilizar a capacidade da usina e/ou a capacidade dos equipamentos de carga para que possam variar ao longo do ano, podendo adequar-se a períodos chuvosos, por exemplo.

Além disso, o SPLAEC proposto possuiria maior aplicabilidade com 0 desenvolvimento de um software que facilite entrada de dados e visualização dos resultados, assim como o desenvolvimento de um visualizador da jazida em três dimensões. 


\section{REFERÊNCIAS}

ALLAHVERDIA, A.; NG, C. T.; CHENG, T.C.E.; KOVALYOV, M.Y. A survey of scheduling problems with setup times or costs. European Journal of Operation Research. v.187, n.3, p.985-1032, 2008.

AMARAL, M. Modelos matemáticos e heurísticas para auxílio ao planejamento de operações de lavra em minas a céu aberto. 2008. 108 p. Dissertação (Mestrado em Engenharia de Produção) - Escola de Engenharia da UFMG, Universidade Federal de Minas Gerais. Belo Horizonte, 2008.

AMARAL, M. PINTO, L., R. Planejamento de operações de lavra em minas a céu aberto com alocação de equipamentos de carga e transporte. XLII Simpósio Brasileiro de Pesquisa Operacional, 2009, Bento Gonçalves. Anais... Rio de Janeiro: SOBRAPO, 2009.

ARAÚJO, F., C., R. Planejamento de lavra $\mathrm{cm}$ alocação dinâmica de caminhões: abordagem exata e heurística. 2008. 123 p. Dissertação (Mestrado em Engenharia Mineral)- Escola de Minas. Universidade Federal de Ouro Preto. Ouro Preto, 2008.

ARAÚJO, F., C., R.; SOUZA, M., J., F. Uma heurística para o planejamento operacional de lavra com alocação dinâmica de caminhões. Revista Escola de Minas, v.64, n.1, p.69-76, 2011.

ARENAles, M.; ARMENTANO, V.; MORABITO, R.; YANASSE, H. Pesquisa Operacional para cursos de engenharia. 1.ed. Rio de Janeiro: Editora Campus, 2007.

Bley, A., Boland, N., Froyland, G., \& Zuckerberg, M. Solving mixed integer nonlinear programming problems for mine production planning with stockpiling. Disponível em <http://web.maths.unsw.edu.au/ froyland/bbfz.pdf>. Acesso em 10/10/2012. 30 p. 
CACCETA, L.; HILL, S. P. An Application of Branch and Cut to Open Pit Mine Scheduling. Journal of Global Optimization, v.27, p.349-365. 2003.

CARMO, F. A. R.; CURI, A.; SOUZA, W. T. Otimização econômica de explotações a céu aberto. Revista Escola de Minas, Ouro Preto, v. 59, n. 3, p. 317-321, 2006.

CECILIANO, W.,R., A. Aplicação de um método simulação-otimização na cadeia produtiva de minério de ferro. 2007. 209 f. Dissertação (Mestrado em Engenharia de Sistemas Logísticos) - Escola Politécnica da Universidade de São Paulo, Universidade Estadual de São Paulo, São Paulo, 2007.

CHICOISNE, R.; ESPINOZA, E.; GOYCOOLEA, M; MORENO, E; RUBIO,E. A new algoritm for the open pit mine production scheduling problem. Operations Research, v. 60, n.3, p.517-528, 2012.

CORDENONSI, A., Z. Ambientes, objetos e diagilocidade: uma estratégia de ensino superior em heurísticas e metaheurísticas. 2008. $228 \mathrm{f}$. Tese (Doutorado). Centro Interdisciplinar de Novas Tecnologias, Universidade Federal do Rio Grande do Sul. Porto Alegre, 2008.

COSTA. F. P. Aplicações de técnicas de otimização a problemas de planejamento operacional de lavra em minas a céu aberto. 2005. $128 \mathrm{f}$. Dissertação. (Mestrado em Engenharia Mineral) - Escola de Minas, Universidade Federal de Ouro Preto, Ouro Preto, 2005.

COSTA, F., P.; SOUZA, M., J., F.; PINTO, L., R. Um modelo de programação matemática para alocação estática de caminhões visando ao atendimento de metas de produção e qualidade. Revista Escola de Minas, v.58, n.1, p.77-81, 2005.

CRAWFORD, J. T.; DAVEY, R. K. Case study in open pit limit analysis. Computer Methods for the 80's in the Mineral Industry. New York, Editora Alfred Weiss, 1979

CUNHA, C., B. BONASSER, U. O. Experimentos computacionais com heurísticas de melhorias para o problema do caixeiro viajante. Anais do XVI ANPET - Congresso 
da Associação Nacional de Pesquisa e Ensino em Transportes, v.2. p.105-117. Natal, 2002.

DAGDELEN, K. Open Pit Optimization - Strategies for Improving Economics of Mining. XVII International Mining Congress and Exhibition of Turkey, p.117-121. Turquia, 2001.

EPSTEIN, R.; et al. Optimizing Long-Term Production Plans in Underground and Open-Pit Copper Mine. Operations Research, v.60, n.1, p.4-17, 2012.

ESPINOZA, D.; GOYCOOLEA, M.; MORENO, E.; NEWMAN, A. Minelib: a library of open pit problems Library of Open Pit Mining Problems. Annals Operations Reserch, New York, p 1-22 Springer US, 2012a.

ESPINOZA, D.; GOYCOOLEA, M.; MORENO, E.; NEWMAN, A, 2012b. Disponível em <http://mansci-web.uai.cl/minelib/kd.xhtml>. Acesso em 16/01/2014.

GOODWIN, G. C., M SERON, M., \& MAYNE, D. Q. (2008). Optimization opportunities in mining, metal and mineral processing. Annual reviews in control, 32(1), 17-32.

GRAHAM, R., L.; LAWER, E., L.; LENSTRA, J. K.; RINNOOY. K., A., H., G. Optimization and approximation in deterministic sequencing and scheduling: a survey. Annals of Discrete Mathematics, 5, p.287-326, 1979.

GUIMARÃES, O. R. A. Aplicação de algoritmos genéticos na determinação de cava final e sequenciamento de lavra em minas a céu aberto. 2007. 153 f. Dissertação (Mestrado em Engenharia Metalúrgica e de Minas) - Escola de Engenharia da UFMG, Universidade Federal de Minas Gerais. Belo Horizonte, 2007.

HADDAD, M., N.; SOUZA, M., J., F.; SANTOS, H. G. Algoritmos genéticos para problema se sequenciamento em máquinas paralelas não-relacionadas com tempos de preparação dependentes da sequencia. XLIII SBPO SIMPÓSIO BRASILEIRO DE PESQUISA OPERACIONAL, 2012, Ubatuba: Anais... 
HOCHBAUM, D. S.; CHEN, A. Performance analysis and best implementations of old and new algorithms for the open pit mine problem. Operations Research, v.48, n.6, p.894-914, 2000.

INSTITUTO BRASILEIRO DE MINERAÇÃO (IBRAM). Informações e análises da economia mineral brasileira. n.6, Brasília, DF. 2011. 28 p.

KAWALEC, W. Modelling of transportation costs for alternative Life-Of-Mine plans of continuous surface lignite mines. Gospodarka Surowcami Mineralnymi, v.28, p.125138,2008

KOZAN, E.; LIU, S., Q. An Interactive Planning and Scheduling Framework for Optimizing Pits-to-Crushers Operations. Industrial Engineering \& Management Systems, v. 11, n.1, p. 94-102, 2012.

MEAGHELER, G., C.; DIMITRAKOPOULOS, R.; AVIS, D., A. new approach to constrained open pit pushback design using dynamic cut-off grades. AusIMM: Orebody Modelling \& Strategic Mine Planning, p.171-176, Australia, 2009.

MELO, V., A. PQA: investigações sobre a metaheurística VNS e sobre o uso da variância em problemas de isoformismo de grafos. 2010. $147 \mathrm{f}$. Tese (Doutorado em Engenharia de Produção)-COPPE, Universidade Federal do Rio de Janeiro. Rio de Janeiro, 2010.

MINISTÉRIO DE MINAS E ENERGIA (MME). Plano Nacional de Mineração 2030. Brasília, DF. 2010. 157 p.

MORABITO, R; PUREZA. Modelagem e Simulação. MIGUEL, Paulo A. C. (Org). Metodologia de pesquisa em engenharia de produção e gestão de operações. 2.ed. Rio de Janeiro: Elsevier, 2010. cap 8, p.165-194.

NEWMAN, A.; RUBIO, E.; CARO, R.; WEINTRAUB, A.; EUREK, K. A Review of Operations Research in Mine Planning. Interfaces, n.3, v. 40, p. 222 -245, 2010. 
NERY, M. A. C. Gestão de Recursos Minerais como Fator de Desenvolvimento. Congresso Internacional de Direito Minerário, Salvador, 2010.

PANTUZA JÚNIOR, G. Métodos de otimização multiobjetivo e de planejamento operacional de lavra em minas a céu aberto. 2011. 89 f. Dissertação (Mestrado em Engenharia Mineral) - Escola de Minas, Universidade Federal de Ouro Preto. Ouro Preto, 2011.

PINEDO, M. L. Scheduling: Theory, Algorithms, and Systems. 3.ed. New York. Springer, 2008.

PINTO, L. R.; MERSCHMANN, L. H. C. Planejamento operacional de mina usando modelos matemáticos. Revista Escola de Minas, v. 54 (3), 211-214, 2001.

RAMAZAN, S. Then new fundamental Tree Algorithm for production scheduling of open pit mines. European Journal of Operational Research, v.177, p.1153-1166, 2007.

SOUZA, M. J. F.; COELHO, I. M.; RIBAS, S.; SANTOS, H. G. MERSCHMANN, L. H. C. A hybrid heuristic algorithm for the open-pit-mining operational planning problem. European Journal of Operational Research, 207, p.1041-1051, 2010.

THORLEY, U. Open pit mine planning: Analysis and system modeling of conventional and oil sands application. 2012. Ph. D. (Mining Engineer) Department of Mining, Queen's University, Canadá, 2012. 